Portland State University

PDXScholar

\title{
Adult daughters as caregivers to elderly parents : an exploration of the care relationship
}

Margaret Anne Reynolds

Portland State University

Follow this and additional works at: https://pdxscholar.library.pdx.edu/open_access_etds

Part of the Gerontology Commons

Let us know how access to this document benefits you.

\section{Recommended Citation}

Reynolds, Margaret Anne, "Adult daughters as caregivers to elderly parents : an exploration of the care relationship" (1987). Dissertations and Theses. Paper 3792.

https://doi.org/10.15760/etd.5676

This Thesis is brought to you for free and open access. It has been accepted for inclusion in Dissertations and Theses by an authorized administrator of PDXScholar. Please contact us if we can make this document more accessible: pdxscholar@pdx.edu. 
AN ABSTRACT OF THE THESIS OF Margaret Anne Reynolds for the Master of Science in Sociology presented December 7, 1987.

Title: Adult Daughters as Caregivers to Elderly Parents: An Exploration of the Care Relationship.

APPROVED BY MEMBERS OF THE THESIS COMMITTEE:

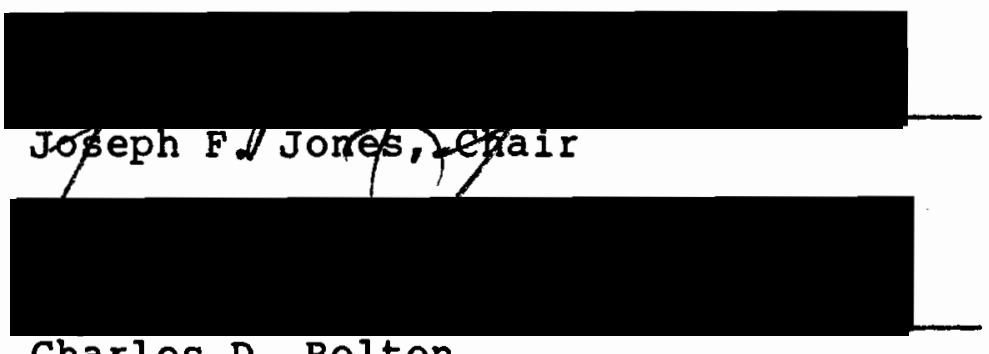

Charles D. Bolton

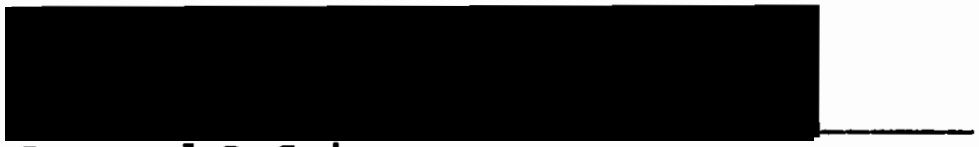

Leonard D Cain

In this study, the nature of a current social problem is explored: the provision of services to elderly parents by their adult daughters - a part of the informal system of social support for the elderly. In particular, the influence of the caregiver's construction of old age on their assessment of parental autonomy is examined.

The specific focus on care to elderly parents by family caregivers is a consequence of the recognition that 
there is increasing pressure on the informal system to provide such care. Some reasons for this are identified, including both demographic and economic factors, such as the need to provide services to an expanding aged sector in the face of resource constraints facing the entire population.

Investigation of the topic employs cross-sectional research methods and incorporates both quantitative and qualitative approaches. Data were collected by personal interviews with a non-probability sample of fifty adult daughters on selected experiences of in-home caregiving for elderly parents. Guided by five research questions generated from the relevant literature data were analyzed to gain impressions of the nature of parent care.

Analysis of the data supports the "social problem" designation of parent care by family caregivers. Typically, the reported caregiving experience involved a lengthy duration of care with high levels of assistance to the parent or parents, supplemented by episodic and often infrequent support from the formal care system. Negative influences on marital and family well-being, on the subjects' employment interests and on other aspects of the subjects' personal life were also reported.

Despite these difficulties, subjects generally reported a strong ethic of responsibility to provide parent care, an ethic which was determined to be stable 
across the two birth cohorts of caregivers in the sample. Evaluation of the research questions showed the sample to hold a relatively neutral view of older persons and a more negative view of old age as a life status. The hypothesized association between a negative view of old age and low levels of assessed parental autonomy was partially supported. Low levels of assessed parental autonomy were found to be substantially associated with parental impairment. Characteristics of the parent, such as advanced age or high levels of impairment did not appear to be important negative influences on the caregiver's perception of older persons or of old age.

other important findings included a substantial relationship between high levels of assistance to the parent and low levels of assessed parental autonomy. This relationship was found to vary with the extent of parental impairment, but not to fall below a moderate association, which supports the findings of other researchers that assistance may of itself encourage dependency.

Lastly, the hypothesized relationship between multiple life changes affecting the parent and low parental autonomy was not well supported.

The investigation concludes with a recommendation for longitudinal research into the nature of the caregiving experience, preferably involving both the care provider and the care recipient. 


\title{
ADULT DAUGHTERS AS CAREGIVERS TO ELDERLY PARENTS:
}

AN EXPLORATION OF THE CARE RELATIONSHIP

\section{by}

MARGARET ANNE REYNOLDS

A thesis submitted in partial fulfillment of the requirements for the degree of

\author{
MASTER OF SCIENCE \\ in \\ SOCIOLOGY
}

Portland State University 
TO THE OFFICE OF GRADUATE STUDIES:

The members of the committee approve the thesis of Margaret Anne Reynolds presented December 7, 1987.

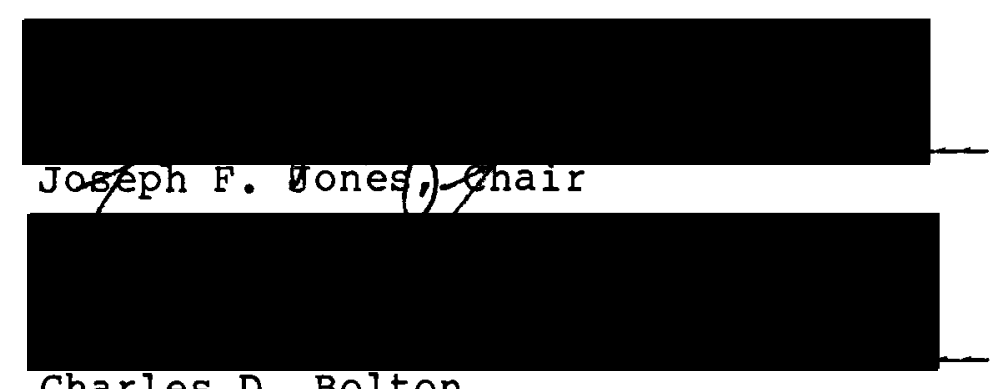

Charles D. Bolton



APPROVED:

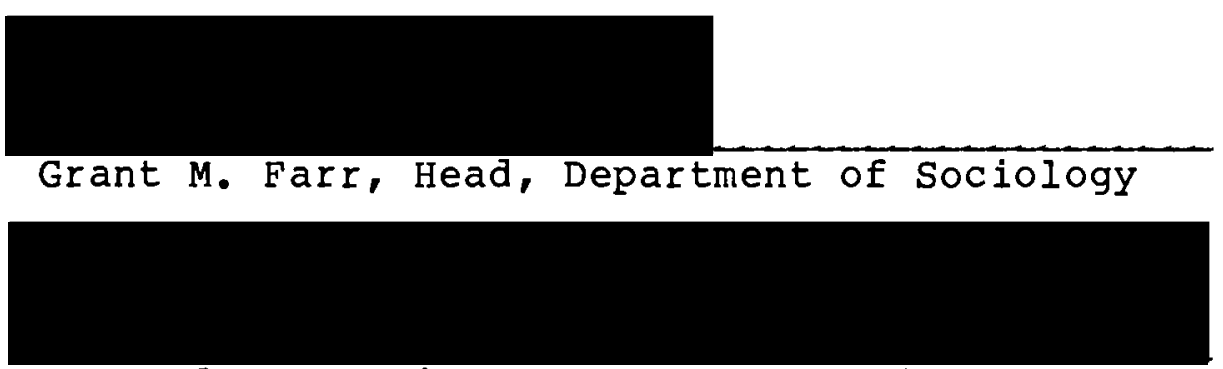

Bernard Ross, Vice-Provost for Graduate Studies 


\section{ACRNOWLEDGMENTS}

The members of my thesis committee, Dr. Joseph Jones, Dr. Charles Bolton and Dr. Leonard Cain, provided valuable contributions at each stage of this endeavor, and I wish to express my gratitude for their encouragement, expertise and willing assistance in this process. Dr. Jones as Chairperson is additionally thanked for his considerable support and assistance with each draft of this thesis.

My gratitude is also extended to Dr. Keren Wilson for her special interest and help, to Dr. Lee Haggerty for his assistance with statistical applications, and to Dr. Kelly Hancock for his assistance with various computer problems.

Acknowledgment is also extended to agency representatives who made possible many of the referrals to caregivers in the community. Special appreciation is due to the fifty-one individuals who participated in the interview process and who willingly discussed their involvement in parent care.

Finally, I wish to give special thanks to my husband for his support, understanding and tolerance during this lengthy process, and to my family in vancouver for their willing hospitality. 
TABLE OF CONTENTS

PAGE

ACRNOWLEDGEMENTS........................ iii

LIST OF TABLES........................ vi

LIST OF FIGURES....................... ix

CHAPTER

I INTRODUCTION...................... I

Statement of Purpose............... 6

II THEORETICAL FRAMEWORK................ 8

Old Age as a "Social Problem".......... 10

Received and Constructed Images of old Age 26

A Model of "Normal Aging" ............ 43

Conceptual Model................... 56

III DESCRIPTION OF THE PROBLEM............. 60

Characteristics of the Aging Population .. 60

Care Systems: Formal and Informal....... 69

The Adult Daughter as Care Provider...... 71

The Elderly Parent - Dependent or

Autonomous?..................... 79

Hypotheses...................... 89

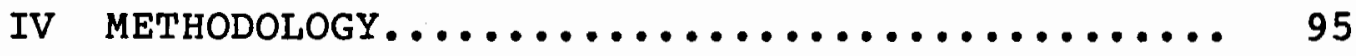

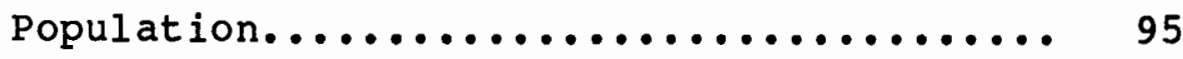

Source of the Sample............... 96

Interview schedule................ 98

Data Collection Procedures............... 101 
CHAPTER

PAGE

IV METHODOLOGY (continued)

Data Preparation and Analysis.......... 103

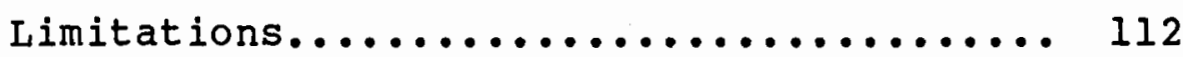

V OBSERVATIONS AND ANALYSES............. 115

Description of the Sample............ 115

Description of the Care Recipients....... 124

Evaluation of the Hypotheses.......... 139

Observations on the Problematic

Nature of parent Care.............. 171

VI SUMMARY AND DISCUSSION............... 196

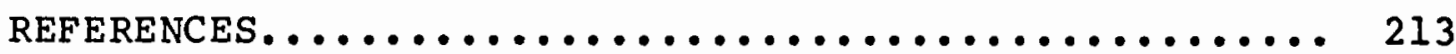

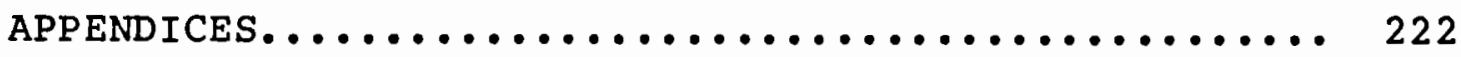

A. Interview schedule.................... 222

B. Coding for Open-Ended Questions........... 245

C. Notification of Approval - P.S.U. Human

Subjects Research Review Committee......... 253

D. Informed Consent Sheet................. 254 


\section{LIST OF TABLES}

TABLE

PAGE

I Factor Analysis of Parental Autonomy

Items Based on Caregiver Assessment



I Factor Analysis of the Instrument

"Image of Older Persons".

II Characteristics of the Caregiver Sample



IV Characteristics of the Care Recipients

in Number and Percent................ 126

V Reported Frequency of Major Life Changes

by Parent Category in Number and Percent..

VI Health status of Parents in Number

and Percent.

VII Rating of Parents' Cognitive Status

in Number and Percent................. 136

VIII Caregiver Assessment of Parental Autonomy in Number and Percent.

IX Assessed Parental Autonomy by Caregiver's

"Image of older Persons"

in Number and Percent.

X Assessed Parental Autonomy by Caregiver's

"Image of old Age" in Number and Percent.. 
TABLE

PAGE

XI Caregiver's "Image of Older Persons" by Age Group of Parent in Number and Percent.....

XII Caregiver's "Image of Old Age" by Age

Group of Parent in Number and Percent..... 151

XIII Caregiver's "Image of Older Persons" by

Parental Impairment in Number and Percent. 152 XIV Caregiver's "Image of Old Age" by

Parental Impairment in Number and Percent. 153

XV Assessed Parental Autonomy by Caregiver

Assistance in Number and Percent........ 157

XVI Assessed Parental Autonomy by Caregiver

Assistance Controlling for Parental

Impairment in Number and Percent........ 158

XVII Responsibility Toward Parent Care by Birth

Cohort of Subject in Number and Percent... 161

XVIII Socialization to Parent Care by Birth

Cohort of Subject in Number and Percent... 162

XIX Assessed Parental Autonomy by Major Life

Changes of Parent in Number and Percent... 165

XX Assessed Parental Autonomy by Major Life

Changes of Parent Controlling for

Parental Impairment in Number and Percent. 167

XXI Characteristics of the Parent Care

Situation in Number and Percent.......... 
XXII Type and Frequency of Subject Assistance to

Parents in Number and Percent.......... 176

XXIII Determinants of Caregiver Role by Birth

Cohort of Subject in Number and Percent... 182

XXIV Influence of Caregiving on Subject's

Employment by Birth Cohort of Subject

In Number and Percent.............. 188

$X X V$ Influence of Caregiving on the Subject by

Birth Cohort in Number and Percent....... 191

XXVI Influence of Caregiving on Subject's

Children by Birth Cohort of Subject

in Number and Percent................ 194 


\section{LIST OF FIGURES}

FIGURE

PAGE

1. Representation of the Social Breakdown

Syndrome Applied to Old Age............ 52

2. Conceptual Model for the study............. 58

3. Distribution of Population 65 Years and Over

by Living Arrangements: 1981 
CHAPTER 1

\section{INTRODUCTION}

Traditionally, adult children, particularly women, have assumed a primary caregiving role in the support of non-institutionalized elderly parents (Cantor, 1980; Brody et al., 1984). Despite gender role changes and increased employment by women, adult daughters still provide the greater share of services received by elderly parents (Brody et al., 1984:736). This pattern of caregiving is likely to continue with greater burdens on adult daughters anticipated as the percentage of elderly persons in the population increases (Neugarten, 1982; Shanas and Sussman, 1981; Siegel and Davidson, 1984).

Care provision for the increasing elderly population in the United States, and particularly for the increasing numbers of "old-old" persons with extended life expectancies (Neugarten, 1982), is becoming an urgent issue, and appears to have achieved designation as a "social problem." The sub-population of persons 75 years or older is growing at a rapid rate, and in 1980, according to Bureau of the Census reports, represented 398 of the elderly - or about ten million people, out of a total aged population (65 years and over) of 25.7 million persons (Seigel and Davidson, 1984). 
The vast majority of persons over 65 live within the community, with only 5-68 requiring institutional care at a given time (Shanas and Sussman, 1981; Brody, 1981; Siegel and Davidson, 1984). However, this relatively low percentage does not indicate an absence of need in elderly persons living in the community. Although figures are imprecise, Stoller (1983:851) suggests that between 13218 of non-institutionalized elderly persons require informal home assistance, possibly from family caregivers, while soldo (1985:286) suggests that a further 128 of this group require formal assistance. The extent of assistance required increases with advanced age, as does the need for institutionalization, probably due to associated greater levels of impairment (Brody, 1981:472). It is the advanced age, or "old-old," segment of the population, which is increasing so rapidly and which supposedly requires greater assistance. Kane and Kane (1981:262) suggest that "...for every person in institutional care, two persons with equal physical or mental impairment reside in the community" and, supposedly, these persons are in need of both informal and formal care. This point is echoed by Doty (1986:36).

The shortage of funding for elder care at all levels, local, state and federal, is of concern; stoller (1983) suggests that a decline in funding is leading to an increased expectation of care from the informal system, 
that is, from family members.

In counterpoint to the demographic changes in the elderly population is the falling birth rate, and the associated loss of potential caregivers for the older parent (Brody et al., 1984). When these demographic data are coupled with another social trend, the changing role of women, and particularly their widespread involvement in the labor force, the question of caregiver availability for elderly parents is raised (Treas, 1977; stoller, 1983; Brody et al., 1984).

These data emphasize the problems and the need for continued elder care of all types in the future. With reference to informal care, Stoller (1983) suggests that despite competing responsibilities such as work or family, which may reduce the time allocated to caregiving, the commitment to assist the elderly parent is strongly retained by adult children.

The caregiving behavior of adult children on behalf of elderly parents merits attention; indeed, considerable investigation of this has occurred, spurred most recently by large corporations which perceive an economic cost drain incurred by employees, mostly women, who also have elder care responsibilities (Freudenheim, 1986). Associated research, which appears to have received less attention, relates to the influence of the social environment and the caregiver on learned dependency or its 
converse, continuing autonomy, in the elderly person.

In the social environment of the united States, the prevailing "reality" of old age, as indicated in the literature, suggests a status that is widely perceived to be a period of decline, of decreasing competence, and of dependence rather than autonomy - in general a negative portrayal of a life stage (Ruypers and Bengtson, 1973; Harris, 1975; Achenbaum, 1978; Estes, 1979; Levin and Levin, 1980; Langer, 1983; Arluke and Levin, 1986). Of interest is whether the level of dependence or of autonomy exhibited by the elderly person is related more to the construction of old age held by society than to chronological age and associated factors per se. Ruypers and Bengtson (1973), Estes (1979), Russell (1981) and Langer (1983) suggest that the labeling and stigmatization engendered by such societal devaluation do indeed influence the competence of older persons. Similarly, Comfort (1976:9), in earlier writing, promotes the concept of "sociogenic aging" to indicate society's role in the construction of what the everyday person sees as a "normal" aging process.

When one considers that adult children, as caregivers, and elderly parents as potential recipients of care, are each socialized in this negative "reality" of old age, and that both have internalized to some extent the devalued roles of advanced age, is it not possible 
that learned dependency on the part of the parent is a result? Feedback resulting from actual impairment may reinforce this reality. Additionally, what, if any, consequences arise from potentially different socialization experiences regarding parent care encountered by different generations of caregivers? Possibly, these differential, largely negative perceptions of old age may contribute to unequal relationships, involving more help from the caregiver and less autonomous action from the parent than is indicated by objective impairment. For instance, Kane and Kane (1981:191) and Langer (1983:102) suggest that elderly persons may be susceptible to increased dependency or nlearned helplessness" in some care situations.

Cain (1985) speaks to the concern of a negative "reality" for the aged. He emphasizes that for many persons of advanced age a problem DOES exist; consequently the elimination of the problem orientation is not entirely appropriate, and could cause underservice to aged persons in real need. The old age status appears to demand a more balanced understanding of reality which will recognize individual variation in the continuum from full autonomy to potential dependence, as is expected in a heterogeneous population spanning a wide age range.

While changes in constructions of reality occur over time, especially in pluralistic societies, Berger and 
Luckmann (1967:125) also warn of inertia to such change. Estes (1979:5), for instance, cites the considerable influence of the "aging network" as a factor in retarding change in the social reality of old age. Possibly the increased visibility and educational level expected of future cohorts as they reach age 65 will force a change in this reality.

\section{STATEMENT OF PURPOSE}

Assuming the continuation of a negative construction of reality or image of old age, at least in the short term, it is desirable to investigate the nature and effects of this reality on the older person. The adult child as caregiver is likely, by definition, to be close to the elderly parent; consequently he or she may be in a position to reflect and contribute to different constructions of reality, which in turn may affect the parent. In particular, this process may have an influence on the level of dependency or of autonomy exhibited by the parent.

Parental autonomy, which is a central variable in this study, refers to the degree of perceived control, choice or self-governance of the parent over his or her immediate environment (Kane and Kane, 1981:202).

To summarize: The purpose of this study is to explore the problematic nature of family care to elderly parents. 
and in particulare to examine the social construction of old age as held by adult daughters providing care to elderly parents, and the relationship of this construction to perceived parental autonomy.

This investigation can be introduced most usefully by drawing upon three theoretical sources, which are reviewed in sections of Chapter II: Old Age as a Social Problem, Received and Constructed Images of Old Age, and A Model of Normal Aging. A conceptual model for this study completes Chapter II.

Chapter III provides a short literature review on the nature of the problem: characteristics of the aging population, formal and informal elder care systems, the role of the adult daughter in parent care, and the influence of the care situation on parental dependence and autonomy. A presentation of the study hypotheses drawn from the relevant literature completes this chapter.

Chapter IV, on methodology, outlines the procedures followed in operationalization, data collection, and data analysis, and addresses certain study limitations.

Chapter $V$ reports on specific findings, including descriptions of the sample, the care recipients and the problematic nature of parent care, and reports on the evaluation of the hypotheses.

Chapter VI completes the document, with a summary of pertinent results and suggestions for further research. 


\section{CHAPTER II}

\section{THEORETICAL FRAMEWORK}

In the United States, old Age is widely perceived to be a social problem. Aged persons themselves are likewise viewed as part of this problem. At both social system and individual levels, and in different arenas (political, economic, health, social, etc.), the responsibilities associated with an increasingly large aged population are the subject of considerable debate. Part of this debate is focused on the provision of services for elderly persons in need, and in particular the services provided by the informal system as demonstrated by adult children caring for elderly parents.

The theoretical framework of this research project is discussed in three parts. The first part focuses on the emergence of social problems generally, and on the problem of old age and family care services specifically. secondly, the process by which images or realities are received and constructed is identified, again using old age as the example and drawing from Berger and Luckmann's concept (1967) of the "social construction of reality." Finally Kuypers and Bengtson's model of "normal aging" (1973) is outlined as a means of including both social system and individual forces related to old age. 
The review of social problems attempts to explain the process by which social phenomena develop and become recognized as problems in society. Using old age and aging as the focus, this review outlines the emergence of old age as a social problem, and attempts to "set the stage" for recognition of the problematic nature of the topic of this study. Specifically, the extent of routine, unpaid, caregiving services to elderly persons from family members is increasingly recognized as a social problem by some groups in society.

The second part of the theoretical framework discusses the construction of images, perceptions, attitudes or "realities" in society, both on (1) a personto-person and (2) on a collective or institutional level. Using the model proposed by Berger and Luckmann (1967), it is suggested that the "reality" of old age in American society influences how care is provided, and also influences the roles of both the caregiver and the care recipient. It is further suggested that the meaning or "reality" of old age at both levels, while persistent, may evolve or be modified in the process of person-to-person interaction over time, as in a parent care relationship.

The third part of the theoretical framework describes the interplay between structural and individual forces in the process of aging as outlined by Ruypers and Bengtson (1973:181) in their model of "normal aging." In this 
model, negative effects of aging on a personal level are perceived as adaptive responses to the changed position of the aged person within the social system, specifically the loss of clear role guidelines and norms for the old age status, the loss of social position and value, and the loss of appropriate reference groups. For Kuypers and Bengtson (1973), the social system reflects a cycle in which a negative construction of the aged calls forth a negative response by the older person, resulting in less than competent behavior, thus compounding and perpetuating the negative problem orientation.

With reference to the caregiver and the care recipient, the last model suggests that negative images of old age or the aged, if held by the caregiver, could have a compounding negative effect on the care recipient with greater dependence and less autonomy as a possible outcome. Consideration of this effect, from a caregiver perspective, is posed later in hypothesis 1.

A conceptual model drawn from the theoretical framework is presented to complete this chapter.

\section{OLD AGE AS A SOCIAL PROBLEM}

The process by which a condition comes to be defined as a "social problem" has been examined by a number of different authors (e.g.: Fuller and Myers, 1941; Blumer, 1971; Ross and Staines, 1972; Wiseman, 1979; Wiener, 
1981). Some authors view the recognition of social problems as a collective process emerging from different groups in society in response to a given phenomenon at a point in time (Fuller and Myers, 1941; Blumer, 1971).

Although many conditions fail to receive a "problem" designation, both Ross and staines (1972:19) and wiener (1981) argue that more social problems are being recognized currently than during any previous period. They suggest that the increased recognition of social problems in the United states is associated with a number of factors, one of which is the proliferation of occupational categories whose expertise and interest lead them to identify discrepancies between the real and the ideal. Certainly there has been a proliferation in occupations associated with the problem of old age, as exemplified by the "aging enterprise," a network of programs, organizations, providers, bureaucrats, professionals, interest groups and others associated with the aged in the United States (Estes, 1979:2).

There is considerable difficulty in defining a social problem given the variety of relevant factors: social problems vary with the culture, with the historical period and with their location (Blumer, 1971). What is identified as a social problem by one culture or in a given period of history is not by another. Additionally, the manner in which the problem is defined may vary with 
the social context. For example, despite long standing deprivation and difficulty associated with aging, old age per se was not identified as a social problem until the mid-1930's, as a consequence of the Great Depression (Pratt, 1976) and in concert with changes in agriculture, industrialization, urbanization and labor force practices after the First World War (Achenbaum, 1978). At this point old age was largely defined in economic terms, which reflected concern with the Depression economy.

In contrast, present day definitions of old age are largely in terms of a health orientation with a decremental decline and/or dependency notion of aging in terms of individual physical, psychological and social functioning (Estes, 1979:17; Phillipson, 1982; Weg, 1983). A current alternate orientation may perceive the older population to be an economic burden, with little contribution except as a reserve of labor for the employment market (Phillipson, 1982:16).

The differential experience of a social condition by diverse groups in society influences whether or not it is perceived as a social problem. In terms of aging, de Beauvoir $(1972: 16,101,253)$, Estes (1979:27) and Phillipson (1982:10-11, 110) suggest that inequalities of class and/or gender relations impose very different experiences of aging: those with means and power have greater choices to circumvent the negative aspects of aging; those 
without have few alternatives and are more likely to experience poverty and deterioration. Women particularly, due to greater life expectancy and a less favorable social position, are more likely to experience these problems.

The unequal distribution of power, income and property by class, gender and ethnic group influences the definition of old age as a problem. Old age historically, and continuing in the present, has been largely defined by the privileged members of society, meaning the middle and upper classes with largely male representation (de Beauvoir, 1972:101; Phillipson, 1982:11). This definition largely ignores the class/sex dimension and transforms the problem of old age into a private experience (Phillipson, 1982:110). It is possible that the perpetuation of a health deterioration model in aging (oriented toward the individual), rather than a model based on structural factors (collective), represents a need by the privileged to retain economic power (Phillipson, 1982; Estes, 1979). The notion of a political dimension involved in the definition of a social problem - that is, the social control of one group, designated as a problem by another (Abercrombie et al,,1984) - is thus reinforced.

How is the term "social problem" defined? The definition of this term has been the focus of considerable debate over the years. Fuller and Myers (1941:320) represent one of the first attempts to clarify 
characteristics associated with the concept. For them:

A social problem is a condition which is defined by a considerable number of persons as a deviation from some social norm which they cherish. Every social problem thus consists of an objective condition and a subjective definition.

This statement suggests an objective component which can be measured, but which in itself is not enough to permit the designation of social problem, and also a subjective component, which reflects the awareness of groups of people that the condition is a threat to collective values. Both elements, according to Fuller and Myers (1941), must be satisfied before a condition can be labeled as a social problem. Many conditions exist which have a problematic objective nature, but which pose no threat to collective values; therefore they do not enter the awareness of society, and are not constructed as a social problem, at least at that point in time.

Returning to the example of old age as a social problem, pratt (1976) suggests that, prior to the Depression, cultural values tended to emphasize private rather than collective responsibility in providing for one's old age. Consequently there was little interest in arriving at a public definition of the problem. Only with the Depression of the 1930's did the objective condition and subjective definition of the elderly begin to change. During this period, the unfortunate objective condition of the elderly became more obvious on many levels - chronic 
unemployment, decline in value of savings and real property, largely non-existent pension plans, etc.. Increasingly, younger family members found difficulty in supporting their immediate families, to say nothing of aging parents or relatives (Achenbaum, 1978). Consequently the plight of the aged came to be perceived as a threat to societally held values. Increasingly, people came to realize that economic security was beyond the control of the average person, especially the aged, and that some form of government security was essential. In this way a subjective definition of the aged as a social problem developed and paved the way for subsequent public recognition. According to Pratt (1976:17), it became increasingly apparent, as the Depression deepened, that local and state involvement would not be adequate or possible, and that federal involvement as collective action was the only viable option.

More recently, Herbert Blumer (1971:298) described social problems as a function of collective behavior. For Blumer:

...social problems are fundamentally products of a process of collective definition instead of existing independently as a set of objective social arrangements with an intrinsic makeup.

Using this approach, Blumer suggests that social problems emerge and are first recognized by elements of the public, and only subsequently are recognized by sociologists and other professionals. He further suggests 
that "The societal definition, and not the objective makeup of a given social condition, determines whether the condition exists as a problem" (1971:300). Ross and Staines (1972) agree that private recognition of a social problem usually precedes public recognition; however, they differ with Blumer on the objective component, and suggest that "objective social conditions constrain what people will perceive as social problems" (1972:21).

According to Blumer (1971:298), his definition stands in contrast to the functionalist sociological approach, which attributes social problems to abnormal, malignant or dysfunctional states which upset the normal, healthy operation of the social system. This view emphasizes the objective nature and probable causes of the social problem, but lacks the element of public identification. According to Blumer, only the process of collective definition explains why some conditions are labeled as social problems and others are not.

The process of collective definition appears to be operative with reference to the focus of this study, the provision of care to elderly parents by adult children. Although a part of the wider concern with old age, elder care appears to be developing as a legitimate social problem of its own, particularly as it relates to economic considerations. For instance, parent care responsibilities of employed persons, particularly women, 
are "starting to exact a toll on productivity and morale," which is causing company executives and researchers to examine the extent of the problem and to develop initiatives for possible assistance (AARP News Bulletin, september 1987:1,13). Concurrently, the realization by executives of the "baby boom" generation that they themselves are faced with difficulties of parent care is further contributing to the collective definition of a social problem (Wood, 1987:34). The increased numbers of women in the work force and the greater longevity of the older population, together with inadequate formal systems for long term care, suggest that this problem is likely to continue (Brody et al., 1984).

The process by which social problems have developed over time has been examined by many authors (Fuller and Myers, 1941; Blumer, 1971; Ross and Staines, 1972; Wiener, 1981 and others). While not the central task of this discussion, a few comments on the natural history of social problems are in order.

Fuller and Myers (1941:308) argue that "social problems do not arise full-blown...." Rather they appear to exhibit different stages over time, and are always seen to be in a dynamic stage of "becoming." These authors identify three specific stages: awareness, policy determination and reform, which overlap with elements of each stage possibly present at any one time. 
Five stages in the natural history of social problems are identified by Blumer (1971:301), which add to the prior work by Fuller and Myers (1941). These include: "...emergence of a social problem," "...legitimation of the problem," "...mobilization of action," "...formation of an official plan of action," and "...transformation of the official plan in its empirical implementation." For Blumer, the process of collective definition is a thread which is woven throughout the career of a social problem; without recognition of this process, understanding of the career of a given social problem, such as old age, is incomplete.

A somewhat different approach is employed by wiener (1981:6-7), who examines the building of an arena around a specific social problem: alcoholism. Her analysis suggests that the stages identified by Blumer are intertwined and that the process of collective definition does not pass sequentially through different stages. Further, her findings suggest that the "official plan of action" is less purposeful than portrayed by Blumer, and instead is constantly emerging and being refashioned. Wiener identifies slightly different components in the collective definition of a social problem. Specifically these are: "animating the problem, ...legitimizing the problem, ... and demonstrating the problem" (1981:6). While these elements were identified in relation to the building of an 
arena around the problem of alcohol use they appear applicable to the problem of old age and to parent care.

According to wiener (1981:6), animating the problem refers to "establishing turf rights, developing constituencies, funneling advice and imparting skills and information." Pratt (1976) documents extensive efforts in the 1930's and 1960's by different actors in private and public agencies, in creating initial and subsequent interest in the problems of old age. This type of process clearly occurs today in relation to the aging network and the Older Americans Act (Estes,1979). This process is also occurring in reference to parent care, with investigation into the extent of the problem, such as an extensive grant allocation to Portland State University for research on "Work and Elder Care" (1987), The Traveler's Corporation research into caregiving in the workplace (Freudenheim, 1986), and others.

The second element, legitimizing the problem, refers to "borrowing expertise and prestige, redefining its scope, building respectability, [and] maintaining a separate identity" (Wiener, 1981:6). With reference to aging, advocates, special interest groups, and more recently gerontologists and other "experts" have been widely involved in this type of activity (Pratt, 1976; Estes, 1979). Parent, or elder, care is more recently attracting the attention of gerontologists and others. 
Wiener's final element, demonstrating the problem, refers to "competing for attention, combining for strength, selecting supporting data, convincing opposing ideologists, [and] enlarging the bounds of responsibility" $(1981: 6)$. These activities typically have occurred with reference to the aging problem and legislation: professionals, experts, political interests, provider groups, etc., all attempt to demonstrate and extend the awareness of the problem, and to build the arena, although not necessarily in concert with the concerns and needs of the elderly (Pratt, 1976; Estes, 1979). Like Fuller and Myers (1941), wiener suggests that these elements do not occur in specific stages but occur as a "continually ricocheting interaction" (1981:7). This would also appear true of the interactions within the aging enterprise. In terms of parent care, the Family and Medical Leave Act (H.R. 925) is an attempt to legislate a method of assisting employees with parent care responsibilities (AARP News Bulletin, September 1987:13). Finally, wiener, like Blumer (1971), emphasizes that the actors involved in defining the problem and in building an arena are doing so from their own distinctive realities; thus conflict and differing perceptions can be expected in the natural history of collective definition.

There appears to be agreement that the designation "social problem" is linked with political intervention 
(Blumer, 1971; Ross and Staines, 1972; Wiseman, 1979; Wiener, 1981). Similarly, Estes (1979) suggests that the "solutions" to the problems of aging are perceived largely to be associated with governmental intervention.

According to Blumer, intervention or implementation of an official plan (fifth stage, 1971:304-305) evokes subsequent changes in the plan and a redefinition of the social problem. With reference to aging, the passage of the Social security Act in 1935, and subsequent amendments such as Medicare and Medicaid (1965), have fallen far short of the initial intent and definition of the problem (Pratt, 1976; Estes, 1979). A similar process has occurred with the enactment of and amendments to the older Americans Act (Estes, 1979). The implementation process of these official plans has changed the plans themselves and has been a part of the continuing change in the collective definition of the old age problem, a sequence that Blumer (1971) argues is typical.

As an example of change in the collective definition of the aged, Estes (1979:228) and Levin and Levin (1980:57) suggest that the particularistic or exceptionalist programs of current legislation, in which the aged are targeted specifically and are "helped" to live with their problems in society, have produced a more negative definition of old age and a "blame the victim" approach. This is in contrast to a universalistic 
approach, aimed at the root cause of problems in the social structure which would align the aged with other groups according to need rather than age. Whichever way is chosen it appears that the collective definition of a social problem is changed throughout the policy formulation, enactment and implementation process.

A "blame the victim" approach is also associated with the explanation of social problems. Estes $(1979: 12,228)$, Levin and Levin (1980) Ross and Staines (1972:26) and Abercrombie et al. (1984) describe the tendency for the explanation to derive from the personal characteristics of the problem group, rather than from structural forces in society. This approach in effect "blames the victim" for the occurrence of the social problem, even when aspects of social structure are more likely to be the root cause. Levin and Levin (1980:35) suggest, for example, that biological, psychological and behavioral research in aging clearly "blames the aged for the problems they suffer," to the exclusion of investigation into structural forces which influence sociogenic aging problems. The underlying theme appears to treat the problem of old age as an aberration "from the essentially stable and desirable norms that comprise the dominant social structure" (Levin and Levin, 1980:41). Phillipson (1982) similarly suggests that overemphasis on health problems at the individual level masks the part played by economic and social forces 
in the production of problematic aging. The very fact that health changes actually occur in conjunction with aging has probably increased the acceptance of this approach.

The debate over which elements of society have the right or responsibility to define other elements or conditions as social problems is long-standing (Lopata, 1984). Manis (1984:9), suggests that the collective definition or public opinion perspective, as described above, is flawed due to its reliance on "what most people or the powerful segments of a society consider undesirable." In effect this suggests that the conditions of the few or the powerless are unlikely to be viewed as social problems unless in some way they are perceived as a threat to the powerful. Manis (1984:10) further suggests that "The public opinion definition places the sociologist in the position of supporting the beliefs and values of the dominant groups of the society." Wiseman (1979:3) similarly suggests that studies on the development of social problems of the 1940's and 1950's were "valueladen."

The above concerns are legitimate. For instance, Estes (1979) provides considerable evidence, in the case of aging, that definitions of the problems of aging are indeed constructed by those with power and influence, such as politicians, researchers, bureaucrats and service providers, rather than by representatives of the older 
population themselves.

Estes (1979:16-18) further suggests that the dominant perspective characterizes the aged "by an inevitable physical decline" and as "dependent and in need of help" with little consideration of their actual status and despite great variability in the older population. In effect, this definition of the aging problem labels older people and "...justifies the stigmatization and continuing marginality of the aged" (Estes, 1979:12,16,228). The relative power of those involved in defining the aged problem has produced considerable acceptance of this negative labeling by the public and by the elderly themselves. Estes (1979:13) suggests important consequences for the elderly in regard to loss of power, negative self-perception, and dependency behaviors, if such labeling is accepted. (This consequence of negative interactions and cultural meanings will be explored further in regard to a Model of Normal Aging, and in regard to autonomy or self determination in the parent).

With regard to the problem of parent care, it appears that the powerful rather than the powerless are similarly involved in the process of problem definition. Currently, executives and researchers are defining the problem in response to economic pressures; neither the caregiver nor the care recipient has succeeded in creating a collective definition, despite the objective nature of long term care 
provided by adult daughters to aging parents over past years.

Finally, there is additional evidence to suggest that care of elderly parents and relatives by family members is developing as a legitimate social problem of its own.

This evidence includes the following factors: increased publication in both professional and lay journals and newspapers relating specifically to the topicl; specific radio and television programming; prominence of the topic as a part or as the focus of professional and non-professional educational seminars or meetings; good attendance by family caregivers at lay meetings; newspaper reports of concern and research by large employers such as The Traveler's Corporation, into employee care for dependent elderly family members (Freudenheim, 1986); consideration and/or initiation of employee benefit systems for dependent elder care (e.g. Traveler's, AARP); funded research on caregivers of dependent elderly persons locally and nationally (Portland State University, 1987; Oregon Health Sciences University; Corporate Eldercare Project, University of Bridgeport [Wood, 1987:33]); concern by the women's

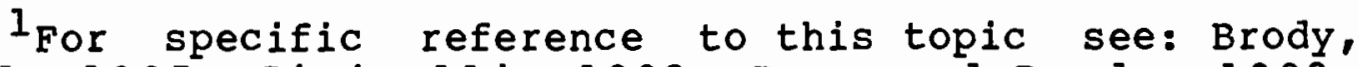
1981 , 1985; Cicirelli, 1983; Lang and Brody, 1983; Stoller, 1983, 1985; Brody et al, 1984; Bayless, 1985; Gelman and Hager, 1985 [Newsweek]; Brody and Schoonover, 1986; Brozan, 1986; Freudenheim, 1986; and Crossman, 1987. 
movement of the de facto women's role as primary care provider (Brozan, 1986); emergence of small caregiver support groups; eagerness with which caregivers embrace assistance in their role; increased resources for elder care such as respite services and adult day care; and increased recognition by informal (family) caregivers of government limitations with respect to elder care.

While care of the elderly parent by family caregivers constitutes one aspect of the larger problem of old age, it may also be designated as a social problem in its own right. This designation is suggested from the visible activity surrounding the topic, which may be equated with a process of collective definition (Blumer, 1971), and which, in Wiener's terms, is animating, legitimizing and demonstrating the problem (1981).

With the above discussion as background, attention may now be focused on received and constructed images of old age, and their relationship to this research project.

RECEIVED AND CONSTRUCTED IMAGES OF OLD AGE

Related to the development of social problems is the process by which collective images or "realities" are developed, transmitted, and subsequently held by individual members of society. The following discussion is presented to clarify this process, and to apply the information to the field of aging and, specifically, to 
the parent caregiving situation.

To initiate this clarification, a number of rhetorical questions may be posed: for instance, how are images or realities developed or acquired? What is the relationship between a collective image or a reality held by a larger public, and face-to-face interaction, as occurs in the caregiving process? Specifically, is there a typical public image of old age or of older persons, as suggested by a review of some relevant literature? Do images held by members of the general public vary according to characteristics of the holder such as age, type of contact or proximity to elderly or infirm persons, and other variables? Furthermore, are images or attitudes modified in the process of interaction and/or by the environmental context? Does the image held by a daughter caregiver about old age or an elderly parent coincide with images held by the larger public? Also, are there any outcomes of images held by one group for a second group, such as decrements of personal functioning in older persons supposedly associated with negative societal views of old age (Ruypers and Bengtson, 1973)?

The discussion attempts to respond generally to the above questions and concerns, using concepts developed by Berger and Luckmann (1967) regarding the "social construction of reality." Their conceptual framework has been applied usefully to the topic of old age by carroll 
Estes (1979) and Cherry Russell (1981).

Berger and Luckmann (1967:15) argue that knowledge, particularly commonsense knowledge, is "what people 'know' as 'reality' in their everyday ... lives." They also suggest that understandings of "knowledge" and "reality" pertain to specific social contexts and vary from one context to another $(1966: 3)$. With this view of knowledge, they proceed to explain the development "of knowledge that guides conduct in everyday life," and from this, the development of "reality" (1967:19).

For Berger and Luckmann, all "reality" is socially constructed and is the product of a reciprocal relationship between individuals, on the one hand, and the social environment, on the other. They see this relationship in two ways: as existing prior to a given individual, in which the social world is perceived to be objective, and to have a "reality" of its own (1967:21); and at the same time, as the product of shared interaction with others, in which there is relative congruence between the meanings and understandings of one person vis-a-vis another. Thus, there is a common, or shared, sense of social reality $(1967: 23)$.

According to Ritzer (1981:198), the position taken by Berger and Luckmann (1967:18) is that of "the dual character of society in terms of objective facticity AND subjective meaning" (emphasis in the original). This 
position is explained by three phases of a dialectical process: externalization, objectivation and internalization, which operate simultaneously in a dynamic, nonlinear manner (Berger and Luckmann, 1967:61; Lemert, 1979:153). This is further characterized by Berger and Luckmann as a process of social reality in the following statement: "Society is a human product. Society is an objective reality. Man is a social product" (1967:61).

This attempt to explore the "reality" of old age can be facilitated by the use of some additional concepts.

The phenomenon of objectification implies that elements of the the social world are perceived by humans to have a concrete, real or tangible nature despite their emergence from the subjectivity of face-to-face interaction (Berger and Luckmann, 1967:89). This perceived factual nature of the social world appears to impose itself on the individual and to be coercive over human behavior; that is, there is a need to modify individual behavior to "fit in" with the "reality" of the social world. However, Berger and Luckmann (1967:89) clearly emphasize that "...the social world was made by men [sic] - and therefore, can be remade by them."

The ability to communicate through symbols is seen as the primary vehicle by which prior and ongoing knowledge of social reality is received, shared and constructed. For Berger and Luckmann (1967:21,22,36-41), language is 
encountered as a fact external to the self, which objectifies, gives order or makes "real" the elements of everyday life, past, present and future. Language allows the meanings inherent in face-to-face interaction to be detached from and to transcend the subjective "here and now" and to inform others in different spatial, temporal and social situations (1967:39). Through language ${ }^{l}$ and in the process of face-to-face interaction a "social stock of knowledgen is constructed or modified. This knowledge is also accumulated over time and is "transmitted from generation to generation" (1967:41). The stock of knowledge varies with the relevance of a particular domain of interest or "relevance structure," (1967:45), and guides interactions with others both in the "paramount reality" of everyday life and within different domains $(1967: 25,45)$.

Applying this schema to images or realities of old age, a specific stock of knowledge on aging and old age is developed over time, transcending the subjective person to person level, and being transmitted through the vehicle of language and symbols. Achenbaum (1978) and Fischer (1978) have traced the historical development and

${ }^{1}$ Paul Higgins $(1980: 24)$ in discussing the sociology of deafness, argues that language and speech capability is not a requirement for thinking and competence; hence the transmission of knowledge and socialization experiences are effected more accurately through the use of symbols, and not language alone. 
maintenance of attitudes or images regarding old age. Both these authors and others (Estes, 1979; Levin and Levin, 1980; Russell, 1981) have documented pervasive negative societal views on old age in contemporary society.

An additional concept is that of habitual action or "typification" (Berger and Luckmann, 1967:30). For Berger and Luckmann, typifications serve to guide the individual in both face-to-face and more distant or anonymous interaction. Even though face-to-face interactions are by their nature flexible and open, typical patterns develop which guide meanings in an encounter and serve to relieve the individual of the need to pay close attention to all facets of an interaction or in the environment (Berger and Luckmann, 1967:30,31). These "typifications" are open to negotiation and change during interaction, as evidence renders the meaning of their content inappropriate $(1967: 31)$.

For example, an individual may hold a relatively negative typification of elderly persons, based on prior socially transmitted and/or personal knowledge. In a faceto-face reciprocal interaction with an elderly person, this typification may not hold, due to the "massive evidence of the other's subjectivity" which clearly renders the content incorrect (1967:30). If subsequent frequent interactions with elderly persons result in 
similar realizations, then a modification of the typification may result; if such interactions are limited, then the older person is more likely to be viewed as unique and as an exception to the typification (1967:32). In this case, a lasting change in the image of the elderly is less likely.

Similarly, Berger and Luckmann (1967:31-33) suggest that as the distance increases from direct person-toperson interaction, or as the interest level decreases, there is a corresponding increase in anonymity and in the reliance on typifications. This anonymity reduces the probability of modifying typifications from personal evidence and allows a greater filling-in from the social stock of knowledge, both contemporary and historical $(1967: 32,33)$. The relative persistence of typifications, as intimated in the work of Berger and Luckmann referred to above, suggests difficulty or inertia in the modification of currently held, societal images of old age or the aged.

An example of exceptions to typifications, and of image persistence, is found in the report by Harris and Associates (1975:53) in which respondents, themselves over 65, were found to hold negative images of "most people over $65, "$ somewhat similar to younger members of the public. At the same time, the older respondents considered themselves to be exceptions to this image. In this 
example, greater contact with older persons did not appear to erase long held typifications, possibly due to the interaction of other variables, such as perception of the self as a member of a younger rather than older age group. For Berger and Luckmann (1967) typifications or habitual actions are considered to be the source of collective behavior and "social structure." They assert that "Social structure is the sum total of ... typifications and of the recurrent patterns of interaction established by means of them. As such, social structure is an essential element of the reality of everyday life" (1967:33). While this characterization of social structure is questioned by some sociologists (see, for example, Ritzer, 1981:199-200), it serves to link the emergence of images from socially transmitted and face-to-face knowledge with images which are objectified, are sustained in the greater social structure and which become part of a social reality. In this way an image of old age or the aged develops or is acquired, becomes objectified, and takes on its own reality.

The process of "institutionalization" also follows from habitual action and becomes part of social structure. In its most basic form, Berger and Luckmann argue, an institution emerges from habitual actions or interactions by individuals in face-to-face situations over time $(1967: 53,54)$. Habitual action allows the individual to 
repeat frequent patterns with a minimum of effort while retaining meaning, thus leaving energy for problematic activity $(1967: 25,53)$. For Berger and Luckmann, "the background of habitualized activity opens up a foreground for deliberation and innovation" (1967:53). When habitual action is reciprocated in a typical manner by typical actors, over time, then institutionalization is said to occur (1967:54). Thus institutions are characterized by typified, shared activity of a social group; these institutions endure over time, and develop expectations of conduct, such that they are controlling of human behavior $(1967: 54,55)$. Berger and Luckmann suggest that institutions become more formalized with the occurrence of transmission through socialization to new generations, which in turn endows the institution with an objective reality and "confronts the individual as an external and coercive fact" (1967:58).

An example of institutionalization pertinent to the problem of old age, and fairly well illustrative of Berger and Luckmann's conception, may be seen in the bureaucratization and extensive network development attendant on the older Americans Act and other legislation aimed at the elderly. This bureaucratization and its coercive power over the elderly has been described clearly by Carroll Estes (1979:54): 
The Older Americans Act...has imposed limits on choice and [has] created structural mechanisms for institutionalizing those limitations... The planning and coordination strategy not only reflects the dominant view of the experts on the nature of the problems, the action required to solve the problems, the methods to be used, and who will carry out the tasks, but it legitimizes the role of expertise and the status of experts.

Estes is speaking to the process of legitimization, and to the status of experts, which introduces a further concept from Berger and Luckmann, namely institutional legitimation and maintenance (1967:71).

The maintenance of institutional meanings and the transmission of knowledge to individuals over time requires some form of educational process or transmission apparatus (Berger and Luckmann, 1967:70). This statement applies as much to the institutionalization of the old age status and the associated bureaucratic network surrounding the Older Americans Act and related legislation as it applies, for example, to the economy or the family.

Berger and Luckmann (1967:71) suggest two problems related to legitimation, maintenance and transmission: those of (1) "logical coherence" or unified institutional understandings, and (2) "socialization," or the transfer of a stock of knowledge. The emergence of specialists who become largely responsible for specialized knowledge and its mediation within the institution is seen by Berger and Luckmann (1967:78) to respond to these problems.

Socialization is essential to the construction and 
transmission of reality, and, in terms of institutionalization, is a component of Berger and Luckmann's concept of a dialectical process (1967:61), previously described. Specifically, socialization, both primary and secondary, is the path by which institutional meaning, indeed all knowledge, is transmitted over time, and between generations. Berger and Luckmann (1967:130) define socialization as "the comprehensive and consistent induction of an individual into the objective world of a society or a sector of it."

Primary socialization occurs with the initiation of the child into society, and is effected by significant others, such as parents, in a specific social environment. Through primary socialization, the child identifies with and takes on, or internalizes, a specific social world to include, initially, roles and attitudes of significant others and, subsequently, roles and attitudes of society in general (Berger and Luckmann, 1967:131). This social world becomes the "known" social world for the child, and is the child's "reality" (1967:134). Participating in this process, the child forms an identity and becomes a member of society. For Berger and Luckmann, the affective involvement and the inevitability explain the firm entrenchment and lasting influence of primary as against secondary socialization (1967:135).

Secondary socialization "is the internalization of 
institutional or institution-based 'subworlds'.... [These] are generally partial realities in contrast to the 'baseworld' acquired in primary socialization" (Berger and Luckmann, 1967:138). Identification and internalization in secondary socialization are more likely to occur if the content is not in conflict with the persisting reality of primary socialization $(1967: 140)$. With regard to the transmission of institutional knowledge, the role of the expert becomes important due to the more problematic nature of secondary socialization, as previously indicated (1967:71, 78). This applies to the bureaucratization of programs and services for the elderly as well as for other institutions.

With reference to aging, attitudes toward old age and older people and expectations of care for older family members may be conveyed and internalized during primary socialization. The variation in these attitudes may be associated with differential perceptions of old age and subsequent involvement in parent care. Following from the reasoning of Berger and Luckmann, it is probable that these values, attitudes, roles, images, etc., would have a more lasting effect than knowledge deriving from secondary socialization.

The specialists or experts described by Estes $(1979: 6,54,57)$ as central to the aging enterprise (bureaucrats, administrators, researchers, technocrats, 
gerontologists and other professionals) function also as agents of secondary socialization; they comprise the same group that is involved in the definition of the aged as a social problem. While Berger and Luckmann do not expand on Mannheim's view that "knowledge must always be knowledge from a certain position" (1967:10), the role of social position in the development of knowledge and in the definition of social problems is important. Both Estes $(1979: 6)$ and Russell $(1981: 28,29)$ suggest that prevailing, largely negative, images of old age or the elderly are products of individuals who hold supraordinate positions in the dominant culture. According to Estes, $(1979: 6)$ :

Knowledge is socially generated; it emerges from the ordering and interpretation of facts. It may be accepted as factually legitimate, based upon empirical demonstrations of proof or upon the judgments of proclaimed experts and authorities who possess status and power. The less the knowledge base is empirically proven, the greater the influence of social and political factors in the interpretation and acceptance of the data as knowledge.... Although socially generated, such knowledge and expert opinion take on the character of objective reality, regardless of inherent validity. This "knowledge" in turn heavily influences both the perception of social problems and ideas on (sic) how to deal with them.

One difficulty arising from reliance upon "the expert" in the legitimation and maintenance of institutional knowledge is that "what is taken for granted as knowledge in society comes to be coextensive with the knowablen (Berger and Luckmann, 1967:66). 
With reference to the aging enterprise, Estes suggests that the knowledge generated orders "what is considered relevant and valid knowledge" (1979:5) and "...set[s] limits even on what is conceivable" (1979:3), which may not be in the best interests of those persons being served - the elderly. The institutional view of reality comes to be perceived as reality in fact, even by the elderly themselves (1979:4) and, by extension, the wider public. A similar process of internalization is described by scott $(1969: 21-23)$, in which the blind also respond and come to hold, in varying degrees, society's negative appraisal of their reality. In this manner, dominant institutions, such as the aging enterprise, prevail in the understanding of reality external to the institution, specifically the "public" image of old age or the elderly.

From this negative definition of old age, Estes suggests that: the aged are widely perceived to be a problem (partially of their own creation), to manifest inevitable physical decline, and to be dependent and in need of special services $(1979: x, 4,16)$.

Similarly, Russell (1981:14), in her research on the aging experience in Australia, speaks to

...the set of socially constructed meanings which attach to the category of 'old' - meanings which define its members as people of reduced capacity and social value and which confront the elderly as inescapable objective conditions of their existence. 
These negative images of old age persist despite the fact that the elderly population in the United States is increasingly diverse and includes a "young-old" segment that is independent, vigorous and competent (Neugarten, 1982). The presence of this negative image is confirmed, with variation, by other authors and by "common knowledge" (Harris and Associates, 1975; Comfort, 1976; Achenbaum, 1978; Levin and Levin, 1980; Arluke and Levin, 1986).

More positively, Berger and Luckmann suggest that any body of knowledge is open to change, in that it "has the capacity to act back upon the collectivity that has produced it" (1967:86). They assert that "the relationship between knowledge and its social base is a dialectical one, that is, knowledge is a social product AND knowledge is a factor in social change" (1967:87; emphasis in the original). From this, it is possible that within the aging enterprise, experts themselves have the capacity, through the dissemination of their form of knowledge, to act back on the institution to change the negative image of the elderly. The critical works of Carroll Estes (1979) and Cherry Russell (1981) may be considered examples of this attempt.

Change in a body of knowledge, although possible, is not without problems. Integral to this process is an ongoing tension between stability and change which occurs in institutional maintenance (Berger and Luckmann, 
1967:106, 118). With reference to the aging network, Estes (1979:5), speaks to the political and economic benefits which accrue to those engaged in providing services to the elderly under the auspices of the Older Americans Act and other legislation. These benefits, and the associated power accumulation, function to maintain the status quo, and constitute an impediment to change in the present reality of old age. This inertia to social change (Berger and Luckmann, 1967:122,123) may help to explain the relative persistence of negative images of old age and the elderly.

A consequence of the pervasive negative image of old age and the aged is the effect on the older person as an individual. Estes (1979:13), with reference to the symbolic interactionist literature, suggests that:

Older persons, like everyone else, operate from a premise of meanings derived from, and modified on the basis of, the interactions they have with others in their environment. If, in these interactions, old people encounter negative perceptions and labels, they are likely to come to share similar negative perceptions both of themselves and of other older persons.

In a similar vein, Russell (1981:8, 9), observes that the older people in her study appeared to have "spoiled identities" and to have a "constant struggle to cope with society's denial of them as normal, competent, adult human beings."

Harris and Associates in The National Council on the 
Aging study (1975:48), reported that older respondents (65 and over) were inclined to view the elderly, as a group, negatively; however, they tended to exempt themselves from the designation. The rationale for this finding can be traced to the socialization experience and the acquisition by the respondents of negative societal images regarding the aged when they themselves were younger (1975:48). By exempting themselves from the category of old age, some persons of 65 years or older appeared to deflect or not recognize the potentially harmful stigmatization of old age, thus retaining their self esteem. According to Russell (1981:80), "cognitive distancing" of this type serves an integrative function, so that the aged person can exercise some control or have autonomy over a preferred reality. Even so, the Harris study (1975:54) found self esteem to decrease after age 65, suggesting difficulty in complete exemption from the influence of stigmatization in old age.

Considerable information exists on the consequences of stigmatizing labels for individual action and integrity. These influences on the aged person and on the caregiving situation will be discussed further, with reference to a Model of Normal Aging. 


\section{A MODEL OF NORMAL AGING}

A model of "normal aging," proposed by kuypers and Bengtson (1973), is the final part of the theoretical framework. As previously mentioned, this orientation provides a link between the social system level and the individual level of analysis. In this regard, it provides insight into possible effects on the aged individual of exposure to the generally negative view of old age and aging held by society.

Using as a format "the social breakdown syndrome," originally developed by Gruenberg (1964) and zusmann (1966) in relation to mental illness, Kuypers and Bengtson (1973:186-187) posit a relationship between socialenvironmental conditions and individual problems of aging. In their words, "The 'symptoms' of being old are associated with the negative attitudes and actions accorded the symbols of aging in today's society" (Ruypers and Bengtson, 1973:187). For these authors, "typical" aging is seen to have a pathological nature engendered by negative social-environmental changes (1973:182).

Kuypers and Bengtson suggest that, typically, an older person is faced with a "variety of social reorganizations" which render the person more susceptible to negative labels associated with old age (1973:181-182). 
They identify three examples of social reorganization facing the older person; these have been reiterated a decade later by Bengtson and Haber (1983:87-90).

First, Kuypers and Bengtson (1973) suggest a loss of clear and appropriate normative guidelines or expectations for behavior during old age. This is at variance with the more clearly defined norms extant for other age grades. In the absence of specific norms for the old age status, expectations of middle age and basic social values for all adults appear to occupy a substitute position (1973:183). Second, they identify the loss, shrinkage or change in social roles as a person ages, retires, loses a productive identity, experiences loss of a spouse, family members, and/or friends, and experiences reduced social contacts secondary to health problems, financial and mobility limitations, etc. (1973:182,183; Bengtson and Haber, 1983:87-88). These role losses in effect may reduce the person's social position and presumed value, particularly since personal worth is assigned largely through productivity in mainstream American culture (Kuypers and Bengtson, 1973:187, 191). Third, they suggest that there is a lack of appropriate reference groups as one enters the period of old age. Indeed, data from the Harris and Associates study (1975), suggest that people over 65 strongly attempt to resist association with an old age reference group, preferring 
instead to continue a midale age orientation.

Ruypers and Bengtson (1973:182) argue that these

social conditions in the normal course of aging ... deprive the individual of feedback concerning who he [the authors' gender use] is, what roles and behavior he can perform, and, in general, what value he is to his social world. This feedback vacuum creates a VULNERABILITY TO, and DEPENDENCE ON, external sources of self labeling, many of which communicate a stereotyped negative message of the elderly as useless and obsolete (emphasis in the original).

In other words, the social-environmental conditions typically facing the individual with advanced age disturb the sense of self and render the individual potentially susceptible to the effects of negative labeling from the environment. This, in turn, reduces the individual's sense of competence and diminishes the level of performance, in effect validating the label applied by society. For this reason, Kuypers and Bengtson (1973:182) suggest that "normal" aging as experienced by the individual has a pathological quality. Similarly, Comfort (1976:9) suggests the notion of "sociogenic" aging - society's role in the construction of the aging process.

It is possible that there have been some changes in the social-environmental conditions affecting the elderly, since initially identified by kuypers and Bengtson in 1973. The elderly population in the united states is continuing to increase, and to differentiate into distinct sub-groups; this provides potential for more 
appropriate reference group formation, and for differential influence by cohorts of the elderly on the larger social system. Possible changes in these conditions have not been examined for this review, because, while changes may have occurred, it is assumed that aging individuals are still faced, to some extent, with similar social system experiences.

Considering further the social-breakdown syndrome, kuypers and Bengtson identify seven steps to the formulation originally specified for mental illness. These steps $(1973: 187)$ include:

1. Precondition of susceptibility;

2. dependence on external labeling;

3. social labeling as incompetent;

4. induction into a sick, dependent role;

5. learning of 'skills' appropriate to the new dependent role;

6. atrophy of previous skills; [and]

7. identification and self-labeling as 'sick' or inadequate.

With reference to step one, Ruypers and Bengtson (1973:187, 191) posit that the elderly, as an entire age grade, meet the precondition of susceptibility to this syndrome by virtue of their common experience with the aforementioned social-environmental conditions. This is not to suggest that all elderly persons are necessarily vulnerable, when the heterogeneous nature of this group is considered (Neugarten, 1982:36); rather, there is a heightened susceptibility in contrast with other age grades. Favorable socio-economic status, employment, or 
other characteristics of the aged individual or of a subgroup may decrease this susceptibility. Applying this initial step to the focus of this study, the caregiver and care recipient, it is likely that the aged parent receiving care is indeed in a situation of heightened susceptibility to the syndrome due to the factors of dependence, impairment, advanced age, and multiple losses.

Step two refers to dependence on external labeling. While individuals of any age typically define themselves on the basis of cues or feedback from others in their environment (Blumer, 1969:2-13), Ruypers and Bengtson suggest that an aged person relies to a greater extent than a younger person on external sources for current guides to action. They argue that "...the social changes experienced late in the adult life line are likely to create a vacuum of information concerning one's personal action and position in the wider society" (1973:188). This step would not be problematic, except for the fact that information typically received by the elderly person points to negative qualities such as "incompetence, uselessness, and obsolescence" (Kuypers and Bengtson, 1973:188). Thus "the nature and quality of the cues available" and the person's confidence in his or her own judgment is critical in whether a dependence on external labeling occurs and is dysfunctional for the individual (1973:188-189). The aging parent as a care recipient is 
more likely than an independent older person to rely on external cues; if these external cues arise largely from the caregiver and the care environment, then the nature of the views held and reflected back to the parent becomes critical.

step three, social labeling as incompetent, refers to the negative process by which social groups in Western society, from a functionalist perspective, inform older persons of their "uselessness, obsolescence, low value, inadequacy and incompetence" (Ruypers and Bengtson, 1973:189). The process of labeling the older person does not necessarily imply either agreement with or acceptance of the label by the older person. Rather the process of agreement and/or acceptance of a label, if it occurs, starts with induction into a sick or dependent role and progresses thereafter. Self-labeling, or the adoption of "a generalized self-view of incompetence, uselessness, and worthlessness" occurs as the end point of the negative cycle - step seven in the social breakdown syndrome (1973:189, emphasis in the original).

Step four involves induction into a sick, dependent role. Although Kuypers and Bengtson (1973:190) suggest that this step is more characteristic of the person experiencing mental illness than aging per se, it appears applicable to those in dependency situations such as the aged parent as the recipient of care. For some parents, 
particularly those who relinquish separate living, the act of entering another household as a non-equal member is tantamount to induction into this dependent role.

Step five, the learning of "skills" appropriate to the new dependent role, follows this induction. For the care recipient in particular, dependency, passivity and associated behaviors may be activated, varying with the response of the caregiver, the position of the parent in the care situation, and the parent's level of impairment.

step six, the atrophy of previous skills, such as work and social skills if not demanded in the new status is more likely to occur. Kuypers and Bengtson (1973:190), question "whether basic psychological skills previously used to cope with, and adapt to, environmental change might not also atrophy." If so, "the loss of ... coping processes - which provide the foundation for competent behavior," represents a consequence of the labeling (1973:190). In the caregiving situation, some atrophy of a parent's skills is considered likely; thus a reduction in the parent's level of personal autonomy or selfdetermination is hypothesized.

Step seven, identification and self-labeling as 'sick' or inadequate is the final outcome of the social breakdown syndrome. Although self-labeling as 'sick' may be too strong an outcome for many elderly susceptible persons, self-identification as useless, incompetent, of 
low value, and with limited ability to influence the environment is possible, together with the development of a sense of generalized external locus of control (Ruypers and Bengtson, 1973:190, 194). According to this schema, losses in self-determination or personal autonomy by the care recipient and the internalization of a 'sick' label may indeed occur.

In that much of the "reality" of old age is negative, albeit ill-defined, an alternative strategy for the individual is to deflect the feedback by disclaiming membership in the older age grade. This was apparent for many respondents in the Harris and Associates study (1975), as previously discussed, who considered themselves to be unique, and not part of an old age group; this exemption allowed them to retain a more positive view of themselves. Possibly, these same respondents were also less susceptible initially. Russell (1981:72), citing Rosow, agrees that the negative attributes of the "old age" label lead individuals to attempt to avoid the designation and thus to avoid its implications. Russell (1981:70) suggests that beginning acceptance of an "old age" label does not occur until the development of an agerelated crisis, such as illness, dependency, problematic retirement, economic difficulties, etc.. At this point, the individual, according to Berger and Luckmann's framework (1967:30), is confronted with "the massive 
evidencen of his or her own frailty and its congruence with the 'old age' status in contemporary society. This recognition is likely to apply to the care recipient, by definition a person with varying problems of impairment and dependency, who would thus have greater difficulty in avoiding a negative self-view, even when varied feedback from the caregiver is considered.

To summarize, Kuypers and Bengtson suggest that the social breakdown syndrome operates as a ncycle of interaction," or as "a vicious feedback loop with negative inputs" (1973:190). Thus, there is a circular effect in which the person so labeled comes to act in accordance with the label, which reinforces the accuracy of the label and perpetuates the negative image of the aged person in society. On a personal scale, a similar cycle can be envisioned for the elderly parent and the caregiver. As shown in Figure 1 , taken from Kuypers and Bengtson's interpretation of the social breakdown syndrome applied to old age (1973:190), the aged person is enmeshed in an ongoing process of continuing loss of social and personal skills.

Assuming the existence of a negative social reality for the aged, the foregoing discussion suggests that the social breakdown syndrome is a clear hazard for susceptible members of the entire age grade, and also that the aged parent receiving care is likewise susceptible. 


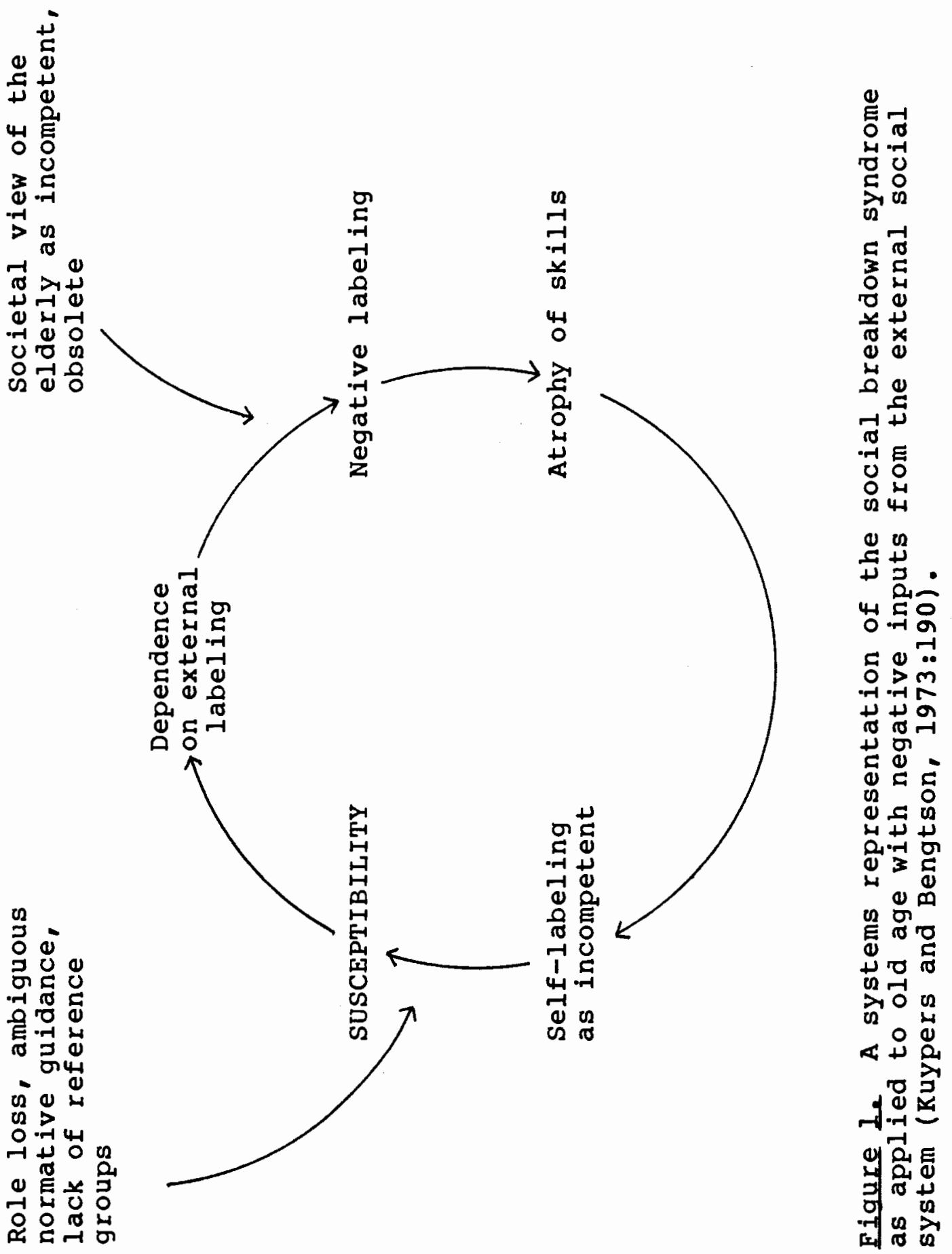


However, there is an alternate response the older person may make to the social reorganization affecting people in later life. Kuypers and Bengtson (1973:191) suggest that for some individuals the lessened normative guidelines, the reduced social constraints and role obligations, and the decrease in age-appropriate reference groups for patterning behavior provide greater opportunity and freedom for individual action. Thus, quite similar changes in the social system affecting an individual can have opposite consequences - opportunity rather than anomie, freedom rather than curtailment (1973:191).

Scholars have suggested various factors that may predispose the aging individual to one course of action over another. Phillipson (1982:10-11) and de Beauvoir (1972:16, 101) cite the differential experiences of aging by class and gender; personality traits may account for varying levels of susceptibility in different individuals, particularly since there is considerable evidence to support stability of personality over time (Reedy, 1983:121); prior or present employment, levels of education, ethnicity, and cohort membership likewise may have some effect; and finally health status and the presence or absence of impairment, as previously suggested, may be influential.

Ruypers and Bengtson (1973:192), not surprisingly, support the view that aged persons, when faced with their 
changed position in the social system as described, are likely to be susceptible to the consequences of negative social labeling. Their rationale is, firstly, the existence of a strong value base for assigning individual worth in American society - a value of "social utility through productivity," in which the elderly are negatively rated; and, secondly, the fact that members of present elderly cohorts themselves have been socialized in this same reality and are unlikely to change their views purely as a function of age (1973:192).

other authors support, in concept, the model described by Kuypers and Bengtson. For example, Wolinsky (1980:198) suggests that:

Once old age is reached, the aged are faced not only with the inevitable physiological decline, but, more important, with their reassignment to a lower social status... based on the negative stereotype of the aged. As a result... the closer an individual gets to old age, the more fully he or she accepts the negative stereotype of the aged, and the more fearful and anxious he or she becomes about being identified as an old person. Once the individual has been identified as an old person, society reacts to that "old person" label rather than to the true identity of that individual, redefining that individual as something different and of less value and status.

Similarly, Carroll Estes (1979:12-13,227-228) speaks to the process of labeling the aged, and of the consequences of group labeling on individual functioning. This issue of labeling is linked to the previous discussion on social problems, for "aging becomes a social 
problem only when it is successfully labeled as such by some social group. Further, the more influential the group doing the labeling, the more widespread the acceptance of the label" (Estes, 1979:13).

In terms of the consequences of labeling for the aged person, Estes (1979:13) refers to the symbolic interactionist literature on the development of selfconcept. For instance, Blumer (1969:12-13), following George Eerbert Mead's work, suggests that the self is formed through an ongoing process of social interaction in which individuals define themselves largely according to the actions of other people toward them. Thus selfconcept is developed as a reflection of the regard toward an individual, from persons in his or her particular environment. Estes (1979:13) suggests that this same premise applies to older persons, who may come to define themselves, and others in their age group according to the negative perceptions and labeling reflected by their environment. In this way, negative stereotypes educate the elderly person that he or she is indeed incompetent, irrespective of actual ability. Thus "social context and cultural meanings are important" in shaping the experience of growing old in society (1979: 14, 227).

In a parallel manner, scott (1969:15) discusses the socialization experiences of blind people, and its influence on self-concept, social identity, and competence 
of those who are blind. Scott $(1969: 16,17)$ recognizes the importance of socialization on three levels: general socialization to stigmatized roles in childhood, socialization as a consequence of face-to-face interaction, and secondary socialization effected by specialized organizations (as also described by Estes, 1979, regarding the aged). Of note is scott's additional comment on the mechanical difficulties of face-to-face interaction with a blind person; these difficulties have the effect of validating the stigmatized role for both parties in the interaction $(1969: 17,28-32)$. In a similar manner, visible signs of impairment in an elderly parent may validate an incompetent or 'sick' role for the parent and for the caregiver.

The three parts of the theoretical framework, as presented, provide a foundation and rationale for the research study. The first part regarding old age as a social problem, is an attempt to "legitimize" the focus of the study as a current social problem. The second and third parts of the framework are synthesized into a conceptual model to clarify the process of investigation.

\section{CONCEPTUAL MODEL}

A conceptual model is presented to clarify the relationship of the theoretical framework with the operationalization of the study. Specifically, this model 
suggests an overarching link, through the vehicle of socialization, between the construction of old age held in society with personal constructions of old age held by the caregiver of an elderly parent. It is further suggested, as presented in Figure 2, that characteristics of the caregiver, the elderly parent, and the ongoing interactions of the caregiving situation, all act as intervening variables in modifying the caregiver's personal constructions of old age and the interactive roles of the caregiver and the parent.

Given the caregiver's internalization of a largely negative societal construction of old age as previously discussed, and given an association between vulnerability to labeling and decrements in personal functioning in the older age grade as argued by Kuypers and Bengtson (1973), it is further suggested that an outcome of decreased personal autonomy in susceptible elderly parents may occur.

In this conceptual model the dependent variable of parental autonomy is employed as a proxy for decrements in the parent's functioning, and is based on the caregiver's assessment. The research questions, posed later, do not attempt to respond to all facets of the model as presented. Similarly, the differential construction of old age, held by the elderly parent is not explored. 


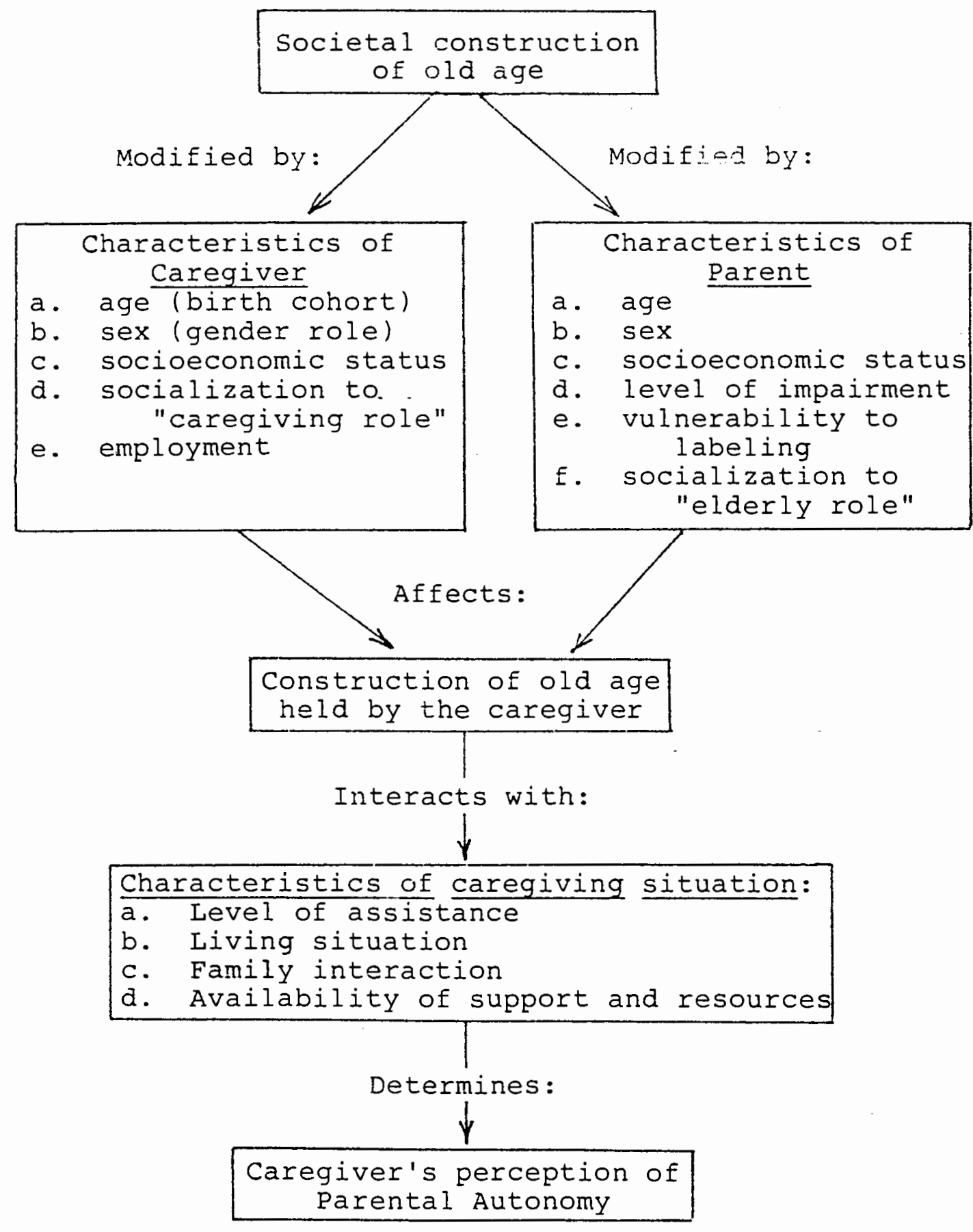

Figure 2. Conceptual model depicting a hypothetical relationship between constructions of old age and the dependent variable Parental Autonomy as modified by intervening variables. 
Chapter III, following, identifies the problem and context for parent care, to include a discussion of the dependent variable parental autonomy, and specifies the research questions or hypotheses to be evaluated. 
DESCRIPTION OF THE PROBLEM

CHARACTERISTICS OF THE AGING POPULATION

As indicated, American society is undergoing a transition from a younger to an older population. In 1900, those 65 years and over represented 48 of the total population $(3,084$ million); in 1980 , this same age group represented $11.38(25,544$ million $)$ of the population. projected to the year 2020, with the "baby boom" cohorts as members of the 65 plus age group, this population will rise to 17.38 (51,386 million), and is likely to rise to over 218 through the year 2050 (Taeuber, 1983:3). Hess (1985:3) suggests that by 2030 , one in five persons in the United states will be 65 years or older. Assuming the accuracy of these projections, and assuming greater levels of need in the "old-old" segment of the elderly population as will be identified, this information has implications for future policy development and implementation.

Even though the percentage of elderly in the general population continues to rise, it does so unevenly. Siegel and Davidson (1984:5-6) illustrate the changes in the population 65 and over: this population increased by 288 in the 1970's and is projected to increase by $24 \%$ in the 
1980's; in the following two decades there will be a drop in the rate of increase to $10 \%$ between 1990 and 2000, and then up to 128 between 2000 to 2010. This will be followed by a sharp increase to 318 between 2010 and 2020, with continued high levels thereafter as the "baby boom" cohort ages.

This analysis suggests a temporary future decline in the growth rate of the overall aging population. However, it is the composition of the population which is relevant to this study, particularly the continued dramatic increase in older age groups in need of care services.

Using the Bureau of the census population designations, the aged population (75 and over) and the extreme aged ( 85 and over), are increasing at a greater rate than the older population as a whole. These populations show similar growth fluctuations as described, but with a lag of some 10 to 20 years (Siegel and Davidson, 1984:1,3). Thus, in 1950, 318 of the older population was 75 years and over, in 1980398 was 75 years or older, and by $2000,50 \%$ of the older population is expected to be 75 or over (Siegel and Davidson, 1984:11). Remembering that the older population itself has also increased relative to the total population, these figures indicate a dramatic rise in the number of 'old-old' people in the population. To illustrate, Taeuber (1983:1), reports that the age group 85 and over has grown by 1658 
between 1960 and 1982 .

Doty (1986:35) reports that "nearly one-quarter $(22.9$ percent) of all United States elderly aged 65 or older are functionally disabled," and thus require some form of physical assistance, mostly provided by family and friends. While this figure does not identify rates of functional disability for different age strata, other authors report that the older segments of the aging population are more disadvantaged in terms of health, financial support, housing, transportation, psychosocial support and other indicators. Consequently, impairment in these older segments is greater than for the population 65 and over as a whole (Feller, 1983:1, 6; Taeuber, 1983:11,15,25). These increasingly large older cohorts are precisely those in need of services from both the formal and informal care systems, such as provided by the adult daughter (Streib, 1983:41; Siegel and Davidson, 1984:11). Feller (1983:1) reports from the National Health Interview Survey (1979) that "fewer than 1 in 10 who are 65-74 years of age needed help, compared with 4 in 10 who are 85 years of age or over." Streib (1983:40) and others have identified this vulnerable group of "old-old" persons as the "frail elderly," although the lower age is variously reported as 75 or 85 . Further, O'Brien and Wagner (1980:81), suggest that the frail elderly in their day-to-day existence have "virtually no margin of error 
or slack in their resources." As a further complication, Taeuber (1983:3) implies that these older persons are themselves likely to have adult children also age 65 or over. When characteristics other than age, such as sex and race, are considered, the population profile changes, with older women and minorities clearly more disadvantaged and more in need of care services than the "average" person aged 65 or over (Taeuber, 1983:4,25).

Although overall population changes are closely related to fertility, they are also related to death rates and immigration.

Regarding fertility, the recent increase in the elderly population is partially a result of higher annual births prior to 1920. The projected decline in new cohorts entering the old age status (1990-2010) is a result of the decline in annual births between 1920 and 1940 (associated with the Depression years). The projected dramatic increase in the size of the older population between 2010 and 2030 is a reflection of the post-World War II baby boom of the 1950's. Finally, the low birth rate period from 1965 through 1973 will result in a projected decline in the growth of the older population in the mid 2000's (Taeuber,1983:4; Deming and Cutler, 1983:22-24; Siegel and Davidson, 1984:6-7). The fluctuating birth rate has implications for elder care in the future, particularly when there will be larger numbers 
of elderly persons with fewer living relatives, including siblings, children and grandchildren, and hence with less access to care traditionally supplied by adult children and family members (Siegel and Davidson, 1984:90). Also affected is the perception of burden in parent care, when caregivers have fewer siblings to share the load (Treas, $1983: 99)$.

While absolute numbers of older people in the population can be determined fairly accurately, the proportion of elderly in the total population is dependent on future fertility; this factor also has implications for the dependency ratio and for the future care of older cohorts and the ability of different institutions to serve their needs (Deming and Cutler, 1983:24).

In attempting to foretell future demands for parent care Siegel and Davidson based estimates on the 1970 census for the percentage of women over 65 with one surviving child. These data indicate an overall percentage of 788 for women of all races, which is expected to rise somewhat by the year 2000, and to decline in $2025(1984: 90,141)$. In estimating data on intergenerational dependency these authors suggest an increasing burden regarding parent care for persons in two age groups: those between 45 and 49 are likely to experience dual burdens of supporting both aged parents over 70 and children in young adulthood - a problem of 
the "middle" generation; and a second group of persons aged 60 to 69 years, themselves elderly, supporting a parent or parents of 80 or over, the extreme aged category. They further suggest that the potential burden may be so great that individual families will require considerable community assistance (Siegel and Davidson, $1984: 09-91)$.

A second factor in the increase of the older population is the dramatic decline in mortality, particularly infant mortality, since the turn of the century. This translates into a marked increase in average life expectancy at birth. For example, as siegel and Davidson show, in 1900-02 the average life expectancy at birth was 49.2 years; in 1980 (provisional) this figure was 73.6 years, a significant increase of over 20 years. Life expectancy at age 65 has also increased although less markedly, from 11.9 years in 1900-02 to 16.4 years (provisional) in 1980, an increase of somewhat over 4 years $(1984: 43,59)$. These authors suggest that this "decline in the mortality of the elderly is intensifying the effect of low and declining fertility in raising the ratio of elderly parents to their adult children" (1984:91). The slower rate of increase in life expectancy at age 65 is associated with the prevalence of degenerative disease and chronic health problems in the older age group, which has consequences for the need for 
increased care services and for demands on adult children (Deming and Cutler, 1983:26-28).

Life expectancy projections differ with sex, with race and with socioeconomic status, all of which have implications for differential care services (Taeuber, 1983:5,6; Siegel and Davidson, 1984:48-51). The extended life expectancy of women, for example, has implications for increased rates of impairment associated with advanced age, for widowhood and non-family living, for poverty and for dependency.

In and out migration are additional factors affecting population composition. The present aged population (1979) includes the last of the great wave of immigrants to the United States before World War I, with about $11 \%$ of those 65 and over ( 1 out of 9) being foreign born, compared with 158 in 1970 ( 1 out of 7 ). Siegel and Davidson do not expect that immigration will have a significant impact on future population composition (1984:23); however, their analysis predates recent legislation relating to immigration and naturalization which could modify such predictions. As in the past, the presence or absence of foreign born persons may influence the character and service requirements of subsequent older cohorts, such as different patterns of parent care espoused by population sub-groups.

Living arrangements characteristic of older age 
groups are also relevant to this study. Siegel and Davidson (1984:87-88) report that these arrangements vary greatly with sex and with advancing age. Institutional residence is reported for only a small percentage of the population 65 years and over -5.28 in 1981 and 48 in 1965. This rate increases with age, but varies for each sex: for instance at age 75 to 79 , the rate of institutionalization for males is 3.98 and for females it is 5.68. At age 85 and over, the rate for males is $16 \%$ and for females it is 27\%. According to siegel and Davidson's estimates, those persons who survive to age 65 or over may anticipate spending approximately one year of their remaining life in institutional care.

For the majority of the older population $(94.88$ in 1981), non-institutional living arrangements are the norm. These arrangements also vary by sex and age. Data presented by Siegel and Davidson from 1981, indicate that for males the prevalent living situation is with the spouse (70\%) in contrast to $34 \%$ for women. In the same year (1981), the prevalent situation for women is living alone $(40 \%)$, in contrast to only $15 \%$ for men. In the older age group there has been a 98 increase in women living alone since 1965 (then 318), and only a 18 increase in men living alone (then $14 \%$ ). This change reflects the greater number of widows than widowers in the older population due to greater female longevity; the tendency for men to 
marry younger women; greater availability of financial support for all older persons through social security, making independent living possible; and the desire by women to live independently (Siegel and Davidson, 1984:87). Living with nonspousal relatives in 1981 is reported for 108 of women and 48 of men; figures for 1965 were 198 and 98 respectively. Living with relatives appears to be declining in favor of living alone in the case of women or, in the case of men, with a spouse. Treas (1983:96) suggests that the incidence of living with family other than spouse is associated with widow or widowerhood, illness, impoverishment and/or extreme age and is initiated reluctantly by the aged person. In a similar vein, Doty $(1986: 44)$ reports that the level of dependency is associated to a statistically significant degree with the locus of caregiving. Elderly parents living with adult children were more likely to be highly dependent and to require ongoing personal care. When dependency is not a factor, "intimacy at a distance" seems to be preferred by all parties as indicated by the finding that less than $5 \%$ of all families included an aged parent or parent-in-law in 1970 (Treas, 1983:96-97). The literature provides considerable support to the notion that elderly parents do not want to be a "burden" to adult children and, hence, prefer to live independently when possible (Schwartz, 1979:121; Doty, 1986:43). 
The final living option, living with non-related others, occurs more often for women than men, and is the least reported arrangement. A summary of the data on living arrangements is given in Figure 3 which depicts the living arrangements, by sex, of the 65 years and over population in 1981 .

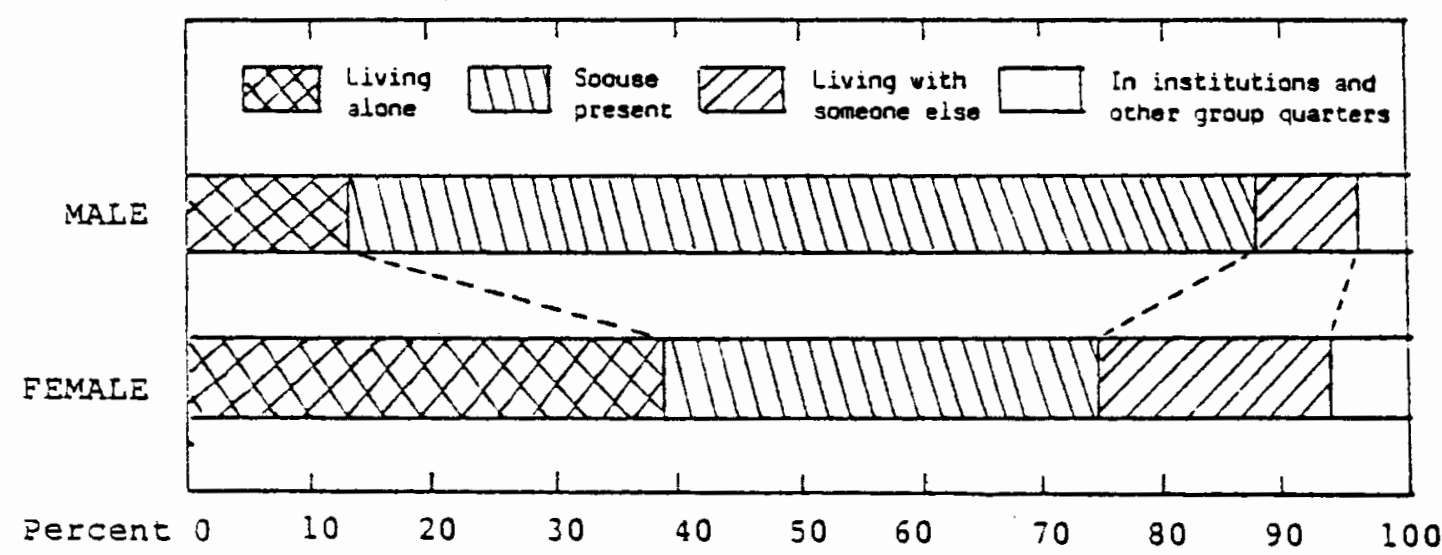

Figure 3 Distribution of the male and female populations 65 years old and older by living arrangements: 1981 (Siegel and Davidson, 1984:87).

CARE SYSTEMS: INFORMAL AND FORMAL

Care or support systems used by the elderly population may be categorized as "informal" or "formal" according to their source. Cantor (1980:132-133) characterizes the informal system as that arising from the "network of kin (particularly children), friends, and 
neighbors," as having an "individualistic and nonbureaucratic nature," and in which the "members are selected by the elderly" themselves. She further suggests that the informal system is influenced by "considerations of affect as well as efficiency, and ... by social class and ethnicity."

In contrast, the formal system depends on "the role of government and other formal organizations in the provisions of broad-based economic, health, housing, educational, safety, and transportation entitlements." This system is largely collective and bureaucratic in nature, and "attempts to function instrumentally and objectively...." (Cantor, 1980:132-134). Less easily categorized is the quasi-formal, quasi-informal "helping function" extended by members of churches, agencies, businesses etc., operating somewhat outside their formal roles (1980:134). O'Brien and Wagner (1980:78) include these sources of support in the informal system.

In that this study design involves support to elderly parents from adult daughters, the emphasis in the research is primarily on the informal system. Cantor (1980:132) argues that this informal system is the preferred source of help by elderly persons in need. However, there appears to be increasing recognition by caregivers and the elderly themselves of the utility of additional services provided through the formal system, as indicated in the three 
generational study of Brody et al. (1984:746). From a policy viewpoint, Huttman (1985:84) reports increased recognition that the informal system can provide some levels of elder care at reduced costs, with reduced institutionalization, if adequate support is provided to the caregiver; in effect this involves greater interaction and interdependence between the formal and informal systems.

THE ADULT DAUGHTER AS CARE PROVIDER

Within the informal care system and in the family it is the women, particularly adult daughters, who traditionally have provided support and care to aged parents (Treas, 1977:488; 1983:99; Phillipson, 1982:64; stoller, 1983:851; Brody et al, 1984:737; Fischer, 1985:105; Doty, 1986:40). Phillipson (1982:64-65) and Glazer (1988) argue that the traditional culturally assigned role of women as a central caring figure in the family has not only been retained but has been expanded to include home care for the elderly in response to demographic and social pressures. Treas (1983:99) and stoller (1983:851) report continued interest and involvement by adult children in the parent care role even though demographic and social change renders this involvement more difficult. Similarly, Brody (1981:471) and Brody et al. (1984:745) report the "strong continuing 
commitment of women to help their aged parents as the need develops."

Notwithstanding this commitment to parent care, it appears that methods of providing care to parents may be changing somewhat in response to social pressures, with greater use by caregivers, where possible, of formal and quasi-formal supports to compensate for competing responsibilities of work and family (Treas, 1983:99; Brody et al., 1983:598). Even so, the involvement with parent care is occurring at considerable personal cost to the caregiving women involved (Phillipson, 1982:64-65: Doty, 1986:49-53; Stoller, 1983:852).

According to Doty $(1986: 68)$, the primary explanations for the provision of care to elderly relatives by family members include: "a sense of family responsibility, affection for the individual, and a desire to reciprocate past help given by the impaired elderly person." The sense of responsibility appears to be linked to socialization, and the allegiance by the adult child to perceived societal norms of filial behavior (1986:46). Given the supposed emphasis toward cost containment in the health care industry and the concomitant withdrawal of care services, Glazer (1988) suggests that women's increasing unpaid work as family caregivers is a factor of necessity rather than choice.

Primary explanations for discontinuing or not 
initiating parent care include, for example, a perception that the extent or the level of care is greater than could be provided by the caregiver, and the perception that caregiving would interfere with or be disruptive of family life to an important extent (Doty, 1986).

The typical profile of the parent caregiver role relationship in the United states encompasses the following set of characteristics:

1. The parent is most likely to be a widowed female (Fischer, 1985:105; Doty, 1986:39).

2. The primary caregiver, if not the spouse, is most likely to be the daughter or daughter-in-law. This selection does not indicate a lack of interest by male family members as much as it does the continuation of gender-based role allocations (Brody, 1981:474). The increased number of women employed outside the home may modify this assignment in the future.

3. The age of the primary caregiver is advancing in concert with the aging of the parent. Most assistance needs occur for parents 75 or 85 years and over; consequently most caregivers are in middle age or early old age - that is, women in their $50 \mathrm{~s}$ and $60 \mathrm{~s}$ (Treas, 1977,:488; Brody, 1981:473), with an average age of 57 years (Retirement Life News, 1987:6). For the caregivers of persons categorized as the "disabled elderly," one third were themselves found to be 65 or older (National 
Center for Health Services Research, 1986).

4. Possibly a third or so of middle-aged children, particularly daughters, are likely to spend some time caring in their own home for an elderly parent (Fischer, $1985: 105)$.

5. Most caregiving is associated with parental needs for assistance in selected activities of daily living (housework, meal preparation, shopping, transportation, yardwork, financial management, and other chores), and with personal care and mobility (eating, bathing, toileting, grooming, dressing, walking, etc.). Some assistance is provided with home health care needs (medications, bladder and bowel care, exercising) and an increasingly important role for caregivers is that of negotiation on behalf of the parent with institutional bureaucracies of the aging enterprise, such as social Security or Medicare (Treas, 1977:486). Estimates of assistance needs of the non-institutionalized older population (65 and over) vary considerably: Soldo (1985:286) estimates that approximately 128 of this population require some assistance; Doty (1986:35) reports that 22.98 of this group are functionally disabled and are in need of assistance; while other estimates suggest that as many as 338 or 8 million of this group need supportive services (Brody, 1981:472). Additionally, 1.2 milion elderly Americans are 
categorized as the "disabled elderly," and are unable to care for themselves without informal help (National Center for Health Services Research, 1986). Finally, daughter caregivers are more likely to give "hands-on" care than sons, and also to give a more extensive range of care (Fischer and Hoffman, 1984:182).

6. The amount of help given increases with the parent's age, presumably in relation to increased impairment. In that daughters age in parallel with their parents, older caregivers provide more help than their younger counterparts. In one study Brody (1981:476) reported a low of 3 hours weekly for caregivers aged 40 to 49 , and a high of 22.7 hours weekly for caregivers of 60 or older. Another report argues that nearly 808 of all caregivers provide approximately four hours of assistance daily, seven days a week (Retirement Life News, 1987:6).

7. Information on the length of care typically given to an aged parent is not clearly reported. As an approximation, Fischer and Hoffman (1984:185) report findings from a National Health Survey (1981) which indicate that almost 758 of those over age 55 who received home care did so for over one year. In the category of "disabled elderly," nearly half of all caregivers were found to provide care for 1 to 4 years, and a further 208 to give help for 5 years or more (National Center for Health services Research, 1986). 
8. Equitable exchange relationships between the caregiver and the parent are typical, allowing the parent to reciprocate to some extent for care provided, such as help with grandchildren or chores, financial aid, etc. Assistance to the elderly parent as a one way process occurs most often in the presence of severe impairment, advanced age or financial need (Bengtson, 1979:51; Treas, 1983:97-98; Stoller, 1985:177; Huttman, 1985:87).

9. Most caregiving occurs with the parent or parents living separately from the caregiver. Although long-term co-residence occurs in a relatively small percentage of cases, it is strongly related to impairment and dependency rather than choice, and increases with advanced age and widow or widowerhood (stoller, 1985:175; Doty, 1986:44). For example, Shanas and sussman (1981:218) report that 118 of elders aged 65 to 69 , and not currently married, live with a child; this compares with 298 aged 80 or over who live with a child. Temporary or crisisrelated care in the caregiver's home is considerably more frequent for all age groups (Fischer and Hoffman, $1984: 189$; Fischer, $1985: 105)$.

10. Social and psychological stress experienced by family caregivers is widely reported, and appears to be a difficult component of both family and parent relationships (Phillipson, 1982:64-66; Cantor, 1983:600-603; Doty, $1986: 49-51)$. 
11. Middle-aged women caregivers are more likely than in previous decades to be employed outside the home - 58.38 of all women aged 45-54 were employed in 1979 - (Stoller, 1983:852). There are conflicting reports of the influence of employment on the incidence and character of parent care; similarly there are reports of parent care influencing employee responsibilities. One recent employer survey (Southwestern Bell) indicates that approximately $25 \%$ of its employees are directly involved in family elder care (AARP News Bulletin, 1987:1). Strategies for managing work and caregiving responsibilities include reduction of hours worked, rearrangement of schedules, and taking leave time (National Center for Health Services Research, 1986). Reports of the level of care provided by employed daughters versus those not employed outside the home are essentially the same (Retirement Life News, 1987:6). It appears that a typical response is for the caregiver to expend her own personal and leisure time in the attempt to balance competing needs of the parent, work and family (Stoller, 1983:852).

12. Social class, as an independent variable, is reported to be a predictive factor regarding involvement in caregiving. Cantor (1980:139-140) reports, generally speaking, that the higher the social class, the less is the ongoing involvement in parent caregiving, and the greater is the parent's circle of functional friends. 
Similar class-based differences are reported by Russell (1981:42). Additionally, class is inversely associated with family size, suggesting fewer potential caregivers as social class rises. Despite these findings, Cantor reports that parent care is given for those in higher social classes when a critical need arises (1980:140).

The foregoing review of population influences and characteristics of the adult daughter in providing parent care supports the notion that parent care may indeed be perceived as a "social problem," as previously suggested. There appear to be two root concerns regarding the "problem" of parent care. One concern, articulated increasingly in the literature, is the perceived societal need to contain a massive expansion of the formal system for elder care, and thus to rely heavily on the informal system to provide low cost alternative care (Phillipson, 1982:65; Doty, 1986:36). Related to this reliance on the informal system, is the perception of "need" for capital accumulation and corporate profit which can be effected through the greater deployment of women in unpaid rather than paid caregiving labor (Glazer, 1988), or in the formal system, of employing women caregivers at a lower cost than men. The second concern is with the economic drain on corporations as employees attempt to handle competing responsibilities of work and elder care.

A strong thread woven into much of the literature on 
family supports for elder care is the retention by adult children of a desire to uphold perceived responsibilities for the care of their parents; that is, there appears to be a strong motivation to fulfill their perception of societal expectations in family care. It appears that the socialization experience is central to the retention of this motivation. It also appears that while methods of providing such care may vary in response to social change (e.g., gender role changes, labor force participation of women), the central ethic and the social reality continues to be upheld. One area of inquiry in this study relates to potential differences in the retention of this motivation between two birth cohorts of caregivers.

\section{THE ELDERLY PARENT - DEPENDENT OR AUTONOMOUS?}

One of the fundamental negotiations that occurs in families centers around the issue of autonomy and dependency. Moreover this issue is central to intergenerational relations at different points in the family life cycle, such as for the adolescent and for the aged parent. Bengtson (1979:49-50) suggests that this issue is especially relevant to relations with the elderly, for societal expectations of the elderly encompass notions of dependency; conversely, societal expectations of the adolescent encourage eventual autonomy. Assuming that a balance between autonomy and 
dependence, or interdependence, is a preferred characteristic of family interaction, this section includes a definition of autonomy and a discussion of the concept as an issue in the parent care situation and as a central variable in this study.

The notion of autonomy as an important value for older persons is gaining recognition as evidenced by a Request for Proposals on "Enhancing Personal Autonomy of Elderly Individuals in Long Term Care," to be funded by The Retirement Research Foundation, 1986-1987. It appears that this interest is part of a larger concern with ethics and aging, particularly as it relates to the rights of the older person as an individual versus the common good. A central concern is how to provide services in an ethical manner for an expanding aged sector in the face of resource constraints facing the entire population (Fahey and Holstein, $1987: 5$ ).

From the viewpoint of the elderly person, the need for autonomy seems to be of "paramount importance" and appears to be a major guiding principle or motivator which influences personal interaction and effectiveness (Russell, 1981:12,42,46,68,80). Further, a perception of autonomous action appears to be closely related to a person's subjective well-being or life satisfaction (Russell, 1981:42). For instance, Russell cites reports on the absence of close correlation between older persons' 
opinions of their health and an objective analysis of their health status. If people see themselves as able to function more or less autonomously, despite impairments, then this engenders a relatively positive self-perception (1981:42). In other words, when a person feels in control of the definition of a situation, there is a greater self perception of well-being (1981:46). Generally, this understanding would not be problematic; it is when the elderly are "denied access to those resources with which independence is typically sustained" that the potential for autonomous action is compromised (Russe11, 1981:68). Assuming that access to such resources is not denied to the somewhat younger adult age grade, this differential access represents a source of conflict and asymmetrical interaction between the generations and may affect parental autonomy in the caregiving situation, although not specifically examined in this study.

Family caregiving differs from care situations associated with the formal system in that the personal needs of the caregiver must receive greater consideration. The problem is that each person in the care situation has a right to personal autonomy. When the rights of the elderly parent and the unpaid family caregiver clash, then conflict is the result. Thus conflict is inherent in the nature of the caregiving situation and is not purely a factor of the individuals themselves (Ambrogi, 1987:7). 
Despite potential conflict, Collopy (1986:1-2) argues that the autonomous person, parent or adult child, is not "... a lone isolated agent making decisions and acting atomistically without ties to other people, to social institutions, to traditions of thought and action." Hence, the autonomous person "...can respond to determinations from outside the self, determinations which, however, are freely chosen and accepted." Still, though, there is the question of differential access to, or ownership of resources, by younger and older age groups.

How, then, is autonomy defined? Previously, in Chapter I, parental autonomy was defined as: the degree of perceived control, choice or self-governance of the parent over his or her immediate environment (Kane and Kane, 1981:202). While this definition is useful as a sensitizing concept some elaboration is warranted. In attempting to clarify the problematic status of the concept for The Retirement Research Foundation, Collopy (1986:1) has developed a working definition of autonomy as " 'self-rule' or 'self-determination,' that is, the control of decisionmaking and other activity by individual agents themselves." Collopy further suggests that "Broadly speaking,....autonomy is synonymous with freedom and liberty, with human agency free of interference and intervention" (1986:1).

Part of the problem is that autonomy can be construed 
in both general and particular terms. In general terms, Collopy suggests that autonomy "... involves the freedom to shape long-range goals and purposes, determine life priorities and commitments, [and] control the content and direction of personal history" (1986:1). In a more particular application, he suggests that "...autonomy means the freedom to manage the short-range, 'ad hoc' aspects of life, the mundane, quotidian realities that measure freedom on a day to day basis" (1986:1). In the family caregiving situation, both the general and the particular applications of the concept may apply. According to Collopy $(1986: 2-7)$ the concept of personal autonomy has many dimensions and represents a definitional challenge. These dimensions include: autonomy versus paternalism, direct versus delegated autonomy, competent versus incapacitated autonomy, authentic versus inauthentic autonomy, immediate versus long term autonomy, and autonomy as a negative right versus autonomy as a positive right. By definition, the caregiving situation is rich with applications for different dimensions of autonomy, both in assumptions of competence or incompetence in older persons, and in more objective changes related to physical, intellectual and social functioning. The very initiation of caregiving suggests dependency in some form and thus some erosion of autonomy. As collopy suggests, there may be a progression in 
caregiving, in which "... autonomy moves from private and 'contained' self-determination through shared, horizontal determination to the acceptance of extrinsic, hierarchic determination" (1986:8) as the individual experiences frailty over time, or exhibits varied levels of performance in different skills. Also inherent in the situation, are the potentially conflicting needs and rights of the caregiver.

It is not the intent of this study to investigate or measure the concept of autonomy in all its dimensions; this is a central task of the research funded by the Retirement Research Foundation. However, some additional comments, specific to the caregiving situation, are justified.

Collopy (1987:3) speaks to the challenge of paternalism, a characteristic typical of formal and informal long term care settings for the aged population. Paternalism stands in contrast to personal autonomy;

...paternalism argues that interference in individual choice and action can be justified if it is carried out for the sake of the individual's benefit or welfare, for his (sic) social, moral, or physical good.... paternalism therefore reverses the priorities of autonomy; it argues consistently for benefit over freedom.

Thus, paternalism provides a ready justification for the helping behaviors typically offered to the elderly person. Is it not at times easier and more efficient to handle a parent's needs, or direct some course of action 
ourselves, particularly in the presence of some impairment? clearly then for caregivers, in both formal care and in the family, there is potential for a clash of values between autonomy and paternalism (Ambrogi, 1987:7). When one adds the influences of a negative construction of reality, paternalism toward the elderly is further facilitated, for the aged are considered to be "...passive and incompetent, in need of benefit as defined and provided by others, in need of protection, most of all, from their own decisions when these are deemed 'harmful'n (Collopy, 1986:3). This characteristic of paternalism and the associated negative construction of old age is so strongly entrenched that researchers in medical-legal affairs are concerned with the erosion of individual rights:

...For the elderly patient the right to selfdetermination is often lost due to a health care provider's or trial court's wrongful assumption of incompetence. To protect the elderly, their competence must be judged on the same basis as everyone else's: an ability to understand and appreciate the information needed to give an informed consent (Annas and Glantz, 1986:149).

Gadow (1980:682-683) similarly speaks to the principle of beneficence and its apposition to the principle of autonomy in relation to medical care and the elderly; she posits that autonomy is perceived by the elderly as a more precious good in view of their limited remaining lifetime. Thus the elderly are in a situation 
which has a double-edged meaning; help, if given and accepted from adult children, has implicit assumptions of dependence, erosion of autonomy, and loss in the definition and control of the situation; and yet help as a benefit in day-to-day life may be a material necessity in the face of increasing impairment (Russell, 1981:162). Thus there appears to be a fragile balance between personal autonomy and dependency based on material need. Schwartz (1979) suggests that mutual dependence or interdependence characterizes a preferred goal of interaction between generations, in which autonomy and assistance needs are recognized in both parent and adult child.

Some of the negative effects of dependency or reduced autonomy are well documented. There is considerable evidence to support the development of learned helplessness or self-induced dependence in health care settings, particularly with reference to institutionalized elderly persons (Solomon, 1982; Langer, 1983). On the basis of laboratory experimentation, seligman $(1975: 23,185,186,188)$ suggests that the elderly in American society are particularly susceptible to learned helplessness produced by loss of control over meaningful events, and further that the perception of declining control in the weakened individual reduces motivation, initiation and ability to engage in future control, even 
to the extent of depression and death. Thus seligman suggests that there is a need to increase instrumental control in the day-to-day lives of vulnerable persons, such as the elderly $(1975: 188)$.

Langer (1983:102) prefers to use the term "selfinduced dependence" in recognition that "helplessness or the belief in one's own incompetence may be inferred from contextual factors [or]...from interpersonal situational factors" rather than only from experience with lack of control as suggested by seligman. Additionally, Langer argues that vulnerable persons, such as the elderly, lack "...a stable sense of their own abilities" and thus need to depend to a greater extent on situational factors (1983:102). Reasons for Langer's inclusion of the elderly as a vulnerable group include the following: "They bear negative labels. They for many reasons do not engage in previously engaged-in activities. They are a group for whom people typically do things" (1983:103), and also they experience an "increased incidence of significant life changes and environmental strains" (1983:219). In effect, Langer's concept supports the model described by Kuypers and Bengtson (1973) reported previously.

Dependency in the parent care situation may have similar effects. Langer reports study findings on the "effect of being helped," which strongly suggest that "...not only do we do people an injustice by not urging 
them to take responsibility for themselves, but we actually may encourage their diminished performance simply by helping them" (1983:209). This balance between encouragement for maximum control and performance, and assistance with material needs, is critical, and is an important outcome of the care situation and the interaction between the parent and the adult child.

Finally solomon, (1982:282) also lends support to the concept of "learned dependency." He suggests that stereotypic negative attitudes of care providers towards the elderly and their care, coupled with status differences of the provider and the recipient, and with typical behaviors of healer and sick roles, all combine to induce a feeling of helplessness or learned dependency in the older person. When the older person's behavior is consistent with helplessness, with decreased motivation, apathy, passivity, incontinence or other physical signs, then the negative stereotype of old age is reinforced and the system is maintained $(1982: 284)$. While this outcome of learned dependency is particularly a factor of institutional or other formal care, it is also relevant to home care, and in each setting is complicated by "the real helplessness that leads these frail or ill elderly to [require care] in the first place" (Solomon, 1982:285).

In sum, the concept of personal autonomy in this study refers to both the general freedom to determine 
aspects of one's personal history, such as the choice over one's living situation, and to the particular or short term freedoms involved in day-to-day decision making, such as what clothes to wear, when to eat, what to do and what help to request. The reality of the older person's status is but one limitation to the exercise of effective agency; the other limitation is the extent to which a perception of incompetence or helplessness has been internalized. From the caregiver's viewpoint, one option is to offer assistance as a means of extending the parent's autonomy; another option is to interpret assistance as evidence of the parent's dependency.

\section{HYPOTHESES}

The hypotheses are drawn from the literature reviewed in Chapter II and the earlier part of this chapter, and reflect some of the research questions so stimulated. The rationale for each hypothesis refers to this review.

\section{Hypothesis 1.}

The first question relates to the influence which the social construction of old age has on the aged individual. More specifically, is it possible that positive or negative views of old age, when held by a significant other, will influence the action of that aged person in a positive or negative direction? There seems to be 
considerable support for the negative influence of the prevailing negative view of old age on the entire age grade of older persons (Kuypers and Bengtson, 1973; Estes, 1979; Russell, 1981; and Langer, 1983). Additionally, Solomon (1982) speaks of the negative influence on the recipients of care when negative stereotypes on aging are held by individual care providers.

Additional justification for this hypothesis derives from theories of socialization which involve the internalization of role specific knowledge (Berger and Luckmann, 1967:138). In that this knowledge reflects societal definitions of reality in which both the caregiver and the elderly parent are socialized, it is anticipated that they each will exhibit role behaviors typical of this reality, such as helping behaviors from the caregiver and dependency responses from the aged parent.

Therefore, it is hypothesized that: Caregiver agreement with the negative social construction of old age is associated with low levels of parental autonomye as assessed by the caregiver.

\section{Hypothesis 2.}

The second concern relates to the perpetuation or continued construction of the negative view of old age in society. A number of authors have addressed this issue at 
both the individual and the societal level. For instance, kuypers and Bengtson (1973) posit that the aged individual, when susceptible, comes to act in accordance with society's negative label, which reinforces the accuracy of the label and perpetuates the negative construction. Similarly, solomon (1982), in discussing care providers and aged care recipients, suggests that helplessness engendered by the sick role reinforces the negative stereotype and maintains the construction. Scott (1969) speaks to the problematic nature of interaction with impaired individuals, a fact which also aids in the perpetuation of a negative viewpoint. Berger and Luckmann (1967), at a higher level of analysis, suggest that change in a body of knowledge does occur, but in order for this to happen systems for institutional maintenance which constitute an impediment to change must be overcome. The influence of the aging network in perpetuating a negative image, as proposed by Estes (1979), is another factor in this regard.

Therefore it is hypothesized that: More advanced age and higher levels of perceived impairment of the parent are associated with a negative construction of old age held by the caregiver. 
Hypothes is 3.

The next concern is with the issue of learned helplessness or self-induced dependency and its association with assistance received from a second party. There is considerable literature to support the development of learned dependency, with some evidence specific to elderly persons (Seligman, 1975; Solomon, 1982; Langer, 1983). However, the extent to which this dependency occurs in association with assistance received from another person is unclear. Langer suggests (1983:209) that assistance to an elderly person may encourage diminished performance by that person, however, the extent to which impairment acts as an intervening variable is unclear.

Therefore, it is hypothesized that: The highest levels of caregiver assistance to the parent are associated with the lowest levels of parental autonomy as assessed by the caregiver, when impairment is held constant.

Bypothesis 4.

The next hypothesis relates to possible differences in socialization experienced by different generations of women, as it relates to the ethic of filial responsibility for parent care. Berger and Luckmann (1967) suggest that the internalization of knowledge gained in primary and 
knowledge between generations, and contributes to the construction of reality, in this case the reality regarding old age and the aged population. Brody (1981), Treas (1983), Stoller (1983), Brody et al. (1984), and others report that the ethic of responsibility for parent care is retained by caregivers of different ages, even though changes in the manner of providing care may occur as a result of social or demographic change.

Given the extent of social change affecting the two birth cohorts, it would be quite possible to argue in the opposite direction, for a difference in the parent care ethic between the two generations. For example, it could be argued that persons socialized after the 1930's would be more likely than earlier generations to expect government solutions to parent care problems, and thus would internalize a less strong parent care ethic. Similarly, womens' employment out of the home is likely to exert an influence.

Therefore, it is hypothesized that: There is no significant difference in the central ethic of responsibility for parent care as held by two different birth cohorts of caregivers.

\section{Hypothesis 5 .}

The final concern is with susceptibility of the aged person as an individual to the effects of negative 
societal labeling, an issue presented by kuypers and Bengtson (1973), and supported by others (Estes, 1979; and Langer, 1983). These authors suggest that personal losses, losses associated with productive roles, the loss of ageappropriate reference groups and vagueness of expectations and values specific to the old age status combine to make the older person vulnerable to negative societal labeling, and hence more likely to internalize the negative attributes associated with the label. Other variables such as advanced age, low income, low education and impairment may further render the individual susceptible. Kuypers and Bengtson (1973:197) posit that autonomy of the older person can be improved by intervention in many areas, to include health, economics, reduction of labeling, development of competence, and de-investment of control by others.

In a limited attempt to explore these relationships it is hypothesized that: A high index of major life changes in the parent will be associated with low levels of parental autonomy as assessed by the caregiver, when impairment is held constant.

These five hypotheses comprise the central issues to be evaluated in this study. Methodology pertaining to this evaluation is presented in the following chapter. 


\section{CHAPTER IV}

\section{METHODOLOGY}

\section{POPULATION}

The population under examination in this study is composed of adult daughters ${ }^{1}$ who, as of summer 1986, were providing care or had recently provided care (since January 1986) to a non-institutionalized parent or parents ${ }^{2}$, aged 65 or over. The adult daughters were those providing regular assistance to parents with varying levels of impairment, but were not required by the research design to be the primary or only caregivers. Both the adult daughter and the parent or parents were residing within the Portland Greater Metropolitan area (Multnomah, Clackamas and washington counties), within one hour of the city center.

The selection of adult daughters as caregivers, rather than sons, is not to suggest a lack of interest or involvement by sons. Rather it is based on a greater probability of parent caregiving from daughters, as noted

$1_{\text {The category "adult daughters" includes natural and }}$ adoptive daughters, step-daughters and daughters-in-law, and is used in this sense hereafter unless otherwise specified.

${ }^{2}$ similarly, "parent or parents" refers to both parents and parents-in-law unless otherwise specified. 
previously, which was expected to facilitate the acquisition of fifty subjects deemed necessary for the sample. This selection also permitted the exclusion of the subject's gender as a complicating variable.

SOURCE OF THE SAMPLE

Initially, the intent was to obtain all members of the sample from a single source. This, however, did not prove feasible and hence a purposive or non-probability sample was obtained from multiple sources. Sources of the sample include the following mixture of formal and informal service providers to families or older persons:

1. Community based agencies and groups

2. Hospital based patient and community programs

3. Government agencies

4. Churches or synagogues

5. Snowball referral from one caregiver to another

The single most difficult factor limiting access to a potential sample of caregivers is the issue of client confidentiality; sources are restricted by mandate or are reluctant to share enrollment lists. A second but associated problem is the actual or perceived work burden to an agency associated with contacting clients regarding their willingness to be included in the study. Additionally, one hospital required completion of the process established by their Committee on Human Research 
for the Protection of Human Subjects before access to any data. These problems resulted in the referral of small numbers of potential study participants from each source, and the use of multiple sources to gain the fifty participants. In all, fifteen organizations were contacted by letter, telephone or in person, with eight of this group becoming actual sources of study participants. Despite these problems the study could not have occurred without the help and support of many agencies.

To facilitate gaining additional participants, informational packets were distributed to communicate the study intent directly to caregivers. The project was also discussed with participants of caregiver support groups. Interested caregivers then responded voluntarily and were screened for study eligibility. Once interviews were initiated, 11 additional subjects (22\%) were obtained using the snowball referral technique.

The source of the sample appears to have had an influence on the research findings, specifically subject education and income. While the sample was obtained from a widely dispersed geographic area, participants referred by a particular medical center $(n=7$ or 148$)$ were found to represent a higher than expected socio-economic status. This occurred to a lesser extent with subjects from a caregiver education program who volunteered their participation. This influence is discussed in Chapter $V$. 


\section{INTERVIEW SCHEDULE}

A single in-depth interview was used to obtain data from the sample of caregivers. To facilitate this process an interview schedule was developed using existing instruments where possible (see Appendix A). In order to obtain objective data on parent care and on caregiver and parent characteristics, closed-ended questions were employed; to gain additional, subjective impressions of parent care, the caregiver role and perceptions of aging and older people, open-ended questions were also used. The rationale for this, following Jick (1979) and Connidis (1983), is that the combination of quantitative with qualitative methods aids in the clarification and interpretation of findings.

A review of the literature for existing instruments suitable to use for data collection was only partially successful, and thus, the development of additional measures for selected variables was required.

To assess the positive-negative continuum of the caregiver's construction of old age and aged persons, two measures were used, one being an instrument developed by Harris and Associates, on the "Image of Most People Over 65" (retitled "Image of Older Persons"), which was used with minor adaptation (see interview schedule, question 2). This index was used in a 1975 representative cross- 
sectional study of the American public on attitudes towards aging and personal experiences of old age. No information on the reliability or validity of the instrument was located in the resource used (Harris et al., 1975:47-55). This instrument was considered a suitable measurement of the caregiver's perception of older people, but not of old age as a status in the life course.

The second measure of the caregiver's construction of old age, an "image of old age," was gained from postcoding of an open-ended question on the meaning of old age (see interview schedule, question 1).

The second published instrument used in the study, the general health profile (interview schedule, question 28) was adapted from the PULSES Profile, a broad based measure of functional status as an outcome of medical rehabilitation, originally developed in 1957 for a chronically disabled and aged population, and modified subsequently by Granger et al. (1979). According to Jette (1985:145) the PULSES Profile exhibits a high correlation with other measures of functional status, and thus may be considered to have evidence of construct validity. However, evidence of reliability was not determined. Although adapted for this study, the measure still exhibits considerable resemblance to its 1979 version, and appears to distinguish levels of impairment and dependency 
in the aged parent. The summary score of this instrument provides measurement of the variable "parental impairment."

Considerable effort was extended to discover a suitable measure of the construct "personal autonomy" for use in the caregiver's assessment of autonomy in the parent, the major dependent variable of the study. Lacking a usable instrument, a set of items was developed hoping to tap different dimensions of the construct and to measure the level of parental autonomy as determined by the caregiver (interview schedule, question 31). The utility of this measure will be discussed further, in relation to data analysis. Exploration and measurement of the construct "personal autonomy" are outcomes anticipated from the research funded by the Retirement Research Foundation (1986-1987).

Additional measures were developed to assess the type and level of caregiving assistance to the parents, and to assess major life changes as an index of parental vulnerability (interview schedule questions 16 and 41 ).

All other questions in the schedule were developed to gain a profile of the caregiver's perception of old age or older persons; to clarify the specific care situation, the care responsibilities, and their influence on the caregiver and family members; to estimate the parent's status and response from the caregiver's perspective; and 
to identify demographic information of both the parent and the caregiver. Pre-coding was established for the closedended questions. The instrument (and the subsequent codebook) was organized into the following sections:

1. Aging and Older People

2. Caregiving Situation

3. Subject/Family Response to Caregiving

4. General Health Profile of Parent(s)

5. Parental Response to Caregiving

6. Background Information - Parent

7. Background Information - Subject

In order to discover potential problems with the interview schedule, the instrument was used in a pilot survey of five daughter caregivers, using the eligibility criteria as described above except for recency of the caregiver experience. This pilot process resulted in a number of changes in the content and format of the schedule for clarity, sequence and coding purposes.

\section{DATA COLLECTION PROCEDURES}

Prior to the initiation of data collection, approval for the study was obtained from the portland state University Human Subjects Research Review Committee. A copy of the Notification of Approval, and of the amended informed consent sheet, are located in Appendices $C$ and $D$. Personal contact with potential participants was 
established prior to each interview to explain the nature of the study, their eligibility for participation, the format of the interview, and to establish the date, time and location of the meeting. Subjects were given a chance to withdraw from the study before, during or after the interview. Only one individual was unable to participate, due to the very recent death of her parent. Interviews occurred during June, July and August of 1986, and were scheduled at a time and location suitable to the participant. The majority of interviews occurred at the caregiver's home $(n=39)$, with others scheduled at the person's place of work, at a restaurant, or at Portland State University. Some participants indicated a preference for a neutral location to allow a frank exchange without concurrent complications of parent care. In all but one case, interviews occurred alone with the caregiver without the presence of the care recipient. This exceptional case was deemed contaminated and was subsequently withdrawn from the study, requiring an additional interview to complete the target number of fifty. Characteristics of the sample are reported in Chapter $v$.

Regarding the interview format, each participant was requested at the outset to read and sign the informed consent sheet, and was given in exchange a fact sheet on the study. Each question in the interview schedule was read to the participant and coded response cards were 
shown for specified questions. No tape recordings were used, although extensive notation of participant responses occurred throughout the process. Each interview lasted approximately one and one-half hours, depending on the complexity of the caregiving situation. In general, the participants expressed considerable interest in the topic and a willingness to discuss their concerns regarding parent care, even after the completion of the formal interview schedule.

Following the interview, the data were reviewed for clarity and completeness, a process which discovered a few instances of incomplete or unclear responses.

No additional sources of data, such as medical records or agency reports were employed.

\section{DATA PREPARATION AND ANALYSIS}

\section{Data Preparation}

As indicated, both quantitative and qualitative methods were used in analysis, requiring different preparation of data from closed-ended and open-ended questions. Data from closed-ended questions were precoded; however post-coding was required for data from the open-ended questions.

The process of post-coding involved a content analysis of the narrative responses to each question allowing a series of response categories to emerge from 
the data. These response categories were further refined into a mutually exclusive set of codes. Subsequently, all open-ended questions from each of the interviews were scored, using the newly developed codes. In this process, responses containing elements of more than one category were coded based on the dominant element.

In order to assess the reliability of the investigator's coding, an outside person unfamiliar with the study was requested to score the same open-ended questions using the codes as developed. Approximately one quarter of the interview schedules (12 out of 50$)$ were selected from different periods in the interview process for dual coding in this manner. The mean inter-rater reliability score resulting from this procedure was .62 with a range of .33 - .92, considered to be a low score in social research (Phillips, 1985:121-122). Three explanations for the low score were apparent: first, the additional rater had considerable difficulty with the handwritten responses on the interview schedules; second, the coding categories for selected questions were too numerous or precise, allowing greater potential for disagreement between the raters, thus adversely affecting reliability (Phillips, 1985:122); and third, the total number of interviews rated in this manner was small, only 12. Although revision of coding for some questions might have been appropriate, this was not undertaken due to time 
Iimitations.

A final aspect of coding involved the treatment of missing data. Missing data codes were assigned to different instances of missing data, such as "not applicable," or "not ascertained." In that variables were established for each of four parent categories (mother, father, mother-in-law and father-in-law), and in that $78 \%$ of the sample $(n=39)$ cared for a single parent, the "not applicable" missing code was used extensively. The establishment of separate parent variables in this manner was thought to capture the combinations of parents receiving care from a given adult daughter. The modal response of a given question was not used to substitute for missing data. Instances of missing data are reported where necessary in Chapter $V$.

\section{Data Analysis}

In that the purpose of this study is exploratory in nature, the intent of analysis is to describe characteristics of the sample and to identify patterns of response. Thus descriptive statistical methods are appropriate. Subsequent use of inferential statistical methods did not occur because, in general, a purposive or non-random sample does not permit generalization of study findings to a wider population (de Vaus, 1985). Initial analysis involved the completion of frequency 
distributions and measures of central tendency and dispersion for each variable, for the dual purposes of description and for data cleaning.

Following this, certain variables were recoded so that bivariate analysis could be performed to detect relationships between variables and thus to offer some explanation for the findings. Variables recoded in this manner were guided by the hypotheses and included caregiver's construction of old age, birth cohort of subject, parental autonomy, age group of parent, parental impairment, caregiver assistance to parent, major life changes in the parent, and ethic of responsibility for parent care.

Further analysis indicated by the hypotheses involved elaboration of bivariate relationships, controlling for additional variables as necessary. For example, greater understanding of the variable "parental autonomy" occurs if the variable "parental impairment" is held constant.

In that a number of contingency tables of specified variables by birth cohort were constructed to see whether cohort membership of the caregiver had an explanatory value, a rationale for the selection of the birth cohorts is in order. While division of the sample into three birth cohorts makes sense from an historical viewpoint, it would give relatively few subjects in each division. Consequently, two birth cohorts, 1914-1933 and 1934-1953, 
were selected, each spanning 19 years, with 24 subjects in the earlier cohort (aged 53 through 72) and 26 subjects in the later cohort (aged 33 through 52). For the most part, this division represents individuals socialized prior to and after the Great Depression of the mid-1930's, with additionally, the older cohort experiencing each of the two World Wars, and the younger cohort experiencing only the Second World War. It is assumed that these events have had a differential effect on the two cohorts, which could have potential value in explaining outcomes of the study. With reference to the interpretation of contingency tables, the selection of summary statistics to describe linear association is guided by Costner's argument, in which he proposes a proportional reduction in error (PRE) basis as a standard for measures of association in sociological research (1965:342). Measures with a PRE interpretation indicate the extent to which error can be reduced in predicting a score on one variable from knowledge of the score on another (Bailey, 1987:388). One of the primary values of the PRE measure, identified by Costner (1965) and others is the normative or operational interpretation that exists despite variation in the level of measurement, number of cases, table size and variables being measured.

With regard to the ordinal level of measurement, Costner (1965:350) suggests that the correlation co- 
efficient "gamma" is the preferred measure due to its PRE interpretation. Gamma is also appropriate for use in tables presenting dichotomous nominal level with ordinal level variables (de Vaus, 1985:135).

With regard to the nominal level of measurement, the measure selected is the "uncertainty coefficient." Following Costner's argument (1965:350), this is also a PRE measure, and in its asymmetric version "is the proportion by which 'uncertainty' in the dependent variable is reduced by knowledge of the independent variable" (Nie, et al., 1975:226). The preference for this coefficient over lambda (also a PRE measure for nominal levels) is based on its greater precision secondary to consideration of the entire distribution and not just the mode $(1975: 226)$.

These coefficients (gamma and the uncertainty coefficient) are used in subsequent tables of Chapter $v$. The interpretation of gamma values, also in Chapter $V$, is based on conventions outlined by Pine (1977:136).

In that the variable "parental autonomy" is the central dependent variable of the study, an evaluation of the adequacy of the instrument developed to measure autonomy was considered necessary. Factor analysis of the eight items pertaining to the subject's assessment of autonomy in the mother was performed, as shown in Table I. 
TABLE I

FACTOR ANALYSIS OF PARENTAL AUTONOMY ITEMS BASED ON CAREGIVER ASSESSMENT OF 39 MOTHERS*

1. Engages in activities

.92749

2. Attempts to cope with own needs

3. Dependent - lets others manage needs**

4. Opportunity for decision making

5. Takes responsibility for action

6. Asserts independence regardless .80756

7. Expresses helplessness**

8. Uses "good" judgment

** Coding for items 3 and 7 is reversed.

* Responses pertaining to the 39 mothers in the parent group, rather than to the 12 fathers, 8 mothers-in-law and 2 fathers-in-law, were used, in that these data represented the largest category, that is 648 of the parents.

This analysis produced an item correlation matrix and the extraction of one factor, indicating that all items were highly correlated with a single underlying dimension, namely parental autonomy. According to this evaluation, the single factor accounts for 748 of the variance in the eight items. Inter-item correlations ranged from a low of .56 for items 6 and 7 , to a high of .95 for items 1 
and 5 (figures rounded here and after). This finding allows confidence to be placed in the use of the instrument to measure the dependent variable "parental autonomy" in subsequent evaluations of the hypotheses.

Factor analysis of the seven items in the instrument "Image of older Persons" developed by Harris and Associates (1975) was also performed. As mentioned, this instrument is used to assess one aspect of the caregiver's construction of old age, the view of older persons. This analysis produced an item correlation matrix and the extraction of one factor, showing that the seven items measure one dimension, as identified in Table II. According to the analysis, this single factor accounts for 378 of the variance in the seven items. Inter-item correlations were considerably lower for this instrument, and ranged from a low of .12 for items 1 and 4 , to a high of .61 for items 3 and 6 . Even so, the instrument is considered a usable measure of the caregiver's construction of old age applied to older persons.

The second measure of the caregiver's construction of old age, the "image of old age," was developed from content analysis and post-coding of the open-ended question on the meaning of old age (interview schedule, question 2). In using the two measures, the intent is to capture the caregiver's perception of old age as it relates to older persons specifically and as it relates to 
the later period in the life course. These measures incorporate both objective and subjective responses. The relationship between these two measures of the variable may be summarized by the statistic gamma at a value of .46 indicating a moderate, positive association, and suggesting that use of both measures of the caregiver's construction of old age in subsequent evaluation of the hypotheses is appropriate.

\section{TABLE II}

FACTOR ANALYSIS OF THE INSTRUMENT

"IMAGE OF OLDER PERSONS"

Item

Factor 1

1. Friendly and warm

.30863

2. Wise from experience

.52441

3. Physically active

.66475

4. Good at getting things done

5. Bright and alert

.66931

6. Open minded and adaptable

.80660

7. Sexually active

.47587

A final issue specific to analysis is the transformation of separate parent data into composite parent variables. In that data were collected from the 50 caregivers on 61 separate parents, and in that these data 
were identified by parent category (mother, father, mother-in-law and father-in-law) the construction of a composite parent variable to be used in the evaluation of the hypotheses was important. This issue involved a number of variables, specifically the following: parental autonomy, parental impairment, age group of parent, major life changes of parent and caregiver assistance to the parent.

The transformation of these data was performed statistically, based on the specification of a set of logical conditions involving sequential consideration of the separate parent values (father-in-law, mother-in-law, father and mother). In this way, separate observations for the 61 parents were collapsed into 50 caregiver observations of the constructed "parent" variable; this however, occurred with some loss of detail and with a systematic bias in favor of responses concerning the mothers. Without this transformation, evaluation of the hypotheses would have had to occur for each parent category, a difficult procedure with the small number of cases involved.

\section{LIMITATIONS}

In that the caregiving experience by nature involves a relationship between two parties, the care recipient and the caregiver, a limitation of this study is the 
collection of data from only one of these two sources. Townsend and poulshock (1986:101) suggest that this limitation is common to many studies of caregiving to noninstitutionalized elders, where typically either the care provider or the care recipient provides information. This limitation becomes important when it is realized that there is evidence to suggest that reports from these parties are likely to differ (1986:101).

For instance, empirical evidence suggests different generational perspectives, and theoretical arguments from the symbolic interactionist literature on the definition of a situation suggest additional differences of meaning and interpretation. In addition, the respective roles of elder care recipient and care provider carry symbolic interpretations associated with dependency and inequity, leading to differential reports of functional limitations and assistance needs in the elderly person. Townsend and Poulshock (1986:102) suggest that this leads to under reporting of impairment and care needs by the care recipient, in the hope of retaining maximum self-esteem. Assessment of the parent from the caregiver's perspective only was chosen in order to simplify sample selection and to obtain a sample of adequate size $(n=50)$ for basic statistical analysis.

An additional limitation includes the non-probability sample and the consequent inability to generalize findings 
to a larger population. However, daughter caregivers of noninstitutionalized parents are not easily amenable to random sampling techniques and additionally, the focus of concern is on exploratory knowledge of parent care within a small group, rather than on generalization to a larger and incompletely known population. 


\section{CHAPTER V \\ OBSERVATIONS AND ANALYSES}

This chapter outlines the findings and provides some explanation for the outcomes of the investigation. Descriptions of the sample and the care recipients are presented followed by evaluation of the hypotheses. The final section presents findings regarding the impact of parent care and the problematic nature of caregiving.

\section{DESCRIPTION OF THE SAMPLE}

As mentioned, personal interviews with a sample of 50 adult daughters reporting present or recent experience with parent care, provide the data for the study.

A brief description of the characteristics of these caregivers is presented.

\section{Age Range}

The mean age of the subjects is 53 years, with a median age of 52. Subjects range in age from 33 through 72, a spread of 39 years. The standard deviation of 10.4 represents this wide spread of ages, not unexpected for caregivers of elderly parents. (See Table III for this and subsequent Caregiver Characteristics. Also note that percentages hereafter are rounded). 
Birth Cohort

Roughly half of the sample (48z) belong to the birth cohort of 1914 through 1933 (ages 53 to 72). The remaining 528 belong to the birth cohort of 1934 through 1952 (ages 33 to 52). Selected differences between the two cohorts are employed in further description of the sample.

\section{Marital Status}

Almost three quarters of the subjects (728) reported being married, against 288 reporting a not married status. Younger subjects were more likely to be married (818) than older subjects (638), not an unexpected age association, with greater levels of both widowhood (1008) and divorce or separation (578) in the older cohort.

\section{Relationship to parent}

Based on reports specific to 61 parents, the majority of caregivers were found to be natural daughters ( 808 ), very few were adoptive or step-daughters $(n=2)$, and the remainder were daughters-in-law (16\%).

\section{Perceived Caregiver status}

Being a primary caregiver was clearly the majority perception, with 908 of the subjects in this category. Only $10 \%$ of the subjects considered themselves to be secondary providers of parent care. 


\section{TABLE III \\ CHARACTERISTICS OF THE CAREGIVER SAMPLE \\ IN NUMBER AND PERCENT:}

AGE

$\begin{array}{llll}33-43 & 228 & (n=11) & \\ 44-53 & 328 & (n=16) & \text { mean: } 53 \\ 54-63 & 268 & (n=13) & \text { range: } 33-72 \\ 64-75 & 208 & (n=10) & \text { s.d.: } 10.4\end{array}$

BIRTH COHORT

$1914-1933$

$1934-1953$

$488 \quad(n=24)$

(aged 53-72)

$528 \quad(n=26)$

(aged 33-52)

MARITAL STATUS

$\begin{array}{lrl}\text { Married } & 728 & (n=36) \\ \text { Widowed } & 68 & (n=3) \\ \text { Divorced/separated } & 148 & (n=7) \\ \text { Never married } & 88 & (n=4)\end{array}$

RELATIONSHIP TO PARENT
Natural daughter
Adoptive/step-daughter
$808 \quad(n=49)$
Daughter-in-law
$38 \quad(n=2)$
(Note: percentages derived from 61 parents)
PERCEIVED CAREGIVER STATUS
Primary caregiver
$908 \quad(n=55)$
Secondary caregiver
$108 \quad(n=6)$

(Note: percentages derived from 61 parents)

SUBJECTS PROVIDING CONCURRENT CARE
Care to one parent
$788 \quad(n=39)$
Care to two parents
$228 \quad(n=11)$

EMPLOYMENT STATUS, OUT OF HOME

$\begin{array}{lll}\text { Full time } & 28 \% & (n=14) \\ \text { Part time } & 268 & (n=13) \\ \text { Not employed } & 248 & (n=12) \\ \text { Retired } & 228 & (n=11)\end{array}$


CHARACTERISTICS OF THE CAREGIVER SAMPLE (continued) OCCUPATION

Managerial

Professional/technical $388 \quad(n=17)$

Sales/service

Clerical

Homemaker

$188 \quad(n=9)$

$188 \quad(n=9)$

$228 \quad(n=11)$

EDUCATION

Twelfth grade or less

High school graduate

Some college

College graduate

Graduate school

$\begin{aligned} 68 & (n=3) \\ 88 & (n=4) \\ 328 & (n=16) \\ 368 & (n=18) \\ 188 & (n=9)\end{aligned}$

HOUSEHOLD INCOME, 1986

Less than $\$ 7,999$

$\begin{aligned} 88 & (n=4) \\ 148 & (n=7) \\ 408 & (n=20) \\ 228 & (n=20) \\ 88 & (n=4)\end{aligned}$

CHILDREN

$\begin{array}{lrr}\text { No children } & 128 & (n=6) \\ \text { One child } & 68 & (n=3) \\ \text { Two children or more } & 828 & (n=24)\end{array}$




\section{Subjects Providing Concurrent Care}

Over three quarters of the sample (788) provided care to one parent only, and less than one quarter (228) provided care to 2 parents. No subject in the sample cared for more than two parents concurrently.

In the one parent situation, 29 subjects (58\%) cared for their mothers only, 4 subjects (88) cared for their fathers only and 6 subjects ( $12 \%$ ) cared for their mothers-in-law only.

In the two parent situation, 8 subjects (16\%) cared for their own parents, 1 subject cared for both her parents-in-law, and 2 subjects cared for a combination of parent and parent-in-law.

\section{Recency of Parent Care}

A large majority of the subjects reported involvement with current care of a parent or parents, and a minority reported parent care involvement in the preceding twelve months. Specifically, 908 of the parents $(n=55)$ were receiving current care, and $10 \%(n=6)$ had received recent care. Reasons given for the termination of care by the subject included death (2), and admission to a health care facility (4).

\section{Employment}

Employment, either full or part time, was reported by 54 of the sample. An additional 248 reported no 
employment outside the home, and 228 considered themselves to be retired. Most of the retired group had retired from employment $(n=10)$ and only one subject reported being a retired homemaker. An employment history outside the home appeared usual for close to $75 \%$ of the subjects.

A larger percentage of the younger birth cohort was employed at the time of interview (778) versus 298 from the older cohort, an expected association as a function of age. Subjects from the older cohort, aged between 53 and 72 would have been approaching retirement at the time of the interview, if they were not already retired.

The finding that a majority of the subjects reported parent care to be problematic for their employment is discussed later.

\section{Occupation}

Primary occupation of an upper white collar nature was reported by the largest group of the sample (46\%). The next most frequently reported occupation was that of homemaker (22\%) while occupations of a lower white collar nature were reported by the remainder (36\%). Of suggested importance in the evaluation of the hypotheses, is the finding that 328 of the caregivers reported work experience with older clients or in health related fields.

Reported occupations were almost equivalent in each birth cohort, with an exception in the number of subjects 
reporting themselves to be homemakers (178 of the older cohort against 278 of the younger cohort). The feminist movement, with greater emphasis for women on career over home management activities, was not apparently an influence on most of the subjects in the younger cohort. Possibly this finding is related to high reported income levels in the presence of parent responsibilities, making possible home care without additional employment.

\section{Education}

The educational attainment of the sample members is high. That is, 868 completed some level of college education. Only 3 people (68) did not complete high school. These figures may be compared with the educational attainment of the parents, in which approximately half of the group did not complete a high school education. Differences in educational attainment between the two birth cohorts appeared to be small, also a somewhat unexpected finding.

It is suggested that the relatively high educational level of the sample is an artifact of case finding, and that it has some influence on the evaluation of the hypotheses, as discussed later.

\section{Household Income}

Reported annual household income for 1986 ranged from less than $\$ 4,000$ to over $\$ 55,000$ - a spread of over 
$\$ 50,000$, with 408 of reports being in a moderate category of $\$ 16,000$ through $\$ 34,999$. A further 308 of subjects reported higher incomes (over $\$ 35,000$ ) and 228 reported lower incomes (less than $\$ 15,999)$. Some subjects $(n=4)$ did not know or did not respond to the income question. Income in this question was specified as including annual household income and not other assets or wealth, and was assessed separately for the caregiver and her family even if the parent was in the same household. It is suggested that case finding methods and the relationship of socioeconomic levels with location of residence may have had some influence on reported income.

Few differences were revealed in reported income between the two cohort of caregivers although large differences were observed between the sample and the parent group, with the sample clearly having a greater reported household income.

\section{Children}

A majority of the subjects reported having two or more children (868), and a few subjects (68) reported having one child. Being childless was reported by 128 of the sample. Age reports of children ranged from 1 through 43 years, a spread which mirrors the spread of the caregivers' age range.

Most of the children, particularly the adults, were 
not living at home during the period of parent care. The influence of parent care on the subject's minor and adult children will be addressed later.

\section{Residence}

All subjects were residents of the Greater Portland Metropolitan area, as required by the research design. Residence was found to be widely dispersed geographically, with interviews taking place in the following locations: Central Portland, N. Portland, N.E. Portland, N.W. Portland, S.E. Portland, S.W. Portland, Beaverton, Cedar Hills, Corbett, Damascus, Estacada, Gladstone, Gresham, Hillsboro, Lake Oswego, Lake Grove, Milwaukie, Sandy, St. Johns, Tigard, Troutdale, and West Linn. Location of residence appears to have some bearing on the socioeconomic data of the sample.

\section{Ethnicity}

No data were collected regarding race or ethnicity although the majority of subjects appeared to be of Caucasian origin. Worthwhile future research would be to investigate possible differences in parent care patterns between various peoples or ethnic groups. 
DESCRIPTION OF THE CARE RECIPIENTS

This description of the recipients of care is offered to clarify the nature of the parent group, and for comparison with the sample. As mentioned previously, data regarding the parents were requested from the adult daughters and not from the parents themselves.

\section{Parent(s) Receiving Care}

Reports from the 50 adult daughters in the sample identified 61 parents as the recipients of care. This group of parents includes 39 mothers $(648), 12$ fathers (208), 8 mothers-in-law (138) and 2 fathers-in-law (38) Clearly, caring for a mother is the norm for this group of subjects, a factor which may reflect population parameters of greater female longevity, as previously discussed. These and subsequent parent data are reported in Table IV.

\section{Age of Parent}

The mean age of the parents was 83 years, and the median age was 84 , higher than expected at the outset of the project. The ages of parents ranged from a low of 63 years (a mother) to a high of 98 years (also a mother), a wide range of 35 years, as indicated by the standard deviation of 8.03 .

The mean ages of the separate parent categories showed parents to be slightly younger than parents-in-law 
(mothers: 83 years; fathers: 82 years; mothers-in-law: 86 years; fathers-in-law: 87 years).

Not surprisingly, a strong association was found between the subject's birth cohort and parent age group, with older subjects caring for older parents, and younger subjects caring for younger parents. (For the largest parent category, the mothers $(n=39)$, this association was found to be very strong, at a value of gamma .95).

\section{Parents' Marital Status}

Data on the parents' marital status indicates a predominantly widowed status (65\%), and secondarily, a married status (31\%). Divorced or separated status was reported for only 2 parents, both mothers. As expected, all parents were reported to have been married at some point in their lives.

Since the group of mothers represents the majority parent category ( $n=39$ or $64 \%$ ), the overall parent figures somewhat reflect the mothers' representation. Fathers as a group $(n=12)$ did not follow the same pattern, with more being married (67\%) than widowed (33\%); and parents-in-law were reported more often than parents to be widowed. 
TABLE IV

CHARACTERISTICS OF THE CARE RECIPIENTS

IN NUMBER AND PERCENT

PARENTS RECEIVING CARE

$\begin{array}{lrcc}\text { Mothers } & 648 & (n=39) & \text { Total number } \\ \text { Fathers } & 208 & (n=12) & \text { of parents: } \\ \text { Mothers-in-law } & 138 & (n=8) & 61 \\ \text { Fathers-in-law } & 38 & (n=2) & \end{array}$

AGE OF PARENTS
$60-69$
$70-79$
$38 \quad(n=2)$
318
$(n=19)$
mean: 83
$80-89$
438
$(n=26)$
range: $63-98$
$90-99$
$238 \quad(n=14)$
s.d.: 8.03

MARITAL STATUS

$\begin{array}{lcl}\text { Married } & 318 & (n=19) \\ \text { Widowed } & 658 & (n=40) \\ \text { Divorced/separated } & 38 & (n=2) \\ \text { Never married } & 08 & (n=0)\end{array}$

PARENT'S LIVING SITUATION

$\begin{array}{lrl}\text { Living with subject } & 628 & (n=38) \\ \text { Living with spouse } & 188 & (n=11) \\ \text { Living alone } & 188 & (n=11) \\ \text { Living with non-family } & 28 & (n=1)\end{array}$

EMPLOYMENT STATUS, OUT OF HOME
Retired
$1008 \quad(n=61)$

OCCUPATION

$\begin{array}{lrl}\text { Managerial } & 08 & (n=0) \\ \text { Professional/technical } & 88 & (n=5) \\ \text { Sales/service } & 168 & (n=10) \\ \text { Clerical } & 68 & (n=3) \\ \text { Craftsman } & 128 & (n=7) \\ \text { Homemaker } & 518 & (n=31)\end{array}$


CHARACTERISTICS OF THE CARE RECIPIENTS (continued) EDUCATION

Twelfth grade or less

High school graduate

Some college

College graduate

Graduate school

$\begin{aligned} 518 & (n=31) \\ 138 & (n=8) \\ 188 & (n=11) \\ 138 & (n=8) \\ 58 & (n=3)\end{aligned}$

INCOME, 1986

$\begin{array}{lrl}\text { Less than } \$ 7,999 & 558 & (n=32) \\ \$ 8,000-\$ 15,999 & 248 & (n=14) \\ \$ 16,000-\$ 34,999 & 108 & (n=6) \\ \$ 35,000-\$ 54,999 & 98 & (n=5) \\ \$ 55,000 \text { or greater } & 28 & (n=1)\end{array}$

(Note: figures based on 58 responses)

MAJOR LIFE CHANGES

Low to moderate

Moderate to high

$468 \quad(n=23)$

$548 \quad(n=27)$

(Note: based on 50 observations of 61 parents)

PARENTS' HEALTH STATUS

$\begin{array}{lll}\text { Low to moderate } & 388 & (n=23) \\ \text { Moderate to high } & 628 & (n=38)\end{array}$

PARENTAL AUTONOMY

Low to moderate

Moderate to high

$518 \quad(n=31)$

$498 \quad(n=30)$ 
Parents' Living Situation

Conjoint living with the subject was reported as the most usual living arrangement for 628 of the 61 parents. In that some subjects reported care for two parents, 768 of the subjects had a parent or parents living with them. This arrangement is considerably higher than the level reported by Siegel and Davidson (1984) for persons of 65 or over living with non-spousal relatives (10\% for women and 48 for men in 1981)), and substantiates reports that non-spousal family living is associated with widow or widowerhood, impairment and dependency, and extreme age (Treas, 1983; Doty, 1986).

Subject reports of the parent living with his or her spouse (18\%), and of the parent living alone (18\%) are both at lower levels than suggested by Siegel and Davidson (1984), again probably a factor of impairment, extreme age and widow or widowerhood in the parent group. Finally a single parent (mother-in-law) was reported to live with a non-family person.

\section{Parents' Employment Status}

No variability was observed in the current employment status of the parent group, with all 61 parents reported as being retired. All the men (fathers and fathers-in-law) appeared to have retired from employment, whereas 648 of the women (mothers and mothers-in-law) although considered retired, were never or seldom employed out of the home. 


\section{Parents' occupation}

The occupation most frequently reported for the 61 parents was that of homemaker (518), however this finding is misleading and reflects a gender difference involving only mothers and mothers-in-law. The occupation most frequently reported for the fathers and fathers-inlaw was that of craftsman (118 of the total). Lower white collar occupations were reported for 168 of the parents, once again reflecting the mothers and mothers-in-law, and upper white collar occupations, which were highly reported for the daughters (348), were reported for only 5 parents $(88)$.

\section{Parents' Education}

The norm for this group of parents was to terminate their formal education before high school completion, with approximately one half of the parents (518) in this category. This may be compared with the sample, in which only 3 subjects ( 38 ) did not complete high school. Education following high school completion was also reported less for the parent group ( $n=22$ or $36 \%$ ), compared with $86 \%$ of the sample. Gender differences in educational level for the parents were not great.

\section{Parents' Income}

Subjects were requested to estimate their parent's income for 1986. In all cases, income was estimated 
separately for parents and subjects. In cases where the target parent lived with a spouse, joint or household income was estimated. Most subjects were able to provide estimates of their parent's income, however data on 3 parents were missing.

Parental income ranged from less than $\$ 4,000$ ( $n=9$ or 158) to over $\$ 55,000(n=1$ or 28$)$, a spread of over $\$ 50,000$, also reported for the subjects themselves. However, parental income was generally well below subject income, and was unequally reported by gender, with mothers and mothers-in-law clearly having lower incomes than fathers and fathers-in-law.

Over half of the parents (558) were reported to have incomes of less than $\$ 7,999$; approximately one quarter were reported to have incomes of $\$ 8,000$ through $\$ 15,999$ and the remainder had reported incomes of $\$ 16,000$ and over $(n=12$ or 218$)$. Mothers and mothers-in-law represented $1008(n=9)$ of the lowest income group of less than $\$ 4,000$, whereas incomes for the fathers and father-in-law were more often from the $\$ 8,000$ through $\$ 24,999$ range.

\section{Major Life Changes of the parent}

Subjects were asked to identify whether or not their parent(s) had experienced any of seven major life changes in the preceding year (see interview schedule, question 41). The intent of the question was to examine actual 
major life changes of the parent group against supposed life changes or losses considered typical of the elderly population in general (Ruypers and Bengtson, 1973:182183), and thus to gain a measure of vulnerability to negative labeling.

of the seven major life changes, which are presented in Table $V$, those most frequently reported were associated with increasing impairment (dependency and major illness). The life changes "death of a spouse" and "retirement" were the least reported, with no instances of retirement occurring for the parents in the past year. In view of the high mean age of the parent group, the association of impairment with advanced age, the greater number of women than men in older age groups, and the smaller number of women of this age group engaged in employment out of the home, these findings are not surprising.

In examining the frequencies for each parent group a pattern of greater vulnerability emerges for the motherin-law; however, this finding is proposed cautiously in that it is based on only 8 cases. This pattern of vulnerability holds for dependency, major illness, death of a close friend, change in living situation, and death of a family member, and appears to indicate, together with the slightly greater mean age of the mothers-in-law, that care for this group is more crisis related, and may be delayed longer than care for the subject's own parents. 


\section{TABLE V}

REPORTED FREQUENCY OF MAJOR LIFE CHANGES* BY PARENT CATEGORY IN

NUMBER AND PERCENT

\section{Parent Type}

Life Change

Increased dependency

Major illness

Death of close friend

Change in living situation

Death of family member

Death of spouse

Retirement
M F

299

164

$17 \quad 3$

123

83

10

0
ML

FL Parents

81

47

778

$7 \quad 1$

28

468

51

26

438

61

22

368

$\begin{array}{lll}3 & 2 & 16\end{array}$

268

01

2

38

$0 \quad 0$

0

08

* Reports are specific to 39 mothers, 12 fathers, 8 mothers-in-law and 2 fathers-in-law, and are based on the 12 month period prior to interview.

(M=Mother; F=Father; ML=Mother-in-law; FL=Father-in-law)

In sum, a smaller number of major life changes was reported than expected for a group of people of 65 years and over, based on the arguments of Kuypers and Bengtson (1973). Even so, approximately half of the parents (468) were coded as having a low index and the other half (548) as having a high index of major life changes. This dichotomization is somewhat misleading in that scores clustered at a moderate level of change, with only one parent reported to have 5 of a possible 7 life changes, 
and no reports of parents having more than 5 life changes. Given the high mean age of the parent group (age 83), it is possible that expected rites of passage (e.g., retirement) and personal losses had occurred previously, leaving the group with a relatively stable experience other than increased impairment, over the previous twelve months. Findings from this index of major life changes in the parent, are used subsequently in the evaluation of hypothesis five.

\section{Rating of Parents' Health Status}

Subjects were requested to rate their parent's health status objectively, using six health related dimensions, as identified in the interview schedule (question 28). These dimensions include:

1. Utilization of health services

2. Self care performance

3. Mobility status

4. Speech, hearing and vision status (sensory)

5. Bladder and bowel control (incontinence)

6. Life support requirements

A summary health profile was developed to dichotomize all parental scores into a "low impairment" or "high impairment" category.

Responses, presented in Table VI, indicate that 628 of the parents were rated in the "high impairment" 
category, a category which includes some moderate scores. The remaining $38 \%$ of the parents were rated as having "low impairment," which also includes some moderate scores.

\section{TABLE VI}

HEALTH STATUS OF PARENTS

IN NUMBER AND PERCENT

$\begin{array}{lclllll}\begin{array}{l}\text { Rating of Parents' } \\ \text { Health Status }\end{array} & \text { M } & \text { F } & \text { ML } & \text { FL } \begin{array}{c}\text { All } \\ \text { Parents }\end{array} \\ \text { Low Impairment } & 14 & 6 & 1 & 2 & 23 & 388 \\ & 368 & 508 & 128 & 1008 & & \\ \text { High Impairment } & 25 & 6 & 7 & 0 & 38 & 628 \\ \text { N } & 648 & 508 & 888 & 08 & & \\ & 39 & 12 & 8 & 2 & 61 & 1008 \\ \text { M=Mother, F=Father, ML=Mother-in-law, FL=Father-in-law) }\end{array}$

Differences were noted by gender, with mothers and mothers-in-law showing greater levels of dependency and impairment than fathers and fathers-in-law. Mothers-in-law were reported to have the greatest levels of impairment with 888 rated at this level. Fathers-in-law appeared to have the least impairment, with both rated at a low level. Regarding mother-in-law impairment, again a cautious interpretation, an impression was gained that subjects delayed longer in initiating care for their mothers-in law, until major illness and losses of support from others made subject involvement more necessary.

In reviewing responses to the six health related 
dimensions, the dimension "life support needs" appeared to give the greatest indication of parental need for caregiving. This dimension was intended to reveal the overall ability of the parent to sustain his or her life style in terms of physical, cognitive and social functioning. A larger percentage of the parents were reported to be completely dependent in this category than in any other dimension ( $n=23$ or $38 \%)$.

The second dimension most frequently reported was the rating of "speech, hearing and vision status," with over $85 \%$ of the parents having some impairment, but with only 168 actually dependent $(n=10)$.

Assessment of self care and mobility status indicated that approximately $80 \%$ of the group had some level of impairment in each area. Reports of actual dependency were 168 for self care $(n=10)$ and $15 \%$ for mobility $(n=9)$.

problems of "bowel and bladder control" were reported for over $68 \%$ of the parent group; however only 138 had major problems with dependency $(n=8)$.

Regarding the dimension "utilization of health services" most reports were of infrequent or intermittent (548 and 368) utilization, with only 108 of the parents reported as requiring intensive health services $(n=6)$. This finding suggests that caregivers were responsible for parents with chronic rather than acute medical needs, which is not unexpected, given less governmental support 
in the United States for chronic and long term care than for acute care.

In considering caregiver support, this analysis indicates that 388 of the parents $(n=238)$ required minimal to moderate assistance, and that 628 of the parents $(n=38)$ required moderate to major assistance each as a direct consequence of lower or higher levels of impairment and dependency.

\section{Rating of parents' Cognitive status}

Subjects were requested to provide a gross estimate of their parent's cognitive status during the preceeding 12 months, as identified in Table VII (see interview schedule, question 30 ).

\section{TABLE VII \\ RATING* OF PARENTS' COGNITIVE STATUS IN NUMBER AND PERCENT}

Cognitive status M F ML FL Parent \&





3. Much less sharp $11 \quad 4 \quad 30015$

$\begin{array}{llllll}37 & 12 & 8 & 1 & 58 & 1008\end{array}$

*as perceived by the caregiver

(M=Mother, F=Father, ML=Mother-in-law, FL=Father-in-law) (Missing cases $=3$ ) 
No change in cognitive status was reported for 218 of the parents $(n=12)$, whereas increased cognitive deficits were reported for the remaining $798 \quad(n=46)$. Of those parents with deficits, $538(n=31)$ were reported to be "less sharp," and the remaining $26 \%(n=15)$ were reported to be "much less sharp." It is probable that parents diagnosed as having Alzheimer's disease are included in the last category, although no diagnostic data were collected.

\section{Parental Autonomy}

As previously stated, the construct "parental autonomy" is the primary dependent variable of this study and is central to the evaluation of three hypotheses. The level of parental autonomy is assessed by the caregiver through responses to a set of 8 items identified as parental responses to caregiving (see Chapter IV, Methodology and interview schedule, question 31).

Table VIII, following, displays parental autonomy scores dichotomized into low and high levels. As can be seen, $51 \%$ of the parents were assessed by the caregiver as having a low level of autonomy, whereas the remaining 498 were assessed as having a high level of autonomy.

Analysis of these data suggests a slight gender difference in autonomy levels between the mothers and the fathers with mothers having slightly lower, and fathers 
having slightly higher levels of autonomy as assessed by the caregiver. This pattern does not hold for the mothersin-law, which is somewhat surprising, given the greater impairment, age and life changes identified for this group.

\section{TABLE VIII}

CAREGIVER ASSESSMENT OF PARENTAL AUTONOMY IN NUMBER AND PERCENT

Autonomy Level

Low Autonomy

High Autonomy

$\mathrm{N}$
M F ML

21

548

5 428

18 468

39

$\begin{array}{ccc}7 & 4 & 1 \\ 588 & 508 & 508\end{array}$

12

8

2

$61 \quad 1008$

The relationship of the caregiver's assessment of parental autonomy to the caregiver's construction of old age, to caregiver assistance, to parental impairment, and to major life changes in the parent is discussed further in subsequent evaluation of the hypotheses. 
EVALUATION OF THE HYPOTHESES

This section addresses the evaluation of the five hypotheses and discusses the variables associated with each.

Hypothesis 1.

Caregiver agreement with a negative social construction of old age is associated with low levels of parental autonomy, as assessed by the caregiver.

Evaluation of this hypothesis involves bivariate analysis of the dependent variable "caregiver perception of parental autonomy ${ }^{n 1}$ by the independent variable "construction of old age held by the caregiver."

For measurement of the dependent variable a composite measure of caregiver observations of parental autonomy of the 61 parents was constructed, as previously indicated in the section on data analysis. The use of a composite measure of assessed parental autonomy allowed evaluation of the hypothesis based on reports of the entire parent group as well as comparison based on the separate parent categories (mother, father, mother-in-law, father-in-law).

For the independent variable, "construction of old

$1_{\text {The variable "parental autonomy" as used here and }}$ subsequently is based on assessment by the caregiver, not by the parent. 
age held by the caregiver," two measures are employed, both of which are described in the section on data analysis. The primary measure "image of older persons" (Harris et al., 1975), focuses on the caregiver's image of older people; the second measure "image of old age" focuses on the caregiver's view of the old age status.

With regard to evaluation of this hypothesis: findings are reported first for the association of the constructed variable of perceived parental autonomy with both measures of the construction of old age, and second, selected findings are compared for the separate parent categories.

Analysis of the first aspect of the construction of old age (image of older persons) as it relates to parental autonomy suggests a low level of support for the first hypothesis, as shown in Table IX, which presents the association between the image of older persons held by the caregiver and the caregiver's assessment of parental autonomy •

Caregiver responses appear to favor a neutral orientation to older persons with 498 of the sample responding in this manner $(n=24)$. The remaining responses are evenly divided between negative and positive images of older persons. Parental autonomy is reported most often at moderate $(n=24$ or 498$)$ and low ( $n=16$ or 32.78$)$ levels, and least often at high levels ( $n=9$ or 18.48). 
The coefficient gamma at a value of .10684 suggests a low positive association between the image of older persons held by the caregiver and her assessment of parental autonomy. Detailed comparison of these findings with those from the Harris and Associates (1975) study was not undertaken. However, inspection of Table IX suggests that these findings on the image of older persons are generally less negative than those obtained in the national study.

\section{TABLE IX}

ASSESSED PARENTAL AUTONOMY BY CAREGIVER'S "IMAGE OF OLDER PERSONS" IN NUMBER AND PERCENT

Image of Older Persons Parental Autonomy* Negative Neutral Positive

\begin{tabular}{lcccc} 
Low & 5 & 7 & 4 & 16 \\
Moderate & 398 & 298 & 338 & \\
\multirow{2}{*}{ High } & 7 & 11 & 6 & 24 \\
& 548 & 468 & 508 & \\
& 1 & 6 & 2 & 9 \\
& 88 & 258 & 178 & \\
& 13 & 24 & 12 & 49
\end{tabular}

Gamma : .10684

*as assessed by the caregiver

Missing cases $=1$

Findings from the analysis of the second measure of the construction of old age (image of old age) and 
parental autonomy, as shown in Table $x$, suggest a substantial association between a negative image of old age held by the caregiver and low levels of assessed parental autonomy. Specifically, the correlation coefficient gamma .58140 suggests that knowledge of the caregiver's image of old age can reduce error in predicting the caregiver's assessment of parental autonomy by $58 \%$. This finding strongly supports the first hypothesis.

\section{TABLE X}

ASSESSED PARENTAL AUTONOMY BY CAREGIVER'S "IMAGE OF OLD AGE" IN NUMBER AND PERCENT

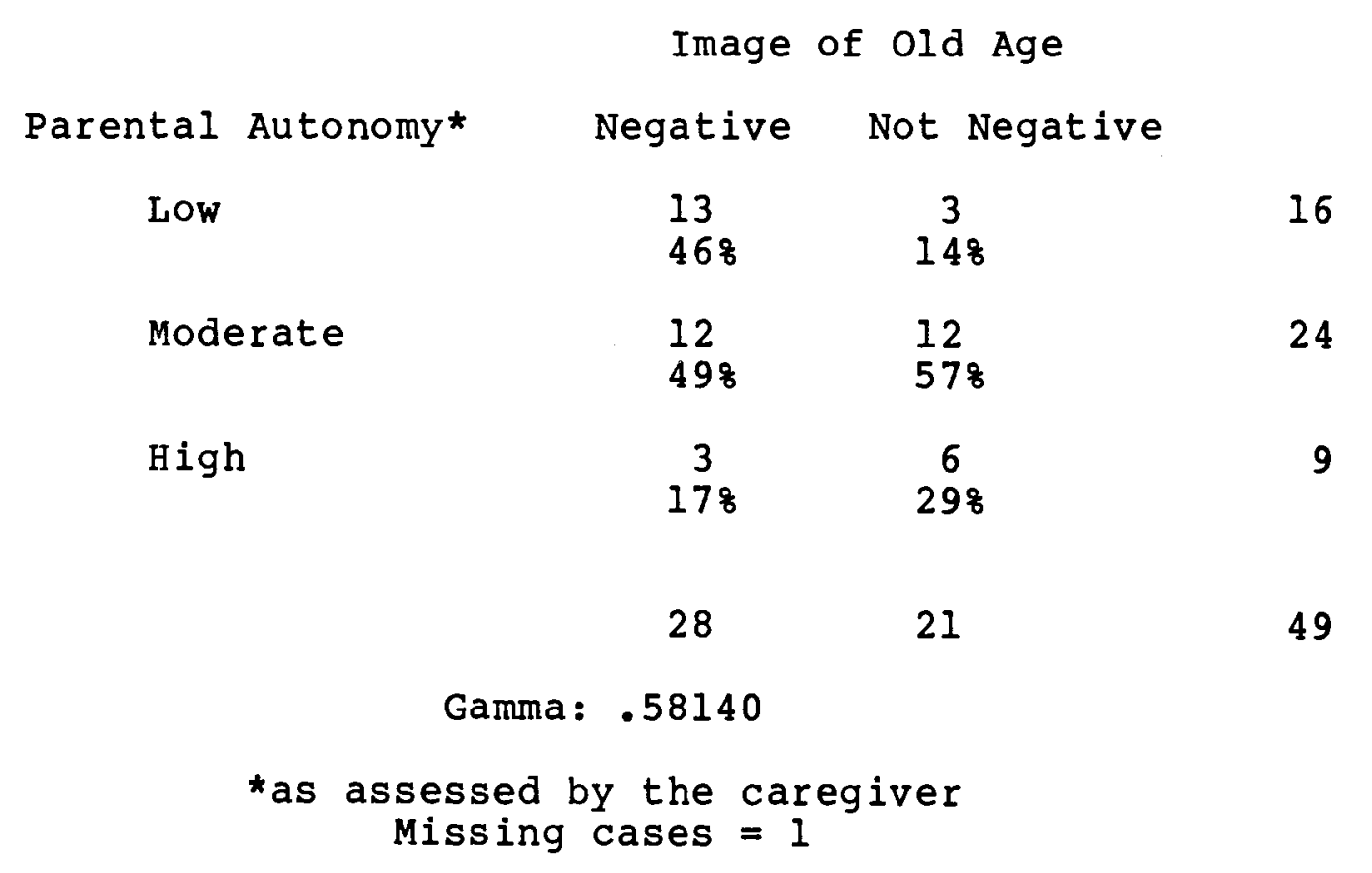

Note: Caregiver responses on the image of old age have been collapsed into negative and not negative categories (positive and neutral) in that relatively few positive responses were received $(n=4)$. 
Consideration of the findings from the analysis of parental autonomy by the two measures on caregiver construction of old age suggests that older people as a collectivity are viewed more positively by the sample than is the old age status in the life course which is viewed negatively. Despite these differences, this analysis suggests some support for the first hypothesis in that there is a positive association between negative constructions of old age held by the caregiver and low levels of parental autonomy.

A possible explanation for the lack of strong support for the hypothesis using the measure "image of older persons," may lie in certain attributes of the caregiver sample. First, the modal educational level of the sample is that of college graduate (36\%), surely a higher level than found in the general public. Secondly, a majority of the sample reported professional or technical occupations (388), with many caregivers ( $n=16$ or 328$)$ having work experience with older clients or in health related fields. Thirdly, the average age of the sample is 53 years.

These attributes suggest that the perception of older people held by this sample of caregivers may differ from that of the general public, particularly in terms of knowledge of older people as individuals rather than in terms of typifications, to use Berger and Luckmann's terminology (1967). Also the relative closeness in age of 
the sample to the lower boundary of the old age status suggests possible anticipatory socialization, which may predispose some of the older subjects to report a more positive image of older persons.

Using the theoretical framework proposed by Berger and Luckmann (1967:30) as previously discussed, typical understandings or typifications are open to change through the accumulation of all forms of knowledge including personal interaction. It is suggested that the high educational level of the subjects, reported work experience with older clients and personal contact with older family members work together to modify typifications of older people held by the sample and to reduce reliance on negative societally held understandings. These factors of secondary socialization may account for the more positive orientation toward older people found in this study, thus education particularly, may modify the hypothesized association between a negative construction of old age and lower assessed autonomy in the parent.

The predominantly negative "image of old age" held by the sample is closer to the expected construction of old age as identified in the literature review. A possible explanation for this more negative view when contrasted with the "image of older persons," has to do with subject knowledge of the link between advanced age and greater levels of impairment. When asked whether being a caregiver 
had made a difference in the perception of their own aging (interview schedule, question 5) $86 \%$ of the sample cited greater concern with the aging process. Specifically fear, anxiety and/or negative concerns were reported by almost a quarter of the group (228). Hence it is suggested that caregiving for an impaired parent, implications of this caregiving for their own personal aging and work experience with older clients (for some of the sample) have contributed to a view of old age which is generally negative. At the same time, occupational, educational and experiential factors serve to create in the caregiver's view a differentiation between images of the old age status and of older people as incumbents of that status.

In evaluating the hypothesis for the different parent categories, a difference is noted by gender particularly with regard to the "image of old age." Reports from caregivers of mothers and mothers-in-law (together 778 of the parent group) indicate a higher association between the image held by them of the old age status and their assessment of parental autonomy at gamma values of .55738 and .42857 , when compared with reports from caregivers of fathers (208 of the parent group) which indicate a low association between the variables (gamma: .14286).

A possible explanation for this finding is a gender difference in socialization favoring greater autonomy in men, and an expectation of more problematic aging for 
women, as indicated by de Beauvoir (1972) and Phillipson (1982).

Findings relating to the "image of older persons" specified separately for caregivers of the four parent categories are more evenly distributed and are not included in tabular form.

In summary, evaluation of the first hypothesis suggests partial support for the statement that negative constructions of old age held by the caregiver are positively associated with low levels of perceived parental autonomy. Of the two measures employed in the construction of old age, one was determined to have a low positive association ("image of older persons," gamma .1068) and the other was determined to have a substantial positive association ("image of old age," gamma .58104) with the dependent variable, parental autonomy.

Hypothesis 2.

More advanced age and higher levels of perceived impairment of the parent are associated with a negative construction of old age as held by the caregiver.

Evaluation of the second hypothesis involves bivariate analyses of the dependent variable "construction of old age held by the caregiver" by the independent variable "age group of parent" and separately by a second 
independent variable "parental impairment."

As in the discussion of the first hypothesis, the dependent variable "construction of old age" is assessed by two measures, "image of older persons" and "image of old age."

For the independent variables composite measures of "age group of parent" and "parental impairment" 2 are employed based upon the 50 caregiver reports specific to the 61 parents. Analysis for each parent category also allows comparison and identification of separate findings where appropriate.

Evaluation of the hypothesis is reported first for both measures of the dependent variable ("image of older persons" and "image of old age") by parent's age group, and second, for the same measures of the dependent variable by parental impairment.

Bivariate analysis of the caregiver's "image of older persons" by parent's age group provides a low level of support for the second hypothesis. As shown in Table XI, there appears to be a low negative association between the two variables as summarized by the statistic gamma at a value of -.14712. This finding indicates an inverse relationship, with greater age slightly associated with more negative views of older persons. The expectation

2 The variable "parental impairment" as used here and subsequently is based on assessment by the caregiver. 
that extremely old persons are viewed more negatively and the converse that young-old persons are viewed more positively by the caregiver is supported at a much lower level than expected.

Possible explanations for this finding include the following. First, as previously discussed, sample attributes such as a high education level, work experience with older persons or in health related fields, the experience of parent care, plus a mean age of 53 , all contribute to a knowledge base of older persons reducing the likelihood of negative typifications and thus accounting for a more neutral orientation ( $n=24$ or 488 ) than expected.

Second, the more neutral than expected view of older persons held by caregivers of the extreme elderly parent may be explained by an interview impression of a sense of admiration for the tenacity exhibited by some parents despite real problems compromising their day-to-day existence. This sense of admiration, it may be argued, is then generalized to foster a less negative view of older persons than expected. This suggestion corresponds with Berger and Luckmann's thesis that face-to-face interaction and closeness contribute to a body of knowledge and reduce reliance on external typifications when evidence renders such typifications inappropriate (1967:30). 


\section{TABLE XI}

CAREGIVER'S "IMAGE OF OLDER PERSONS"

BY AGE GROUP OF PARENT

IN NUMBER AND PERCENT

Age Group of Parent

$\begin{array}{lccc}\text { Image of Older } & \begin{array}{c}\text { Young-Old } \\ 63-74\end{array} & \begin{array}{c}\text { Aged } \\ 75-84\end{array} & \begin{array}{c}\text { Extreme } \\ 85-99\end{array} \\ \text { Persons* } & & 6 & 6 \\ \text { Positive } & & 338 & 268 \\ \text { Neutral } & 5 & 8 & 11 \\ \text { Negative } & 62.58 & 448 & 488 \\ & 3 & 4 & 6 \\ & 37.58 & 228 & 268 \\ & 8 & 18 & 23\end{array}$

*as perceived by caregiver Missing cases $=1$

With reference to the lack of positive regard for older persons associated with caregivers of young-old parents (also shown in Table XI), it is possible that the interview impression of more instances of Alzheimer's and/or related diseases in younger parents has some explanatory value. The greater difficulties of care reported for these parents may, it is argued, be generalized to foster a more neutral or negative view of older persons. No specific data on medical conditions were collected to substantiate this interview impression. Bivariate analysis of the caregiver's "image of old 
age" by the parent's age group similarly demonstrates a low level of support for the hypothesis that advanced age of the parent is associated with a more negative construction of old age held by the caregiver. As displayed in Table XII, the correlation coefficient gamma at a value of -.11111 indicates an inverse relationship, with extreme age of the parent being slightly associated with a more negative image of old age as held by the caregiver. The higher than expected relationship between extreme age of the parent and a not-negative (or neutral) view of old age $(n=11$ or 22.48 total percent $)$ as discussed, may be a factor in reducing the hypothesized association.

The finding that extreme age of a parent is not necessarily linked with a negative image of old age may be explained also by the relative lack of congruence between chronological age per se and the meaning of old age. In the post-coding of interview schedule question 1 , on the meaning of old age, only 6 subjects (128) were found to report chronological age as a central component of the old age status. Instead, subjects linked the meaning of old age more often with deterioration, loss of ability and increasing dependency across a wide age range. 
TABLE XII

CAREGIVER'S "IMAGE OF OLD AGE"
BY AGE GROUP OF PARENT
IN NUMBER AND PERCENT

Age Group of Parent

\begin{tabular}{|c|c|c|c|c|}
\hline$\underset{\text { Age }^{*}}{\text { Image of old }}$ & $\begin{array}{l}\text { Young-old } \\
63-74\end{array}$ & $\begin{array}{l}\text { Aged } \\
75-84\end{array}$ & $\begin{array}{r}\text { Extreme } \\
85-99\end{array}$ & Aged \\
\hline Not Negative & $\begin{array}{l}3 \\
37.58\end{array}$ & $\begin{array}{c}7 \\
418\end{array}$ & $\begin{array}{l}11 \\
468\end{array}$ & \\
\hline Negative & $\begin{array}{l}5 \\
62.58\end{array}$ & $\begin{array}{l}10 \\
598\end{array}$ & $\begin{array}{l}13 \\
548\end{array}$ & \\
\hline & 8 & 17 & 24 & \\
\hline \multicolumn{5}{|c|}{ Gamma: -.11111 } \\
\hline as & $\begin{array}{l}\text { perceived } \\
\text { Missing cas }\end{array}$ & $\begin{array}{l}y \text { car } \\
\mathrm{s}=1\end{array}$ & er & \\
\hline
\end{tabular}

Note: Caregiver responses on the image of old age have been collapsed into negative and not negative categories (positive and neutral) in that relatively few positive responses were received $(n=4)$.

Evaluation of the second part of hypothesis 2, regarding association between parental impairment and the the caregiver's construction of old age provides only slightly more support for the hypothesis.

Bivariate analysis of the caregiver's "image of older persons" by parental impairment essentially demonstrates no association between the variables, as indicated by the statistic gamma of -.00450 , presented in Table XIII. 
TABLE XIII



IN NUMBER AND PERCENT

Parental Impairment* Image of Older Low Moderate Severe Persons

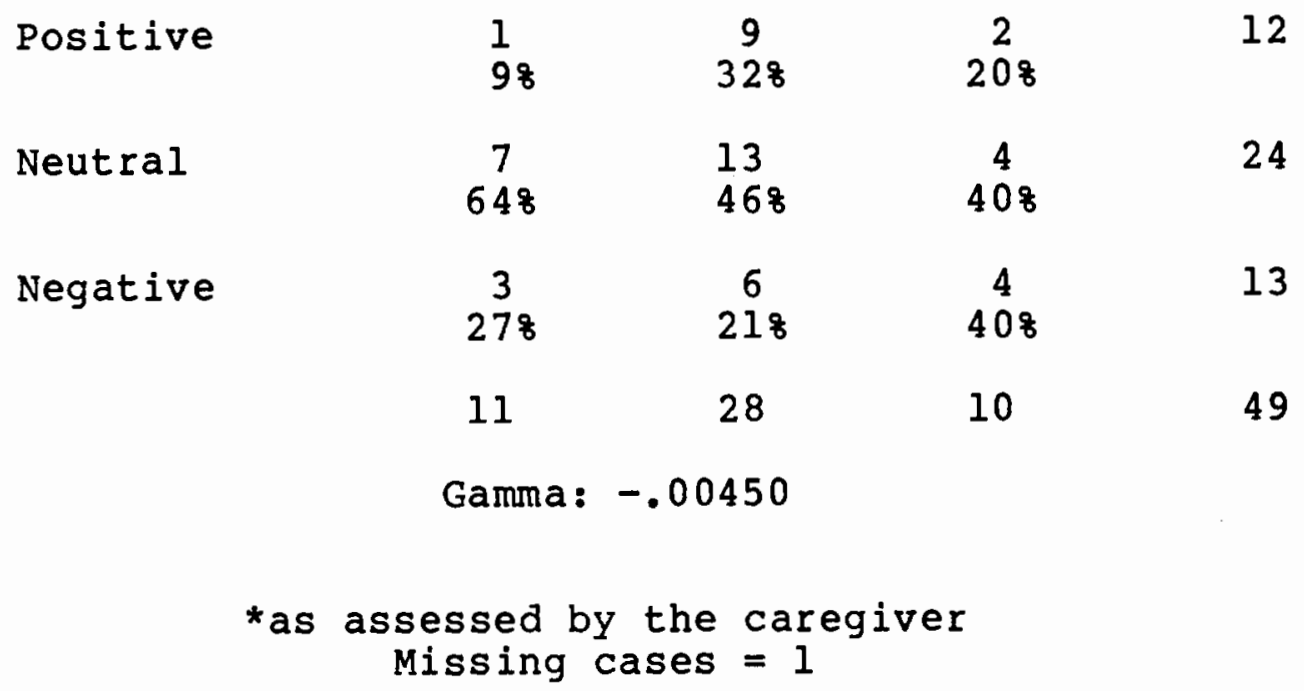

It appears that the caregiver's "image of older persons" is largely independent of both the age and the impairment level of the parent, and is not greatly affected by either of these factors. As mentioned previously, attributes of the sample may account for the predominantly neutral orientation of the caregivers toward older persons.

Bivariate analysis of the association between the caregiver's "image of old age" and parental impairment demonstrates somewhat stronger support for the second hypothesis. As can be seen in Table XIV, the relationship 
between these two variables is summarized by the statistic gamma at a value of .28324 , a low positive association, suggesting that greater parental impairment is related to a more negative image of the old age status, as held by the caregiver.

\section{TABLE XIV}

CAREGIVER'S "IMAGE OF OLD AGE"

BY PARENTAL IMPAIRMENT

IN NUMBER AND PERCENT

\begin{tabular}{|c|c|c|c|}
\hline $\begin{array}{l}\text { Image of old } \\
\text { Age }\end{array}$ & Low & Moderate & Severe \\
\hline Not Negative & $\begin{array}{l}5 \\
45.58\end{array}$ & $\begin{array}{l}14 \\
508\end{array}$ & $\begin{array}{c}2 \\
208\end{array}$ \\
\hline \multirow[t]{3}{*}{ Negative } & $\begin{array}{l}6 \\
54.58\end{array}$ & $\begin{array}{l}14 \\
508\end{array}$ & $\begin{array}{c}8 \\
808\end{array}$ \\
\hline & 11 & 28 & 10 \\
\hline & \multicolumn{3}{|c|}{ Gamma: .28324 } \\
\hline
\end{tabular}

Note: Caregiver responses on the image of old age have been collapsed into negative and not negative categories (positive and neutral) in that relatively few positive responses were received $(n=4)$.

In that sample responses to the meaning of old age were more highly oriented towards deterioration, loss of ability, and dependency (factors that occur with impairment), it is surprising that the association with impairment is not greater. A possible explanation for the 
lower than expected finding may be derived from separate analysis of the "image of old age" and parental impairment in each parent category.

For instance, in separate analysis, a very strong negative association between parental impairment and the caregiver's image of old age was identified in the father's category $(n=12)$ as indicated by gamma -.80000 . That is, lower levels of impairment in the fathers were more strongly associated with a negative image of old age, a reverse finding from that expected. In that values for the fathers are entered into the composite parental variable of impairment, it is suggested that this finding is influential in decreasing the level of the positive association discovered between parental impairment and the caregiver's "image of old age" to gamma .28324, as previously identified in Table XIV.

Separate analysis of the mother's category ( $n=39)$ also supports the second hypothesis, with mother's impairment being related to both the caregiver's "image of older persons" and the "image of old age" at values of gamma .23843 and .41593 respectively. Values derived for the other parent groups are less useful in view of the small numbers involved.

In summary, the second hypothesis is partially supported, but at relatively low levels.

In terms of the independent variable "age group of 
parent" low negative associations with both measures of the caregiver's construction of old age are identified ("image of older persons": gamma -.14712; "image of old age $^{n}$ : gamma -.11111). Contrary to expectations, parent age does not appear to significantly influence the caregiver's construction of old age.

In terms of the second independent variable "parental impairment" no linear association is apparent between parental impairment and the caregiver's "image of older persons": gamma -.00450; however, a low positive association is apparent between parental impairment and the caregiver's "image of old age": gamma .28324. Thus, parental impairment appears to have a low level of influence on the caregiver's construction of old age.

The rationale for the second hypothesis relating perpetuation of the negative view of old age in society to salient characteristics of the older population is not well supported. In this sample parental impairment appears to have greater explanatory value in this regard than does parent's age.

Hypothesis 3.

The highest levels of caregiver assistance to the parent are associated with the lowest levels of parental autonomy as assessed by the caregiver, when impairment is held constant. 
Evaluation of the third hypothesis involves analysis of the zero-order relationship between the independent variable "caregiver assistance to parent" and the dependent variable "parental autonomy as assessed by the caregiver," and subsequently, analysis of the first-order relationship controlling for the test variable "parental impairment." Since the control variable "parental impairment" is supposedly antecedent to both the independent variable (assistance) and the dependent variable (parental autonomy), this elaboration should help to detect a spurious relationship between the variables.

Initial analysis of the variables "assessed parental autonomy" by "caregiver assistance," as shown in Table XV, strongly supports the hypothesis that high levels of caregiver assistance are associated with low levels of assessed parental autonomy. This zero-order relationship is summarized by the correlation coefficient gamma at a value of -.57576 , a substantial negative association. That is, knowing the caregiver's level of assistance to the parent can reduce error in predicting the caregiver's assessment of parental autonomy by 57\%. This finding also supports Langer's statements (1983) that assistance to elderly persons may encourage "self-induced dependency." However, the relationship of impairment to this finding is unclear, and requires further analysis. 


\section{TABLE XV \\ ASSESSED PARENTAL AUTONOMY \\ BY CAREGIVER ASSISTANCE \\ IN NUMBER AND PERCENT}

\section{Assistance Level}

Level of Parental

Autonomy *

Low High

Low

7

358

13

658

20
678

10

338

50

gamma: -.57576

*as assessed by the caregiver

Elaboration of the zero-order relationship by introducing the control variable "parental impairment" is undertaken to clarify the nature of the original relationship between caregiver assistance and caregiver assessment of parental autonomy.

This elaboration, using two values of parental impairment (low impairment and high impairment) indicates a "split" in the findings of the two conditional tables with one coefficient lower, and one higher than the zeroorder coefficient. These findings are illustrated in Table XVI. 
TABLE XVI

\begin{abstract}
ASSESSED PARENTAL AUTONOMY
BY CAREGIVER ASSISTANCE

CONTROLLING FOR PARENTAL IMPAIRMENT

IN NUMBER AND PERCENT
\end{abstract}

\title{
Impairment *
}

Low Impairment

Autonomy* Low Assist Hi Assist Low Assist Hi Assist

LOW

High

$\mathrm{N}$

9

7

gamma -.82857
Bigh Impairment

$558 \quad 708$

$468 \quad 308$

11

23

gamma -.31148

*Parental impairment and parental autonomy as assessed by the caregiver.

specifically, the first-order coefficient for the "low impairment" table has a value of gamma-.82857, whereas the first-order coefficient for the "high impairment tablen has a value of gamma -.31148. These can be compared with the zero-order finding in the original table of gamma -.57576 .

This split finding suggests that the original relationship varies according to the severity of parental impaiment. That is, the control variable, parental impairment, "speciflies] the conditions under which the original relationship occurs" (Babbie, 1983:399). Extending this analysis, it appears that in parents with 
low impairment, there is a stronger relationship between high assistance and low levels of autonomy (gamma value -.82857), whereas in parents with high impairment there is a weaker relationship between high assistance and low levels of autonomy (gamma -.31148). Presumably, impairment itself has a stronger interaction with the original variables when the level of impairment is high and a weaker interaction when the level of impairment is low.

In summary, the findings from this evaluation support the third hypothesis, in which high levels of the independent variable, caregiver assistance, are hypothesized to be associated with low levels of the dependent variable, the caregiver's assessment of parental autonomy. However, this relationship appears to vary, and may be specified by the control variable of parental impairment in that low levels of impairment strengthen, and high levels of impairment weaken the original relationship. Despite this specification, in situations of both high and low parental impairment a moderate association persists, which supports the arguments proposed by Seligman (1975), solomon (1982) and Langer (1983) that helplessness or dependency may be induced in the elderly person, not necessarily as a result of declining capacity, but from the process of being helped. Further exploration of this relationship would best be accomplished through a longitudinal research design. 
Hypothesis 4.

There is no significant difference in the central ethic of responsibility for parent care as held by two different birth cohorts of caregivers.

Evaluation of the fourth hypothesis involves bivariate analysis of the dependent variable "responsibility for parent care" by the independent variable "birth cohort of caregiver." The dependent variable is assessed by two measures "orientation to responsibility for parent care" based on question 21 of the interview schedule, and the "role of socialization to parent caren based on question 25. The independent variable of caregiver birth cohort was dichotomized from birth year of subject, interview schedule question 42 .

As seen in Table XVII, analysis of the first set of variables, responsibility toward parent care by birth cohort of subject, suggests support for the fourth hypothesis. There appears to be little difference between the two birth cohorts in caregiver responsibility toward parent care. This is evidenced by the correlation coefficient gamma at a value of -.04762 , a negligible negative association.

This finding suggests that while methods of providing care to elderly parents may be altered in concert with social change, the "felt" responsibility remains at a similar level across generations, at least in this sample. 


\section{TABLE XVII}

\section{RESPONSIBILITY TOWARD PARENT CARE \\ BY BIRTH COHORT OF SUBJECT \\ IN NUMBER AND PERCENT}

$\begin{array}{lccc} & \text { Birth Cohort of subject } & \\ \text { Responsibility } & 1914-1933 & 1934-1953 & \\ \text { Toward Parent Care } & & 22 & 42 \\ \text { Positive } & 20 & 858 & \\ \text { Negative } & 838 & 4 & 8 \\ & 4 & 158 & 50 \\ & 178 & 26 & \\ & 24 & & \end{array}$

Interestingly, this finding suggests a higher positive orientation to parent care responsibilities than indicated from other responses in the interview, in which many subjects spoke of difficulties and disruption in family well-being secondary to the caregiving episode. Further description of these difficulties is addressed in the next section. The lack of difference in the reports of the two cohorts could indicate the strength of the caregiving ethic, or could indicate a disjunction between expression of feeling and actual behavior regarding parent responsibility.

Findings from analysis of the second measure, the "role of socialization to parent care" by "birth cohort 
of the subject," in Table XVIII, are also supportive of the fourth hypothesis. While there are considerable differences in the nature of socialization to parent care by birth cohort, the overall measure of socialization is not as different, as suggested by the uncertainty coefficient at a value of .06866 .

\section{TABLE XVIII}

SOCIALIZATION TO PARENT CARE

BY BIRTH COHORT OF SUBJECT

IN NUMBER AND PERCENT

Birth Cohort of Subject

Socialization

$$
\text { 1914-1933 1934-1953 }
$$

To Parent Care

$\begin{array}{lcc}\text { Limited } & 5 & 2 \\ \text { Socialization } & 218 & 88 \\ \text { Primary } & 9 & 19 \\ \text { Socialization } & 378 & 738 \\ \text { Secondary } & 10 & 5 \\ \text { Socialization* } & 428 & 198\end{array}$

* Secondary socialization includes adult experiences of education, training, employment and family life as related to care for others, particularly elders.

The difference by birth cohort between primary and secondary socialization experiences is large. The lower number of reports by the older birth cohort of the role of 
primary socialization in subsequent parent care is not in the expected direction, nor was it expected that younger caregivers would report a relatively high role for primary socialization. Similarly differences in the role of secondary socialization were greater than expected.

A possible explanation for these findings lies in the distance of the subject from the two types of socialization. Older subjects, now aged between 53 and 72 , are closer to secondary socialization experiences associated with elder care, and therefore report these more frequently than earlier experiences. Similarly, younger subjects, now aged between 33 and 52 , are closer to their primary socialization and may have had fewer applicable secondary socialization experiences. Different historical experiences by birth cohort such as the two World Wars and the Great Depression for the older cohort, and the second World War and Post-War prosperity for the younger cohort may additionally influence reporting of socialization experiences by the two groups of caregivers. In summary, these analyses provide support for the hypothesis that there is no significant difference in the central ethic of responsibility for parent care as held by the two birth cohorts of caregivers in this sample. This finding supports the position held by a number of authors that there is a commitment across generations towards responsibility for parent care, despite social change 
such as labor force participation of women and gender role changes (Brody, 1981; Stoller, 1983; Treas, 1983 and Brody, 1984). Future change in this commitment may occur as a delayed effect from the social changes mentioned in association with expected greater numbers of older persons in need and lesser numbers of adult children available to provide parent care services.

\section{Hypothesis 5.}

A high index of major life changes in the parent is associated with low levels of parental autonomy as assessed by the caregiver, when impairment is held constant.

To evaluate this hypothesis, a zero-order analysis of the dependent variable "parental autonomy" by the independent variable "major life changes of the parent" is performed. Subsequently, to control the possible effects of impairment on the dependent variable, the test variable "parental impairment" is held constant through elaboration.

Findings from the zero-order analysis (Table XIX) do not support the fifth hypothesis. The zero-order coefficient gamma, at a value of -.06796 indicates a negligible negative association. That is, the hypothesized association between high levels of major life changes in the parent and low parental autonomy is not substantiated. 
TABLE XIX

ASSESSED PARENTAL AUTONOMY

BY MAJOR LIFE CHANGES OF PARENT

IN NUMBER AND PERCENT

Life Changes of Parent

Level of Parental
Autonomy*

Low

High
Low

12

528

11

488

23
$\mathrm{High}$

15

568

12

448

27

gamma: -.06796

*as assessed by the caregiver

The lack of association between major life changes in the parent and the level of parental autonomy as found in this sample, is contrary to the argument outlined by Kuypers and Bengtson (1973). As previously discussed, these authors argue that social reorganizations typically facing the older person render the person susceptible to the effects of negative labeling, and thus negatively influence the person's self-esteem, competence and ability to negotiate the environment. While this hypothesis does not evaluate the more extensive argument proposed by these authors, some association between a proxy for social reorganization (high index of major life changes) and a proxy for the negative effects on the elderly person (low 
parental autonomy) is expected.

Some reasons for the lack of association between these two variables in this study include the following. First, Kuypers and Bengtson (1973) posit that negative labeling by others is a necessary factor in a negative self-identification by the older person. (In that only caregivers, not parents, were included in the sample, the aspect of negative self-labeling was precluded). In this study, the image of older persons held by the caregivers is less negative than expected (488 neutral, 248 positive and 268 negative), suggesting that a largely negative regard from a significant other may not have occurred. This does not account for other sources of negative labeling from the social environment in general.

A second factor has to do with the index of life changes reported for the parent group with a smaller number of life changes reported than expected. Possibly, the limitation of one year for the reporting time, as applied during the interview process was unrealistic, particularly in view of the high average age of the parent group (mean age: 83 years). To clarify, from caregiver reports, the parents appeared to have experienced many life changes in prior years which were not entered into the data base for the study. Greater distance from life changes may also influence self-identification of the older person, with such changes having less influence as 
the elapsed time from the change increases.

Further analysis of the zero-order association between the variables major life changes and parental autonomy while controlling for parental impairment is presented in Table $\mathrm{xx}$.

TABLE XX

ASSESSED PARENTAL AUTONOMY

BY MAJOR LIFE CHANGES (MLC) OF PARENT

CONTROLLING FOR PARENTAL IMPAIRMENT

IN NUMBER AND PERCENT

Impairment*

Low Impairment

Autonomy *

Low

$\mathrm{High}$

$\mathrm{N}$
LOW MLC

228

788

9

gamma -.44828
High Impairment

LOW MLC Hi MLC

718

608

298

408

14

20

*Parental impairment and parental autonomy as assessed by the caregiver.

Findings from this elaboration suggest that parental impairment has a definite role in modifying the original association. In situations of low impaiment the relationship between parental autonomy and parent's life changes becomes greater at a value of gamma -.44828, a moderate negative association in the expected direction. The small numbers included in this table indicate caution in this interpretation. In parents with high impairment 
the relationship between the original variable becomes less and also reverses, with a gamma value of .25000. That is, when high impairment is held constant, there is a low positive association between parental autonomy and parent's life changes, with the levels of each varying together. This second finding is opposite to the direction hypothesized.

A possible explanation for the second finding lies in the strength of the association between parental autonomy and parental impairment, not previously reported. This analysis indicates a substantial negative association at a value of gamma-.60265. That is, parents with high impairment are assessed as having low levels of autonomy to a substantial degree. The likelihood of this association was implicit in the selection of parental impairment as a control variable in two of the hypotheses. In that the zero-order association between parental autonomy and major life changes of the parent is negligible, and in that the association between parental autonomy and parental impairment is substantial, the introduction of parental impairment as the test variable must have some influence.

The influence of parental impairment in specifying the level of association between the zero-order variables parental autonomy and major life changes, may have to do with the inclusion of "increased dependency" and "major 
illness" as items in the index of major life changes (see Table $V$ ). While these items are not measures of impairment, an association between them is likely. Additionally, both of these items were highly reported for the parents, as previously discussed (increased dependency: 778 ; major illness: 468 ).

In summary, evaluation of the zero-order component of the fifth hypothesis does not support the hypothesized relationship between high levels of major life changes for the parent and low levels of parental autonomy. When the test variable, parental impairment, is introduced and held constant, it specifies conditions for the original relationship, and provides some support for the hypothesis.

In situations of low impairment the association is moderate (gamma -..44828) and supports the inverse relationship between high levels of major life changes and low levels of parental autonomy, as hypothesized.

In situations of high impairment the association is low and positive (gamma .25000); that is, levels of major life change and parental autonomy vary together, a finding which does not support the hypothesis.

For reasons stated, this analysis does not attempt to provide adequate evaluation of the position espoused by Ruypers and Bengtson (1973). However, it does suggest that a single model for understanding the effects of social 
reorganization on older persons in the presence of negative labeling is problematic, given the wide variation in personal attributes of older people, and given the long time period supposedly encompassed in the "old age" stage of the life course. 
OBSERVATIONS ON THE PROBLEMATIC NATURE

OF PARENT CARE

The observations to follow as shown in Table XXI, clarify the nature of parent care provided by this sample of caregivers. The content of many of the caregiver reports is considered additional evidence to support the "social problem" designation for the care of elderly parents, as proposed. No attempt was made to emphasize the collection of potentially problematic information.

\section{Duration of parent Care}

The length of care reported for a parent by the caregiver ranged from less than 4 months for a mother-inlaw to 25 years of care for a mother. For all parents, the mean length of care was 5 years; however mothers and mothers-in-law received care for longer periods than did fathers and fathers-in-law, probably reflecting the greater incidence of widowhood in women, and gender differences in longevity.

Specifically, for the 39 mothers, the mean length of care was 6.6 years, with a standard deviation of 5.6 , indicating dispersion in the length of care. For the 12 fathers the mean length of care was 3.6 years, with a standard deviation of 2.7. For the 8 mothers-in-law the mean length of care was 6.9 years, with a standard deviation of 5.8. Of the two fathers-in-law, 1 received care for 1 year and the second for 5 years. 
Some differences were observed in the duration of care provided by the two birth cohorts of caregivers. For both mothers and fathers, the younger birth cohort (19341953) appeared to provide care of shorter duration ( 5 years or less), while the older birth cohort (1914-1933) appeared to provide care of much longer duration (11 years and over). This finding is consistent with the age linkages of the daughters and their parents. Given a positive relationship between age and impairment, younger subjects in general, would have less need to provide services to a younger parent group, and older subjects would have a greater need to provide care over longer periods of time to an older and less active parent group. (with reference to the 39 mothers, the correlation coefficient gamma: -.36134, summarizes this finding).

As suggested by Taeuber (1983), this finding emphasizes the fact that the burden of parent care may fall on the older caregiver, a person who may herself be less able to provide care. Despite this difference, the duration of care provided by the subjects implies a major caregiving responsibility, particularly in association with the high levels of parental impairment also identified. Typically, subjects volunteered the notion that they had entered the caregiving experience partly as a short term response to a crisis situation, and had no idea that the responsibility would continue for so long. 


\section{TABLE XXI}

\section{CHARACTERISTICS OF THE PARENT CARE} SITUATION IN NUMBER AND PERCENT

DURATION OF PARENT CARE

All parents, mean duration: 5 years

Mothers and mothers-in-1aw: 6.8 years

Fathers and fathers-in-law: 3.3 years

Older caregivers (ages 53-72): 11 years or more Younger caregivers (ages 33 - 52): 5 years or less

ASSISTANCE LEVEL TO PARENTS

High assistance

Low assistance

INFORMAL SUPPORT TO CAREGIVERS

$$
\text { None/minimal }
$$

Moderate/high

$\begin{array}{ll}548 & (n=27) \\ 468 & (n=23)\end{array}$

FORMAL SUPPORT TO CAREGIVERS

None/minimal

Moderate/high
$608 \quad(n=30)$

$408 \quad(n=20)$
$668 \quad(n=33)$

$348 \quad(n=17)$

FINANCIAL SUPPORT FROM SUBJECTS TO PARENTS

No direct support

Some direct support

DETERMINANTS OF PARENT CARE ROLE

No alternatives

Subject's resources

(physical and personal)

Extended assistance

Birth status (only or

eldest daughter/child)

SOURCES OF PRESSURE ON SUBJECT TO PROVIDE PARENT CARE

\author{
From themselves \\ From parent(s) \\ From family \\ From the formal system \\ From all other sources
}

$\begin{array}{ll}548 & (n=27) \\ 468 & (n=23)\end{array}$

$308 \quad(n=15)$

$268 \quad(n=13)$

$208 \quad(n=10)$

$228 \quad(n=11)$ 
CHARACTERISTICS OF THE CARE SITUATION (continued)

INFLUENCE OF CAREGIVING ON SPOUSE OR SIGNIFICANT OTHER

Negative effects

Relationship/marital problems

Lifestyle limitations of couple

Discomfort with parent care

Positive effects

(Support, assistance, sharing)
$568 \quad(n=28)$

$168 \quad(n=8)$

$308 \quad(n=15)$

$108 \quad(n=5)$

$368 \quad(n=18)$

INFLUENCE OF CAREGIVING ON SUBJECT'S EMPLOYMENT

Negative

General employment problems

Forced to take early retirement

Forced to quit/change employment

Positive responses

Fully positive

Neutral
$80 \% \quad(n=36)$

$408 \quad(n=18)$

$228 \quad(n=10)$

$188 \quad(n=8)$

$208 \quad(n=9)$

$98 \quad(n=4)$

$118 \quad(n=5)$

INFLUENCE OF CAREGIVING ON SUBJECT

Negative

Negative personal time

Negative goals/lifestyle/health
1008

688

328 $(n=50)$

$(n=34)$

$(n=16)$

Positive

$0 \%$

(No positive category emerged from the post-coding of the open-ended question).

INFLUENCE OF CAREGIVING ON SUBJECT'S CHILDREN

Positive

Negative

Neutral

368

328

118

$(n=18)$

$(n=16)$

$(n=5)$ 


\section{Caregiver Assistance to the parent or Parents}

Information about the type and amount of care given to their parents was requested of the sample (see interview schedule, question 16). To facilitate this data collection, 10 task categories were pre-determined, leaving opportunity for additional subject supplied items. Table XXII following, identifies the task categories and the amount of subject assistance, from low (less frequent) to high (more frequent) levels. Two subject supplied, post-coded items included "management of care services" and "entertainment," both of which might have received greater ratings if they had been included initially. One item, "home and yard maintenance," was deemed not applicable by 508 of the sample.

These data indicate that a relatively large amount of caregiver assistance is given to a parent, and that much assistance is of a regular and time consuming nature. In that most of the subjects considered themselves to be the primary persons helping their parents, and in that caregiver support systems were often ill-defined, the burden of this responsibility is very real. 
TABLE XXII

TYPE AND FREQUENCY OF SUBJECT ASSISTANCE

TO PARENTS IN NUMBER AND PERCENT

Task

1. Counseling/discussion

2. Supervision

3. Meal Preparation

4. Housework and Laundry

5. Personal Care

6. Shopping and Errands

7. Home Health Care

8. Transportation

9. Case Management

10. Financial Management

11. Entertainment

12. Home/Yard Maintenance
Level of Assistance Low $\mathrm{High}$

6

128

8

168

12

248

15

308

16

328

18
36

20

408

11

228

28

568

4

88

14

288
Number Reporting
45

908

44

$88 \%$

42

848

38

768

35

708

34

688

32

648

30

608

28

568

22

448

13

268

50

50

50

50

50

50

50

50

39

50

17

11

228 
Analysis of caregiver assistance by birth cohort did not demonstrate significant cohort differences. In general, both groups of subjects appeared to provide higher levels rather than lower levels of assistance, with the younger subjects providing slightly greater levels of care for the mothers. This difference may reflect the interview impression that larger number of mothers than other parents were victims of Alzheimer's disease and/or similar conditions, and were cared for by younger subjects.

\section{Support to the caregiver for parent care}

Data were collected regarding formal and informal support received by the caregivers to assist them with parent care (see interview schedule, questions 18 and 19). In each of these two major categories, subjects were asked to estimate the level of financial, physical and/or emotional support they received.

Regarding informal support, 548 of the subjects $(n=27)$ reported little or no support of any type, and 468 $(n=23)$ reported moderate to high informal support. Most subjects received some level of emotional support (928 or $\mathrm{n}=46$ ) and physical support ( 888 or $\mathrm{n}=44)$, predominantly from family members and from some friends, however, few received financial support ( 148 or $n=7)$. Only one subject reported no support in any of the three dimensions. 
Disappointment in the level of support received, especially from family members such as siblings was expressed by many subjects. It is possible that different perceptions of the primary caregiver role is held by the caregiver and by the family, and is a factor in the level of support received, although this was not examined.

Formal support was received less frequently by the sample. Overall, $66 \%$ of the subjects $(n=33)$ reported little or no support from organizations or agencies, and $348(n=17)$ reported moderate to high support. Physical support such as regular bathing assistance from a personal care aide, meals on wheels, etc., was most reported (648 or $n=32$ ), followed by emotional support (50z or $n=25$ ), and lastly by financial support ( 248 or $n=12$ ).

of importance is the episodic and time limited nature of much formal support due to an association with the parent's financial status and to frequent coverage limitations for long term or maintenance care needs. This suggests that reliance by the caregiver for assistance from the formal system is problematic.

The two birth cohorts appear to differ in their reporting of both informal and formal support. Younger cohorts reported receiving greater informal support (548 or $n=14)$ than older cohorts ( 378 or $n=9)$; they also reported receiving greater formal support $(398$ or $n=10$ versus 298 or $n=7$ for the older subjects). Possibly 
younger caregivers seek out or have access to systems of support to a greater extent than do older caregivers. For most of the caregivers, the perception of support from whatever source appeared important in encouraging them to continue with their responsibilities.

\section{Financial Assistance to Parent(s)}

Subjects were asked to indicate whether they provided any financial assistance to their parent or parents, and whether or not they perceived this to be a burden (see interview schedule, question 54). Responses indicated that 468 of the subjects $(n=23)$ provided some direct financial assistance to 25 parents. For most subjects, the financial assistance given was not a problem, and only 3 subjects considered it to be a burden, and even then not severe.

Although legally not responsible for a parent's financial needs, many subjects expressed concern over potential future expenditures were it to become necessary for their parent(s) to enter a more intensive level of care. For some subjects, their decision to provide in-home care, particularly for more impaired parents, was in recognition of their inability to assist with the much greater financial costs associated with formal care.

Given the relatively high socio-economic status reported for the sample, it is interesting to speculate whether financial support to a parent is considered a 
greater problem by other caregivers, particularly in view of the generally lower income levels of the older population, as exists even in this group of parents.

\section{Determinants of the Caregiver Role}

Analysis of the subjects' impressions of how they became caregivers to their elderly parents, was made possible from content analysis and post-coding of an openended question (see interview schedule, question 13 and "Coding for Open-ended Questions" in the Appendix).

In this analysis, the concept of caregiver "career" emerged. That is, certain attributes of the caregiver gained over time appeared to determine the caregiver role. This role was activated frequently with the development of a crisis situation or the realization that the parent could no longer manage alone, and was coupled with the subject's perception of a lack of alternative care for the parent or parents. To some extent the subjects appeared designated to occupy a parent care role by virtue of their particular biography and personal history, and interestingly, some subjects expressed prior recognition of this responsibility.

In further analysis, the initial determinants of the caregiver role were recoded, leaving four major items: 1. No alternatives (the parent unable to live alone and/or unaided and no other family members available to assist). 
2. Subject resources (physical/external resources such as time, facilities and finances, and personal/internal resources such as traits, beliefs, skills and experience). 3. Extended assistance (extension of existing or prior living arrangements and/or assistance patterns together with personal ties to the parent).

4. Birth status (the status of being an only child, or the eldest daughter or child, and imputing special responsibility to this status).

In this analysis, item I "no alternatives" accounted for 308 of caregiver responses $(n=15)$, item 2 "subject resources" accounted for 268 of responses $(n=13)$, item 3 "extended assistance" accounted for 208 of responses $(n=10)$, and item 4 "birth status" accounted for 228 of the responses $(n=11)$.

As presented in Table XXIII, some differences in the subjects' career towards caregiving were observed between the two birth cohorts. The greatest reported difference was in birth status: being an only or elder child or daughter was reported by 8 subjects of the older cohort (338) versus 3 subjects of the younger cohort (128). Conversely, greater numbers of the younger cohort reported that they had no alternatives, or that available resources influenced their career as a caregiver. These findings are of interest, and may represent attitude changes or resource differences between the two birth cohorts. The 
overall association between the determinants of parent care and birth cohort is relatively weak, as summarized by the uncertainty coefficient at a value of .02703 or approximately 38 .

\section{TABLE XXIII}

DETERMINANTS OF CAREGIVER ROLE BY BIRTH COHORT OF SUBJECT IN NUMBER AND PERCENT

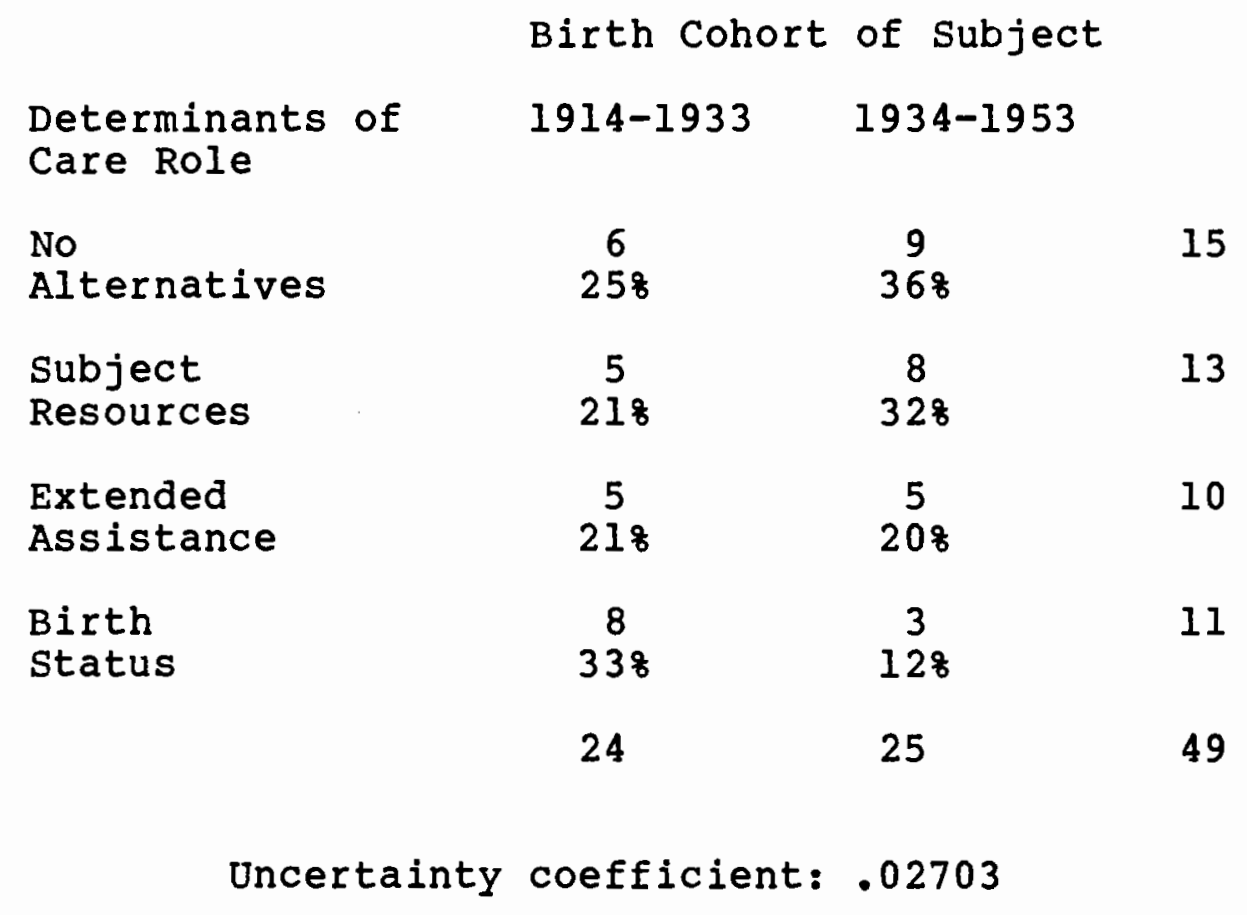

Given the problematic nature of the caregiver role, further exploration of the concept of caregiver "career" and of those factors which could identify persons more likely to become involved in family caregiving could be useful, and could provide recognition and support to some caregivers for their potentially unequal responsibility. 
Pressure Felt by subject to provide parent Care

Subjects were asked to indicate whether or not they experienced pressure from themselves or others to provide parent care (see interview schedule, question 27). "Others" included parent(s), family members, friends or neighbors, religious group members, health or community workers or any other source.

The greatest amount of pressure was reported by the subjects to come from themselves ( 888 or $n=44)$, followed by pressure from the parent or parents (648 or $n=32$ ) and from the family (36z or $n=18)$. The formal system, as a source of pressure was reported by only 88 or 4 subjects. Pressure from all other sources accounted for 308 of reports $(n=15)$, and an absence of pressure from any source was reported by 68 or 3 subjects. Despite 8 identified sources of pressure, few subjects reported more than 3 sources.

To summarize, a total of 868 of the sample $(n=43)$ reported few sources of pressure ( $0-3$ sources), and only 148 or 7 subjects reported multiple sources of pressure (4-8 sources). This finding does not indicate, however, the extent of pressure felt by a subject.

of interest regarding pressure toward parent care is the extent of personal pressure generated by the subjects themselves $(n=44$ or 888$)$, and the lack of pressure reported from formal care sources. A possible explanation 
lies in the socialization of the individual, and in the internalization of values, attitudes, and roles associated with the social structure encountered by the individual (Berger and Luckmann, 1966:131).

In that many of the subjects (568) identified socialization as a contributor to their preparation for the care role, it is possible that the present finding of personal pressure is a reflection of internalized values relating to the family and elder care ethic. External pressure for parent care is not needed by the subject, since internal pressure is an adequate source.

The finding of parental pressure (648 or $n=32)$ may also reflect the parent's socialization experience, with internalization by the parent of role appropriate responsibilities of offspring, to include an expectation of filial care from the subject.

Cohort differences in the perception of pressure were small, with a low negative association between birth cohort and pressure felt by the subject (gamma: -.21053), suggesting that younger caregivers may experience or may report less pressure than older caregivers.

Influence of caregiving on Spouse or Significant other Subjects' perceptions were requested regarding the influence of parent care on the relationship with their spouse or significant other (see interview schedule, 
question 20). After content analysis, responses were coded into "positive" and "less positive" categories.

of importance is the finding that $56 \%$ of the sample $(n=28)$ reported the parent care episode to have a less than positive effect on their primary relationship. A positive effect was reported by $36 \%$ of the sample ( $n=18)$, while $88 \quad(n=4)$ considered the question not applicable (either being single or reporting no significant other).

of the subjects reporting less than positive effects from caregiving ( 568 or $n=28), 8$ subjects $(168)$ reported serious relationship or marital problems, and 5 subjects (108) reported that husbands or others had difficulty in tolerating the situation. Changes and limitations imposed on their lifestyle by parent care were reported by a further 9 subjects (18\%). Some unmarried subjects reported real difficulties with developing and maintaining a social life during the episode of parent care ( $n=6$ or 128$)$. Conflict between the spouse and the parent, and competition for the caregiver's attention was reported by a number of subjects.

of the subjects reporting positive effects of parent care ( 368 or $n=18)$, the strengthening of relationships with husbands or significant others was mentioned as a primary outcome. Support and assistance received from partners was reported frequently and appeared to be highly valued. This support was identified by some subjects as a 
factor in the initial decision to become involved in parent care. Support also appeared to make a difference in the perception of stress by the subject although specific data were not collected. Sharing of tasks and responsibilities, maintaining communication and having a similar or shared view of family commitments toward parent care were mentioned as contributing to this positive outcome.

Birth cohort of the caregiver appeared to make a difference in the perceived influence of caregiving on spousal or other primary relationships. For instance, members of the older cohort who responded to this question were generally less positive $(708$ or $n=14)$ than positive (308 or $n=6$ ) regarding the influence of caregiving. Possibly the greater length of care provided by older caregivers, as previously mentioned, may have influenced spousal or other relationships more negatively.

The younger cohort of caregivers reported a more even positive/less positive response on the influence of parent care on primary relationships (less positive: 548 or $n=14$ versus positive: 468 or $n=12$ ). Although not reported in tabular form, the statistic gamma -.33333 suggests a moderate negative association between birth cohort and the influence of parent care on primary relationships.

For both cohorts of caregivers, even those with supportive partners and a positive orientation, the 
problem of maintaining their own relationships in the presence of caregiving responsibilities was very real.

\section{Influence of Caregiving on Subject's Employment}

subjects were asked to comment on whether and how parent care responsibilities affected their paid employment (see interview schedule, question 20 ). The subjective responses were post-coded into a number of categories and subsequently recoded into 2 groups "positive" and "negative."

As displayed in Table XXIV, over three-quarters of the subjects reported parent care to be a negative influence on their past, present or future employment prospects $(80 \%$ or $n=36)$, an important finding, leaving only 9 subjects (208) reporting a positive influence. (The remaining 5 subjects [108] considered themselves "not employed" during the period of parent care).

of interest is a breakdown of the positive and negative responses given by the subjects:

\section{Positive Responses}

1. Fully positive; parent care experience helpful in the employment situation:

$$
98 \quad(n=4)
$$

2. Neutral; some ambivalence regarding caregiving and employment:

$$
118(n=5)
$$

\section{Negative Responses}

1. General employment problems, past and present, and also affecting potential employment status: 
2. Was forced to take early retirement

$228 \quad(n=10)$

3. Was forced to quit or change employment $18 \% \quad(n=8)$

\section{TABLE XXIV}

INFLUENCE OF CAREGIVING ON SUBJECT'S EMPLOYMENT BY BIRTH COHORT OF SUBJECT

IN NUMBER AND PERCENT

Type of

Influence

Positive

Negative

Birth Cohort of Subject

1914-1933 1934-1953

3
158

17

858
6

248

19

768

25
9

36

45

Gamma: -.28302

(Note: Table is based on reports from 45 subjects, including some not currently employed

at the time of interview).

Some of the positive influences of caregiving on the subject's employment included application of the experience to the health care and education fields. Employment was found to be a effective break from the frustrations of caregiving for some subjects.

Some reports of the generally negative effect of parent care included: the need to adjust working hours or to take leave from work in order to accommodate parent needs; the need to seek employment compatible with parent care responsibilities; preoccupation with parent concerns, 
influencing the quality of work performed; reduced ability to accept extra responsibilities or overtime work; feelings of low reliability, with parent needs coming first; feelings of guilt for not doing justice to either the employer or the parent; a need to have special considerations from both employers and colleagues, and personal medical problems related to stress.

In the analysis of employment concerns by birth cohort, the greater number of "not currently employed" subjects reduced the size of the older compared with the younger cohort $(n=20$ versus $n=25)$. Even so, most not employed subjects (13 out of 17 ) responded to the question regarding influence of parent care on employment.

Cohort differences were not great; both cohorts of caregivers reported greater negative than positive influences on employment, with the older cohort being somewhat more negative, possibly as a consequence of employment frustrations over a longer time span. It is probable that subjects who elected to take early retirement had greater representation in the older cohort although this was not verified. A low negative association between influence of parent care on employment by birth cohort is summarized by the coefficient gamma: -.28302 .

It is clear from this analysis that the combination of parent care and employment interests are troublesome, at least to this sample of caregivers. 
Influence of Caregiving on the Subject

subjects were asked to comment on the influence of their parent care responsibilities on themselves, on their use of time and any other personal factors (see interview schedule, question 20). Responses were post-coded into different categories, all of which developed as negative entities, with a final coding of "negative - timen and "negative - goals, lifestyle and health." No dominantly positive category emerged from the coding.

Examination of responses, as noted in Table XXV, revealed that $68 \%$ of the sample $(n=34)$ found parent care to influence their use of time negatively, and a further $328(n=16)$ found the negative influence to be on lifestyle, personal and family goals and personal health.

Examples of negative influences from the subjects included: 448 of the sample $(n=22)$ reported a feeling of being confined, of being pulled between parent, family and personal needs and of needing to pre-plan most activities, with a resultant loss of spontaneity. Compromises in the quantity and quality of personal time were reported by a further $228(n=11)$. (Responses of 2 subjects were in combination or "other" categories). Lifestyle problems, difficulties in long term planning and goal achievement were reported by a further $148(n=7)$, and personal health problems associated with caregiving stress were reported by a final 168 or 8 subjects. 
TABLE XXV

INFLUENCE OF CAREGIVING ON THE SUBJECT

BY BIRTH COHORT IN

NUMBER AND PERCENT

Birth Cohort of Subject

Influence on

Subject

1914-1933 1934-1953

Negative

14

20

Personal Time

588

77 \%

Negative Goals

Lifestyle

Health

10

428

24
6

238

26
34

16

50

Gamma: $\quad-.40845$

Cohort differences in the influence of caregiving on the subject were observed, with the younger cohort reporting greater time difficulties (77\% or $n=20)$ when compared with the older cohort (588 or $n=14)$. Conversely, the older cohort reported a somewhat greater influence on the areas of lifestyle, goals and health (428 or $n=10$ versus 238 or $n=6$ ). Possibly the greater length of care provided by the older cohort had a more severe influence on the entire lifestyle of the older subjects; similarly more frequent reports of health problems could be a consequence of longer periods of stress. The correlation coefficient gamma -.40845 indicates a moderate association between the subject's birth cohort and influence of caregiving, particularly association of the younger cohort with greater time management difficulties. 
Influence of Caregiving on subject's children

Subjects with children were asked to comment on the influence of parent care on their children (see interview schedule, question 20). These responses were post-coded into "positive" and "less positive" (neutral or negative) categories. Some subjects commented on the changing nature of influences on their children. For example, short term influences induced by parent care were frequently negative and disruptive of "normal" life and activity in the nuclear family, whereas longer term influences on the children were more positive in terms of character building, understanding the realities of aging and/or impairment, understanding stresses associated with caregiving, helping with family problem solving, etc..

positive effects on children were reported by $36 \%$ of the sample $(n=18)$. Examples of positive effects were similar to the long term effects already mentioned. Also included were positive relationships with the grandparent(s), support of their mother's role as caregiver, and closer family ties due to the common concern.

Some subjects perceived the parent care episode to be almost entirely negative for their children, resulting in behavior problems, competition with the grandparent for parental attention, resentment, anger, a feeling of being "cheated" by the situation, and interaction difficulties between children, grandparents and parents. Subjects also 
reported fear, embarrassment and peer concerns particularly from teen-age children regarding their grandparent's appearance and/or behavior; this was associated particularly with less understandable conditions such as Alzheimer's disease. Negative effects on children were reported by 328 of the sample $(n=16)$.

Neutral effects on children were reported by $18 \%$ of the sample $(n=9)$. These children were reported to be less involved, were in less physical contact or had withdrawn somewhat from the care situation. Some adult children were mostly concerned for their mother's ability to withstand the stresses of parent care.

Further analysis, displayed in Table XXVI, showed a moderate, positive association between the influence of caregiving on the subject's children and the subject's birth cohort (gamma .56081). That is, knowing the birth cohort would help to reduce error in predicting the effects of caregiving on children by 56\%. For instance, subjects in the older cohort tended to classify the influence on children as more positive ( $n=12$ or 578) than less positive $(n=9$ or 438$)$, whereas, subjects in the younger cohort tended to classify the influence on children as less positive $(n=16$ or 738$)$ than more positive $(n=6$ or 278$)$. 
TABLE XXVI

INFLUENCE OF CAREGIVING ON SUBJECT'S CHILDREN

BY BIRTH COHORT OF SUBJECT

IN NUMBER AND PERCENT

Birth Cohort of Subject

Influence

1914-1933

1934-1953

on Children

Positive

12

57.18

6

27.38

Less Positive

$\begin{array}{ll}9 & 16 \\ 42.98 & 72.78\end{array}$

21

22

18

25

43

Gamma: .56098

(Table includes only subjects with children).

This finding may be explained somewhat by the short term versus long term influence already mentioned, and by the age of the children. Older subjects linked also to older children may see more of the long term effects of caregiving, (often more positive), whereas younger subjects with younger children may be in the midst of short term parent and child management problems often of a more negative nature.

In summary, it appears that many aspects of parent care are of a problematic nature, even for a sample of caregivers with a relatively positive set of socioeconomic characteristics. It appears that that many caregivers attempt to handle their unique set of problems 
with relatively little organized help, and without a clear appreciation that their problems are shared by others in similar situations.

If pressure exists to encourage the informal system to take even greater responsibility for elder care, then the availability of appropriate resources and greater access to support for the caregiver becomes important. 
CHAPTER VI

SUMMARY AND DISCUSSION

These concluding remarks address some of the concerns raised by each part of the theoretical framework of this study, comment on selected findings from the data analysis, and address some concerns for future research.

This research effort is an attempt to investigate the nature of certain aspects of a current social problem, that of old age in American society. Specifically, the study has focused on the provision of services to elderly parents by their adult daughters, the informal caregiving system of social support for the elderly.

The study involves an exploration of the topic using cross-sectional research methods. Data were collected by personal interviews, with a non-probability sample of fifty adult daughters on selected experiences of caregiving for elderly parents. Data were analyzed to gain overall impressions of parent care and the caregiving role guided by five specific research questions generated from review of the relevant literature.

The specific focus on care to elderly persons by family caregivers is a consequence of the perception that there is increasing pressure on the informal system, particularly the family, to provide such care. Some 
reasons for this perception have been identified including both demographic and economic factors. From a demographic viewpoint, the increase in absolute numbers of the older population, and the increase in the proportion of that population to the total population, are important. Equally important is the more rapid increase in the aged (75 - 84 years) and extreme aged (85 years and over) populations, which has implications for service needs given that advanced age is associated with greater impairment (Siegel and Davidson, 1984). Additionally, decreases in the fertility rate imply a deficit in the number of potential caregivers available to provide care for elderly parents or older family members. These factors have been described previously.

According to Blumer (1971), the objective nature of social phenomena does not necessarily ensure the definition of a social problem. Instead, Blumer argues, the construction and maintenance of a social problem is a function of collective definition (1971). Although in agreement with the process of collective definition, Ross and staines (1972:21) argue that social phenomena set constraints on what is perceived as a social problem. The point is that demographic conditions, as indicated above, are not necessarily sufficient for the identification of informal caregiving for elderly persons as a social problem. However such conditions do provide a basis for 
the occurrence of a subsequent collective definition of a social problem. As previously suggested, economic factors may be a part of this subsequent definition, and appear to be central to the increasing pressure on the informal care system.

Economic factors are operative at both the societal and the individual level. One concern, increasingly articulated, is the potential inundation of the formal care system by the vastly increased numbers of elderly persons in need. Consequently, there is an economic advantage in applying pressure on the informal system to provide elder care. Also, at a societal level, there is increased concern by employers of actual and potential economic drain, as employee-caregivers attempt to juggle both employment and parent or elder care responsibilities. At an individual level, both for the caregiver and the parent, knowledge of the high cost of formal care exerts pressure to provide home care where posible, despite difficulties. Noteworthy also is the fact that home care is often provided at a hidden cost, the cost of limiting the caregiver to employment or non-employment which is compatible with the responsibilities of elder care. Findings from this study support some of these concerns. Interestingly, when asked to identify sources of pressure toward providing parent care, a clear majority (888) of caregivers identified themselves as the primary 
source, and few identified societal sources of pressure. As suggested in previous chapters, internalization of values and roles of the social structure within which the caregiver is located and which occurs as a process of primary and secondary socialization may be an adequate source of pressure and may account for this finding (Berger and Luckmann, 1967:131).

The foregoing discussion suggests that elder care in the informal system has emerged as a legitimate "social problem" through a process of collective definition, particularly in that elder care is a recognized concern of legislators, bureaucrats, "experts" and employers, and in that parent care is becoming a personal problem faced by larger numbers of people, such as the "baby boom" generation.

A number of the study findings, outlined in the previous chapter, describe the difficulties of parent care for both the caregiver and the care recipient, elaborating the general perception of elder caregiving as a social problem.

Typically, the caregiving experience was found to be of approximately five years duration, with high levels of assistance provided to the parent or parents, and with the burden of care being somewhat greater for the older cohort of caregivers. The episodic and infrequent support reported from the formal care system appears to be a 
consequence of the chronic rather than acute character of impairment typically reported for the parents, in that chronic or long term care is less well funded. The negative influences of caregiving on marital and family well-being, on the subjects' employment interests and on other aspects of the subjects' personal lives are additional examples of difficulties identified which contribute to the "social problem" designation.

A second central concern in this study is with the received and constructed "reality" of old age. Specifically, evidence to support a largely negative social construction of old age and aging persons abounds in the Iiterature (Achenbaum, 1978; Fischer, 1978; Estes, 1979; Levin and Levin, 1980, Russell, 1981). Day-to-day life also provides empirical evidence of the difficulties of old age and older people; however such evidence is balanced by positive information of competent and vigorous older persons. The central question has to do with the objectified nature of images of old age and older persons received and internalized by the caregiver, and with how these images are expressed in interaction with the parent. Following from this, as a consequence of face-to-face interaction with an elderly parent, and as a consequence of the caregiving situation, is the continued construction and/or modification of the caregiver's image of old age. According to Berger and Luckmann (1967), all forms of 
knowledge are socially constructed, and result from the ongoing and reciprocal interaction of the individual with the social environment. Hence, past human activity produces a form of knowledge, which becomes habitual and is objectified as "reality." This "reality" faces the individual in primary and secondary socialization, and becomes internalized in the consciousness. Continued human activity, such as personal and environmental interaction and secondary socialization, maintains or modifies the internalized form of knowledge or understanding of "reality."

Thus, a negative understanding of old age or older people may develop in society and become objectified. This understanding may be internalized by caregivers and elderly parents alike in the process of socialization over time and may be maintained if ongoing knowledge is congruent with internalized knowledge. That is, a negative understanding may be maintained if the reality of day-today feedback from interaction with, or care for the elderly parent is negative. If ongoing knowledge from the social environment differs from prior knowledge, and if this new form of knowledge becomes habituated, then a change in the prior internalized understanding may result. Thus secondary socialization experiences such as education and positive experiences with older persons or with parent care may modify prior understandings of reality. 
This discussion is not to suggest that individuals necessarily internalize a negative construction of old age and older people, either in primary or secondary socialization, in that the social structure, the definitions of significant others within the structure, and the influence of institutional understandings are unique for each individual (Berger and Luckmann, 1967). The results of these individual biographic experiences may indeed serve to alter the generally negative image of old age toward a neutral or even positive view.

In terms of research focus, it is suggested that characteristics of the parent and of the caregiving situation may modify the construction of old age held by the caregiver. Aspects of this and subsequent relationships are illustrated in the conceptual model employed (see figure 2).

In concert with Berger and Luckmann's thesis of the social construction of reality (1967) is the notion that understandings held by the caregiver may find expression during interaction with the elderly parent and may thus affect the parent. Therefore, it is suggested that the variable parental autonomy (as assessed by the caregiver) is influenced by the positive-negative quality of the caregiver's construction of old age.

Another notion relates to Berger and Luckmann's discussion of the maintenance of institutional 
understandings through the transfer of knowledge across generations during primary and secondary socialization (1967:71). In the context of this inquiry the question may be posed: "Is responsibility for parent care an ethic which is transferred across time?"

Three hypotheses relating to the caregiver's construction of old age were proposed. Findings from the evaluation of these hypotheses are briefly reviewed, followed by a discussion of the last two hypotheses and some suggestions for future inquiry.

It appears that the variable "construction of old age held by the caregiver" involves at least two different dimensions which includes a focus on old age as a period in the life course and a focus on older persons themselves. Two measures were used to gain an appreciation of these dimensions. Findings from these measures suggest that this particular sample of caregivers has a less negative construction of old age and of older persons than would be expected given a review of the current literature. In particular, a more negative image of old age and a less negative image of older persons was identified. Primary and secondary socialization involving educational, occupational and family life experiences specific to the sample provides a rationale for this finding. That is, subjects tended to be highly educated with 548 being college graduates, and with 328 reporting 
work experience with older clients or in health related fields. In future research, elaboration of the dimensions of the construction of old age, and improved measurement accounting for these dimensions, is indicated.

Although not substantiated in the literature review, it is possible that a less negative societal view of old age and older persons is developing, and is also partly responsible for this more neutral study finding.

The first hypothesis, that a negative construction of old age held by the caregiver is associated with low levels of assessed parental autonomy is not well supported when the measure used is the "image of older persons." When the measure used is the "image of old age" this hypothesis is substantially supported. The finding that perceived parental autonomy may indeed be linked to a caregiver's perception of old age indicates a need for further investigation. If this were to occur, a different determination of parental autonomy is advised, possibly using a similar measure with the parent directly rather than relying on the caregiver's assessment. Reports from the Retirement Research Foundation on the outcome of their research into autonomy could be helpful in this regard (Collopy, 1986).

The second hypothesis, that advanced age and high levels of parental impairment are associated with a negative construction of old age held by the caregiver, is 
supported at a relatively low level. The variable "parental impairment" appears to have somewhat greater value in explaining the caregiver's construction of old age; however, it does not explain the caregiver's construction of older persons. The second parent variable "age group," provides even less explanation for the caregiver's construction of old age and of older persons. Thus, in this sample, the relationship of personal attributes of the care recipient to the perpetuation or continued construction of a negative view of old age is not well supported. This low level of support is surprising in view of evidence in the literature suggesting that characteristics of impaired or stigmatized individuals aid in the perpetuation of a negative construction of reality, and in view of the high level of impairment and advanced age of these care recipients. Possibly attributes of the caregiver sample, such as higher than expected educational levels, provides some explanation for this finding.

In that understanding of the mechanisms by which images are perpetuated in society is desirable, future investigation of this topic is indicated, possibly with improved measures and with a random sample.

The next hypothesis to be reviewed (hypothesis 4), that there is no significant difference in the central ethic of responsibility for parent care as held by two 
different birth cohorts of caregivers is well supported. Two measures of responsibility toward parent care were employed, each of which supports the hypothesis. Differences between birth cohorts of caregivers appeared slight regarding the overall ethic of responsibility; however, differences in the source of the ethic were greater, with younger caregivers reporting more primary socialization and older caregivers reporting more secondary socialization experiences. Support for this fourth hypothesis suggests that socialization is a vehicle for the transmission of knowledge from one generation to another, as suggested by Berger and Luckmann (1967), despite modification in how this occurs. This also supports the assertions of other authors that commitment to parent care continues across generations (Brody, 1981; Stoller, 1983; Treas, 1983 and Brody et al., 1984).

Despite this finding, stability of the ethic of parent care over time would be better measured by a longitudinal study. Measurement over time would have an additional advantage of reconciling subject responses with future parent care involvement, which is not easily determined in cross-sectional research. A longitudinal study could also measure the influence of social change on parent care, including such matters as labor force participation of women and gender role changes, particularly in that the literature reviewed appears unclear regarding the 
influence of these variables.

The third and last part of the theoretical framework, a model of normal aging, requires consideration. A primary reason for the introduction of this framework is the emphasis of this model on the consequences of images held by the social system for the aged individual.

The authors Kuypers and Bengtson (1973) support the notion of a pervasive, negative social construction of old age and older persons. While this negative view is not necessarily problematic for all older persons, they argue that the older population is likely to be susceptible to the consequences of such labeling, as a result of losses in social position typically facing this group.

of particular interest is their suggestion that losses or change in social roles and the socially assigned values for those roles contribute to a "feedback vacuum" in which there is greater vulnerability of the older person to negative labeling. Typically, an older person may face the loss of a productive identity, loss of a spouse or siblings, loss of close friends and associates, loss of social contact secondary to impairment and loss of vigor and independence. Ruypers and Bengtson (1973:187) further suggest that the vulnerable older person enters a syndrome of "social breakdown" in which negative societal labeling becomes internalized, which compromises the person's self-identity and sense of competence. In effect, 
the older person comes to act in accordance with the negative label and in so doing, reinforces its accuracy, which perpetuates the negative image of the older person in society.

The choice of parental autonomy as the primary dependent variable in this study is in part a response to the reported consequences of negative labeling for the aged individual. The perception that older persons are indeed subjected to negative social labeling, and that this has consequences in terms of self-esteem, selfdetermination and a sense of competence, is endorsed by other authors (Estes, 1979; Wolinsky, 1980; Russell, 1981; Langer, 1983).

Evaluation of hypothesis five suggests that a high index of major life changes in the parent is associated with low levels of parental autonomy as assessed by the caregiver, when impairment is held constant. The variable "major life changes" identified in this hypothesis represents an attempt to quantify social losses experienced by the individual parent, and hence to measure the vulnerability of the parent to negative societal labeling, as suggested by Kuypers and Bengtson (1973). The dependent variable of assessed parental autonomy is a measure of the outcome of this vulnerability.

Findings from the evaluation of this hypothesis do not support the hypothesized relationship between major 
life changes and perceived parental autonomy, unless the control variable of parental impairment is introduced. With the inclusion of parental impairment, there is partial support for the hypothesis. It is unclear whether Ruypers and Bengtson (1973) considered the relationship of impairment in their assertion of the association between vulnerability and decrements in personal functioning in older persons.

Future examination of this or a similar hypothesis should involve an improved measure of vulnerability in the older person, to include consideration of impairment. As previously stated, the evaluation of this hypothesis is not intended to be an adequate assessment of the position espoused by Kuypers and Bengtson (1973), but rather an exploration of possible relationships.

The last hypothesis to be reviewed (hypothesis three) is posed as an extension of the literature review on autonomy, and is related specifically to the phenomenon of learned helplessness or self-induced dependency, as described by Seligman (1975), Solomon (1982) and Langer (1983). With variation, these authors argue that elderly persons are particularly susceptible to losses in personal autonomy in that instrumental control of their day-to-day Iives is reduced. Langer (1983:219) additionally relates this susceptibility to increased life changes and strains typically facing the older person, also a support for 
Kuypers and Bengtson's model (1973).

The particular assertion on which hypothesis three is based is Langer's statement on the "effect of being helped" and her posited association of assistance with diminished performance in elderly persons (1983:209). Thus, it is hypothesized that the highest levels of caregiver assistance to the parent are associated with the lowest levels of parental autonomy as assessed by the caregiver, when impairment is held constant.

Evaluation of this hypothesis indicates substantial support for the primary inverse relationship between assistance and assessed parental autonomy. When parental impairment is entered into the analysis as a control, it appears to specify the initial relationship. That is, in parents with low impairment, there is an even stronger inverse relationship between assistance and parental autonomy. In parents with high impairment, the original inverse relationship is lessened, but remains at a moderate level, which still supports the hypothesis.

This finding is one of the most interesting outcomes of the study, and has implications for future research on two counts. First, assistance is a central aspect of caregiving both in formal and informal settings and warrants improved understanding from both caregiver and care recipient perspectives. Second, there is a delicate balance between adequate and inadequate assistance which 
is complicated by physical and cognitive impairment, and by differential perceptions of what constitutes adequate assistance. In considering assistance and autonomy, reduced service to an older person implies increased opportunity for self-determination; it does not necessarily imply simply the reduction of assistance which could cause underservice to individuals in real need.

An additional comment relates to the research design and the reality of assistance by the caregiver to more than one parent concurrently, as is documented in this study. To facilitate data collection and analysis, and to ensure greater accuracy of data pertaining to the parent in future research, improved management of this reality is recommended. A research design excluding caregivers providing care to more than one parent is a simpler, although not altogether preferable approach.

In conclusion, this study has explored a number of relationships specific to the parent care situation. The study differs from many reported in the literature in that there is concern with the outcomes of caregiving for the elderly parent as well as for the caregiver.

In preceding pages the works of a number of scholars have been reviewed, pointing to the process of the creation of a social problem, and to the growing recognition that the existence of and the care for an increasing older population is a serious social issue. 
From the data reported as a result of this investigation, it seems clear that this is not a short term issue. Quite the opposite appears true. The economic and interpersonal costs of informal caregiving for the older population can only increase in the future. Political exhortations to the effect that "the private sector must rally to pick up the slack in the provision of human services" or the recent statement that "Home care needs to be the primary care solution and nursing homes the alternative" (Grecny, 1987), simply overlook the very real demands on those in the private sector who are attempting to provide home care and deal with the "slack," ....primarily the adult daughter. 


\section{REF ERENCES}

Abercrombie, Nicholas, Stephen Hill and Bryan S. Turner,

1984 Dictionary of Sociology. Harmondsworth, England: Penguin

Achenbaum, W. Andrew

1978 old Age in the New Land: The American Experience Since 1790. Baltimore: Johns Hopkins University

Ambrogi, Donna Meyers

1987 "Conflicts (and Solutions) in Family Caregiving" The Aging Connection, Newspaper of the American Society on Aging. VIII (2):7

American Association of Retired Persons News Bulletin

1987 "More Firms Aid Workers Who Care for Older Relatives." $28(8): 1,13$. Washington D.C. : AARP

Annas, George J. and Leonard H. Glantz

1986 "The Right of Elderly Patients to Refuse LifeSustaining Treatment." The Milbank Quarterly, 64 (suppl. 2):95-149

Arluke, Arnold and Levin, Jack

1986 "'Second Childhood': Old Age in Popular Culture." Pp. 151-158 in Beth B. Hess and Elizabeth W. Markson, (eds.), Growing Old In America: New Perspectives on old Age. Third Edition. New Brunswick: Transaction

Babbie, Earl

1983 The Practice of Social Research Third Edition. Belmont, CA: Wadsworth

Bailey, Renneth $D$.

1987 Methods of Social Research

Third Edition. New York: Free Press

Bayless, Pamela J.

1985 Caring for Dependent Parents. Frank Gruber and Kelly Leister (eds.). New York: Research Institute of America

de Beauvoir, simone

1972 Old Age. Tr. Patrick O'Brian. Harmondsworth, England: Penguin 
Bengtson, Vern L.

1979 "Research Perspectives on Intergenerational

Interaction." in Pauline $\mathrm{K}$. Ragan, (ed.)

Aging Parents. Los Angeles: University of Southern California

Bengtson, Vern $L$, and Haber, David

1983 "Sociological Perspectives on Aging." Pp. 72-93

in Diana S. Woodruff and James E. Birren (eds.), Aging: Scientific Perspectives and Social Issues. Second Edition. Monterey, Ca: Brooks/Cole.

Berger, Peter and Thomas Luckmann

1967 The Social Construction of Reality.

New York: Anchor Books

Blumer, Herbert

1969 Symbolic Interactionism: Perspective and Method. Englewood Cliffs:Prentice-Hall.

1971 "Social Problems as Collective Behavior." Social Problems. 18(3):298-306

Brody, Elaine M.

1981 "Women in the Middle: Family Help to older People." The Gerontologist. 21:471-480

1985 "Parent Care as a Normative Family Stress." The Gerontologist. $25(1): 19-29$

Brody, Elaine M., Pauline T. Johnsen, Mark C. Fulcomer and Abigail M. Lang

1983 "Women's Changing Roles and Help to Elderly Parents: Attitudes of Three Generations of Women" Journal of Gerontology 38 (5):597-607

Brody, Elaine M., Pauline T. Johnsen and Mark C. Fulcomer

1984 "What Should Adult Children do for Elderly Parents?" Journal of Gerontology. 39:736-746

Brody, Elaine M. and Claire B. Schoonover

1986 "Patterns of Parent-Care When Adult Daughters Work and when They do Not." The Gerontologist. $26(4): 372-381$

Brozan, Nadine

1986 "Unequal burden of caring for aged emerges as new issue for women."

New York Times News Service, The Oregonian, November 22

Cain, Leonard D

1985 "Aging, Mirror of Humanity." Canadian Gerontological Collection IV, October, 77-10 
Cantor, Marjorie H.

1980 "The Informal Support System: Its Relevance in the Lives of the Elderly." Pp. 131-144 in Edgar F. Borgatta and Neil G. Mcclusky (eds.), Aging and Society. Beverly Hills: Sage

1983 "Strain Among Caregivers: A Study of Experience in the United States." The Gerontologist

$23(6): 597-604$

Cicirelli, victor G.

1983 "Adult Children's Attachment and Helping Behavior to Elderly Parents: a Path Model." Journal of Marriage and the Family. 45(4):851-858

Collopy, Bart J.

1986 The Conceptually Problematic Status of Autonomy. Unpublished Executive Summary of the Retirement Research Foundation, Park Ridge, Illinois

Comfort, Alexander

1976 A Good Age. New York: Crown

Connidis, Ingrid

1983 "Integrating Qualitative and Quantitative Methods in Survey Research on Aging: An Assessment." Qualitative Sociology, 6:334-352

Costner, Herbert L.

1965 "Criteria for Measures of Association." American Sociological Review, 30:341-353

Crossman, Linda

1987 "Adult Day Care: Coming of Age." The Aging Connection, Newspaper of The American Society on Aging. VIII (4):3

Deming, Mary B, and Neal E. Cutler

1983 "Demography of the Aged." Pp. 18-51 in Diana $S$. Woodruff and James E. Birren (eds.) Aging: Scientific Perspectives and Social Issues. Second Edition. Monterey, Ca: Brooks/Cole

Doty, Pamela

1986 "Family Care of the Elderly: The Role of Public Policy." The Milbank Quarterly. 64 (1):34-75

Estes, Carroll L.

1979 The Aging Enterprise.

San Francisco: Jossey-Bass 
Fahey, Charles $J$. and Martha Holstein

1987 "Ethics and the New World of Aging: Why Now?" The Aging Connection, Newspaper of the American society on Aging, VIII (2):5

Feller, Barbara A.

1983 "Americans Needing Help to Function at Home". Advance Data from Vital and Health Statistics. National Center for Health Statistics, No. 92 DHHS Pub. No. (PHS) 83-1250. Hyattsville: Public Health Service

Fischer, David Hackett

1978 "Putting Our Heads to the Problem of Old Age." Pp. 58-62 in Ronald Gross, Beatrice Gross, Sylvia Seidman (eds.). The New old. New York: Anchor/Doubleday

Fischer, Lucy Rose

1985 "Elderly Parents and the Caregiving Role: An Asymmetrical Transition." Pp. 105-114 in Warren A. Peterson and Jill Quadagno (eds.). Social Bonds in Later Life: Aging and Interdependence. Beverly Hilis: Sage

Fischer, Lucy Rose and Carol Hoffman

1984 "Who Cares for the Elderly: The Dilemma of Family Support." Research in Social Problems and Public Policy. 3:169-215

Freudenheim, Milt

1986 "Care of elderly new problem in work force." New York Times News Service, The Oregonian, July 2

Fuller, Richard C. and Richard R. Myers

1941 "The Natural History of a Social Problem." American Sociological Review. 6(3):307-29

Gadow, Sally

1980 "Medicine, Ethics and the Elderly." The Gerontologist. $20(6): 680-685$

Gelman, David and Mary Hager

1985 "Who's Taking Care of Our Parents?" Newsweek, May 6, 105(18):60-64

Glazer, Nona Y.

1988 "Overlooked, Overworked: Women's Unpaid and Paid Work in the Health Services 'Cost Crisis'." International Journal of Health Services, 18 (I), forthcoming 
Granger, Carl., G.L. Albrecht and B.B. Hamilton

1979 "Outcome of Comprehensive Medical

Rehabilitation: Measurement by PULSEs Profile

and the Barthel Index." Archives of Physical

Medicine and Rehabilitation, 60:145-154

Grecny, Jeff


The Oregonian, November 9

Harris, Louis and Associates

1975 The Myth and Reality of Aging in America. Wasington, D.C.: The National Council on the Aging

Hess, Beth B.

1985 "America's Elderly: A Demographic Overview." Pp. 3-2l in Beth $B$. Hess and Elizabeth W. Markson (eds.), Growing old in America: New Perspectives on old Age. Third Edition.

New Brunswick: Transaction

Higgins, Paul C.

1980 Outsiders in a Hearing World - A Sociology of Deafness. Beverly Hills: Sage

Huttman, Elizabeth D.

1985 Social Services for the Elderly. New York: Free Press

Jette, Alan M.

1985 "State of the Art in Functional Assessment." Pp. 137-168 in Jules M. Rothstein (ed.),

Measurement in Physical Therapy. Clinics in

Physical Therapy. New York: Churchill Livingstone

Jick, Todd D.

1979 "Mixing Qualitative and Quantitative Methods:

Triangulation in Action." Pp. 135-148 in

John Van Maanen (ed.), Qualitative Methodology

Beverly Hills: Sage

Kane, Rosalie A. and Rane, Robert L.

1981 Assessing the Elderly.

Lexington, MA: Lexington

Kuypers, Joseph A, and Vern L. Bengtson

1973 "Social Breakdown and Competence: A Model of

Normal Aging." Human Development. 16:181-201 
Lang, Abigail M. and Elaine M. Brody

1983 "Characteristics of Middle Aged Daughters and Help to their Elderly Mothers." Journal of Marriage and the Family. 45(1):193-202

Langer, Ellen $\mathrm{J}$.

1983 The Psychology of Control.

Beverly Hills: Sage

Lemert, Charles C.

1979 Sociology and the Twilight of Man. Carbondale: Southern Illinois University Press.

Levin, Jack and William C. Levin

1980 Ageism: Prejudice and Discrimination Against the Elderly. Belmont, CA: Wadsworth

Lopata, Helena $z$.

1984 "Social Construction of Social Problems Over Time." Social Problems. 31(3):249-272

Manis, Jêrome $G$.

1984 Serious Social Problems.

Boston: Allyn and Bacon

National Center for Health Services Research and Health

1986 Care Technology Assessment

"Who Takes Care of the Disabled Elderly?"

Research Activities, July, No. 87

Neugarten, Bernice L.

1982 "Older People: A Profile." Pg. 33-54 in Bernice L. Neugarten (ed.), Age or Need? Public Policies for Older People. Beverly Hills: Sage

Nie, Norman H., C. Hadlai Hull, Jean G. Jenkins, Rarin Steinbrenner and Dale $H$. Bent

1975 Statistical Package for the Social Sciences. 2nd. Ed., New York: McGraw Hill

O'Brien, John E. and Wagner, Donna L.

1980 "Help Seeking by the Frail Elderly: Problems in Network Analysis." The Gerontologist $20(1): 78-83$

Pine, Vanderlyn $R$.

1977 Introduction to Social statistics. Englewood Cliffs: Prentice Hall 
Phillips, Bernard

1985 Sociological Research Methods. Homewood, Ill: Dorsey

Phillipson, Chris

1982 Capitalism and the Construction of old Age. London: Macmillan

Pratt, Eenry J.

1976 The Gray Lobby. Chicago: University of Chicago Press

Reedy, Margaret Neiswender

1983 "Personality and Aging" Pp 119-123 in

Diana S. Woodruff and James E. Birren (eds.),

Aging: Scientific Perspectives and Social Issues. Second Edition. Monterey, Ca: Brooks/Cole.

Retirement Research Foundation, The

1986-7 Enhancing Personal Autonomy of Elderly

Individuals in Long Term Care, Phase II.

Request for Proposal: Retirement Research

Foundation

Retirement Life News

1987 "Caregiver Profile." 15 (10):6

Portland: Courier Communications

Ritzer, George

1981 Towards an Integrated Sociological Paradigm: The Search for an Exemplar and an Image of the Subject Matter. Boston: Allyn and Bacon

Ross, Robert and Graham L. Staines

1972 "The Politics of Analyzing Social Problems." Social Problems. 20(1):18-40

Russell, Cherry

1981 The Aging Experience.

Sydney, Australia: Allen and Unwin

Schwartz, Arthur N.

1979 "Psychological Dependency: An Emphasis in Later Years." Pp. 116-125 in Pauline R. Ragan, Aging Parents. Los Angeles: University of Southern California

Scott, Robert A.

1969 The Making of BIind Men.

New York: Russell Sage 
Seligman, Martin E.P.

1975 Helplessness: On Depression, Development and Death. San Francisco: Freeman

Siegel, Jacob S. and Davidson, Maria

1984 Demographic and Socioeconomic Aspects of Aging in the United States. Current Population Reports, Special Studies series P-23 (138), U.S. Bureau of the Census. Washington D.C. : U.S. Government Printing office

Shanas, Ethel and Sussman, Marvin B.

1981 "The Family in Later Life: Social structure and Social Policy." Pp. 211-231 in Robert $W$. Fogel, Elaine Hatfield, Sara B. Riesler and Ethel Shanas (eds.), Aging: Stability and Change in the Family. New York: Academic Press

Soldo, Beth J.

1985 "In-Home Services for the Dependent Elderly." Research on Aging 7:281-304

Solomon, Kenneth

1982 "Social Antecedents of Learned Helplessness in the Health Care Setting."

The Gerontologist, 22 (3):282-287

Stoller, Eleanor Palo

1983 "Parental Caregiving by Adult Children." Journal of Marriage and the Family. 45:851-858

1985 "Elder-Caregiver Relationships in Shared Households." Research on Aging. 7(2):175-193

Streib, Gordon F.

1983 "The Frail Elderly: Research Dilemmas and Research Opportunities."

The Gerontologist, 23 (1):40-44

Taeuber, Cynthia M.

1983 America in Transition; An Aging Society.

Current Population Reports, Special Studies

Series P-23 (128), U.S. Bureau of

the Census. Washington D.C. : U.S. Government

Printing office

Townsend, Aloen L. and S. Walter Poulshock

1986 "Intergenerational Perspectives on Impaired Elders' Support Networks."

Journal of Gerontology, 41 (1):101-109 
Treas, Judith

1977 "Family support Systems for the Aged: Some Social and Demographic Considerations." The Gerontologist. $17(6): 486-491$

1983 "Aging and the Family." Pp. 94-109 in Diana S. Woodruff and James E. Birren (eds.), Aging: Scientific Perspectives and Social Issues. Second Edition. Monterey, Ca: Brooks/Cole.

de Vaus, D. A.

1985 Surveys in Social Research

Studies in Society: 29

Sydney: Allen and Unwin

Weg, Ruth B.

1983 "Changing Physiology of Aging." Pp 242-284 in Diana S. Woodruff and James E. Birren (eds.), Aging: Scientific Perspectives and Social Issues. Second Edition. Monterey, Ca: Brooks/Cole.

Wiener, Carolyn

1981 The Politics of Alcoholism: Building an Arena Around a Social Problem. New Brunswick: Transaction Books

Wiseman, Jacqueline $P$.

1979 "Toward a Theory of Policy Intervention in Social Problems." Social Problems. 27(1):3-18

Wood, John

1987 "Labors of Love."

Modern Maturity. $30(4): 28-34,90,92-94$

Wolinsky, Frederick D.

1980 The Sociology of Health: Principles, Professions and Issues. Boston: Little Brown 
APPENDIX A

INTERVIEW SCHEDULE - CAREGIVER STUDY

Referral source

Interview \#

SECTION 1:

We will start the session by talking about old age, and the feelings that you may have about aging and older people.

(Note: coding for open-ended questions will be developed from data received; for questions that are not applicable [N/A] code as 9, otherwise follow schedule).

01. First, what is the meaning of "old age" for you today? Can you comment on this?

02. In this question, please tell me how you see most people over 65. (Show card with options; scale adapted from Harris, $1975: 47$ ).

$\begin{array}{cccc}\text { quite } & \text { some } & \text { hardly } \\ \text { very } & \text { a lot } & \text { what } & \text { at all } \\ 1 & 2 & 3 & 4\end{array}$

a. Friendly and warm

b. Wise from experience

c. Physically active

d. Good at getting

things done 
e. Bright and alert

f. Open-minded and adaptable

g. Sexually active

03. If I asked you the same questions on your view of people OVER 85 rather than 65, would your responses be the same or different? How?

04. Now please tell me how you think OTHER PEOPLE, about your own age see most people over 65. (Show card).

$\begin{array}{cccc}\text { quite } & \text { some } & \text { hardly } \\ \text { very } & \text { a lot } & \text { what } & \text { at all } \\ 1 & 2 & 3 & 4\end{array}$

a. Friendly and warm

b. Wise from experience

c. Physically active

d. Good at getting things done

e. Bright and alert

f. Open-minded and adaptable

g. Sexually active 
05. Has being a caregiver made a difference or not, in the way you see your own aging? Can you comment?

06. Which, if any of the following, have provided you with sources of information about aging and older people?

a. Talking or being with older $\begin{array}{cr}\text { yes } & \text { no } \\ 1 & 0\end{array}$ family members

b. Talking or being with older non-family persons

c. Caregiving experience with parent(s)

d. Talking or being with your own friends

e. Experience with your own aging

f. Television

g. Radio

h. Written materials - newspapers, magazines, books, etc.

i. Education - formal classes, community programs

j. Informal special interest groups, support groups

k. Formal organizations and agencies

1. Other - specify 
SECTION 2:

In this section I would like to get an idea of the caregiving situation with your elderly parent(s).

07. Who are you / were you assisting by caregiving?

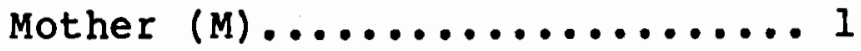

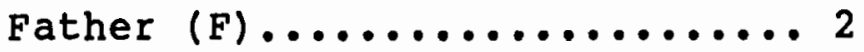

Both parents .............. 3

Mother-in-law $(M / L) \ldots \ldots \ldots \ldots$

Father-in-law $(F / L) \ldots \ldots \ldots \ldots$

Both parents-in-law..........6

Combination, specify..........

(Use codes $M, F, M / L, F / L$ to identify parent(s) hereafter).

08. When did you start to provide caregiving services* to your parent(s)? (*Includes any level of regular services).

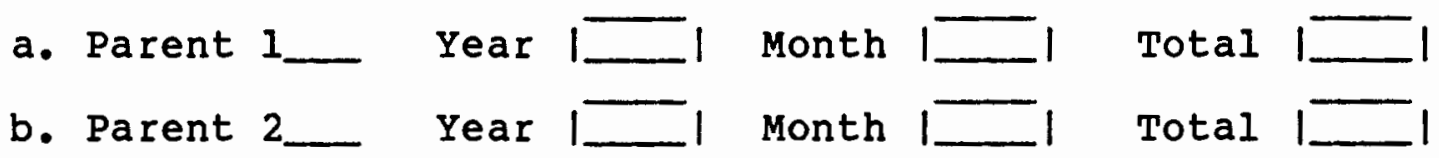

09. If not currently providing caregiving services to your parent(s), when did this stop?

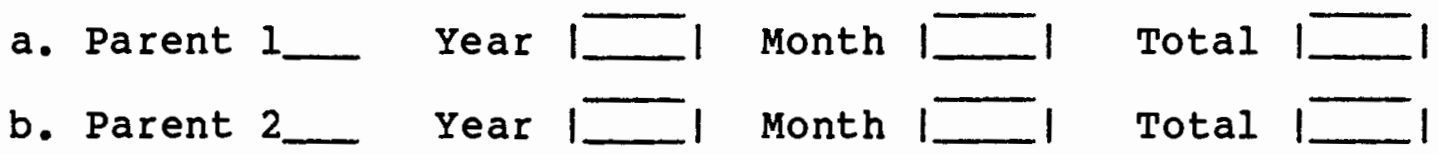


10. If not currently providing caregiving services, why did this stop?
a) parent 1
b) parent 2

11. For your parent(s), do you consider yourself to be: Parent 1 Parent 2 the primary caregiver $\ldots \ldots \ldots \ldots \ldots 1 \ldots \ldots \ldots \ldots \ldots 1$ a secondary caregiver $\ldots \ldots \ldots \ldots \ldots 2 \ldots \ldots \ldots \ldots \ldots 2$

12. If you are a SECONDARY caregiver, which person of the following do you consider to be the PRIMARY caregiver? Parent 1 Parent 2

Parent's spouse (your other

parent/stepparent).....................

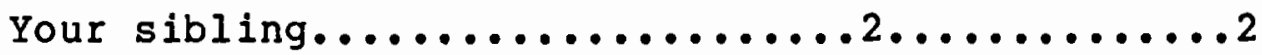

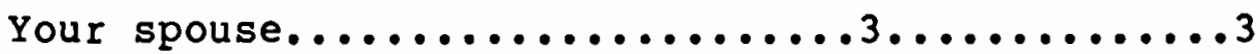

Another relative; specify................4

Friend or neighbor; specify.....5.........5

Paid caregiver; specify................6

Other person; specify..................7

Not sure/not applicable.......9.........9

13. How did you happen to become the/a caregiver for your parent (s)? 
14. Which of the following best describes your parent's living situation? (Show card with response options). Parent 1_ Parent 2

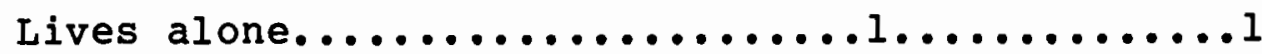

Lives alone, but in senior housing*..........................2

Lives with spouse.....................3

Lives with caregiver, married ...4........4

Lives with caregiver, unmarried...5........5

Lives with other relative(s) $\ldots \ldots 6 \ldots \ldots \ldots \ldots$

Lives with non-family person(s) ..7 .........7

other; describe.......................8

*e.g. retirement center, housing project for elderly. Comments :

15. Does your parent's living situation affect your ability to assist with care? If so, how?

16. In the last three month period, what type and frequency of caregiving services have you provided for your parent? (Show card with response options; insert code for parent). 
Caregiving tasks

never sometimes frequent often seldom monthly $\frac{1}{2} \quad \underset{3}{4} \quad \underset{4}{4}$

a. Shopping/Errands

b. Transportation

c. Financial management

d. Housework

e. Home/yard maintenance

f. Meal preparation

g. Personal care*

h. Home health care*

i. Supervision*

j. Confidant(e)/counselor

k. other

*Personal care = eating, dressing, bathing, etc. *Home health care = medications, treatments, etc. * Supervision = overview/direction for safety/accuracy. Parent 1_ I I Parent 2_ $\square$ Total $016 \square$

17. In the last year or so, has your overall assistance to your parent

Parent 1

Parent 2

Increased $1 \ldots \ldots \ldots \ldots . \ldots 1$ Remained the same.......................2 Decreased............................ 
18. How much support do you receive from family and friends in caregiving ?

$\begin{array}{cccc}\text { none } & \text { little } & \text { some alot } \\ 0 & 1 & 2 & 3\end{array}$

a. Financial.

b. Physical...

c. Emotional.

Total Q18

19. How much support do you receive from health and social agencies ?

$$
\begin{array}{cccc}
\text { none } & \text { little some } & \text { alot } \\
0 & 1 & 2 & 3
\end{array}
$$

a. Financial.

b. Physical

c. Emotional.

Total Q19

Comment:

20. Has the caregiving experience affected your personal life?

a. Your spouse or significant other?

b. Your parent(s)? 
c. Your children, if any?

d. Your work, if employed?

e. Your personal time?

f. Other?

21. Based on this experience, would you again become involved in caregiving for your parent(s)?

22. Which of the following is typical of the decision making process regarding DAY-TO-DAY caregiving responsibilities and activities? (circle one).

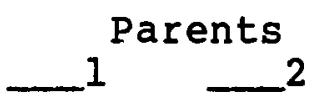

Most decisions are made by the caregiver..........1 Decisions are made by caregiver and

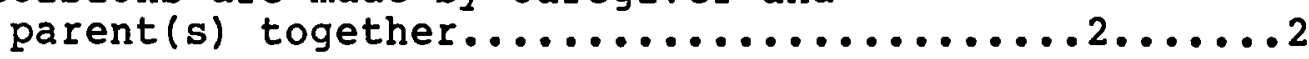
Most decisions are made directly by the parent(s) ............................. Decisions are made indirectly by the parent $(s) \ldots \ldots \ldots \ldots \ldots \ldots \ldots \ldots \ldots \ldots \ldots \ldots 4 \ldots \ldots . \ldots 4$ 
No specific decisions are made, things just happen........................

Decisions are made jointly by family members, specify........................6

Decisions are made by non-family

persons*, specify......................7

Other, specify:........................8

Don't know..............................9

*non-family persons $=$ health/community workers, friends, etc.

23. Using the previous list, (Q22) how would MAJOR decision making occur - for example, sale of your parent's home? Insert response from $\mathbf{2 2 2}$.

Total 023: Parent 1_ I $\square$ Parent 2_ $\square$

24. To what extent do you feel in command of your caregiving responsibilities ?

great deal

not much

1

2

3

4

5

25. In what way has your own upbringing and experience prepared you to take on caregiving responsibilities for an elderly parent? 
26. Do you feel that expectations of adult children caring for elderly parents have changed during the last, say, 25 years?

27. For yourself, do you feel any pressure from the following people or agencies to provide caregiving services to your parent(s)?
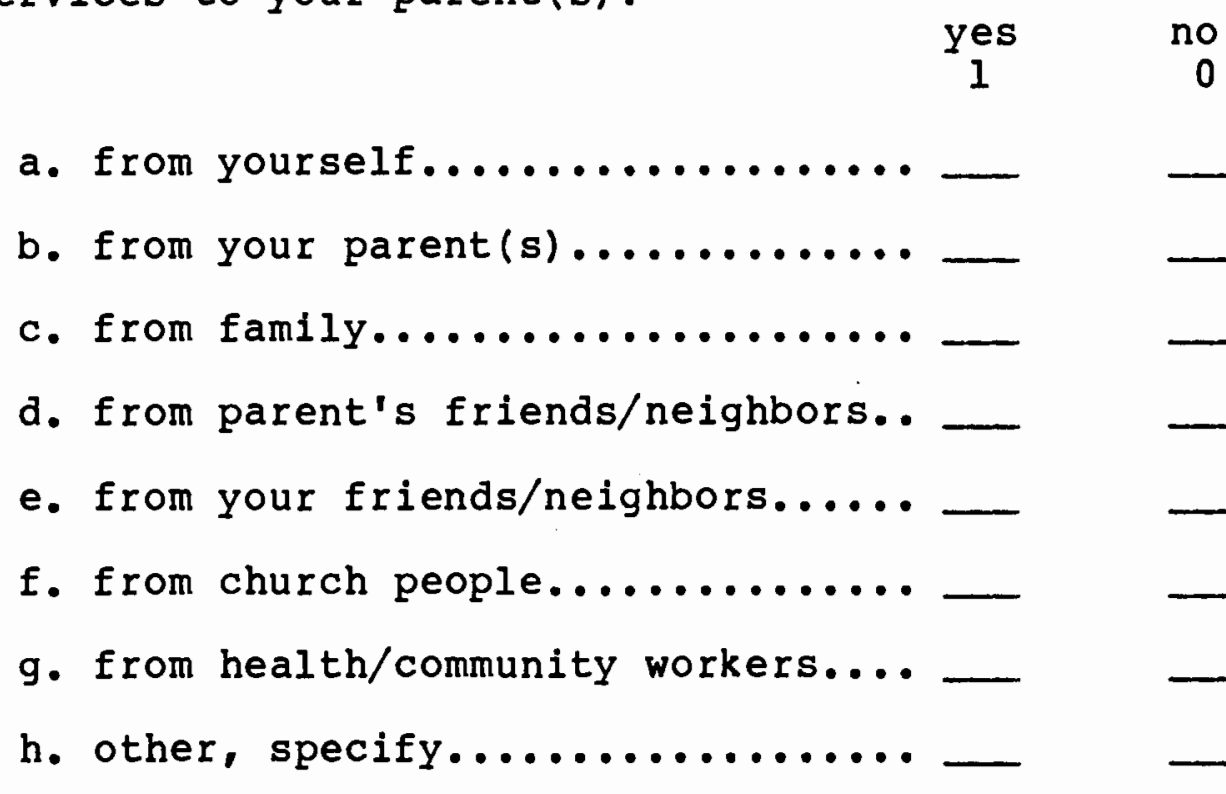

Total Q27

0
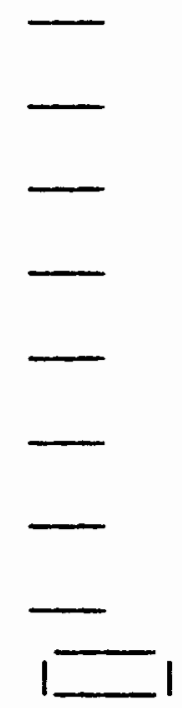

SECTION 3:

In the following six questions, I would like you to estimate your parent's health and ability over the last three month period. (Health profile adapted from PULSES Profile, Granger et al., 1979). 
28. GENERAL HEALTH PROFILE

A. PHYSICAL CONDITION:

Describe how frequently your parent needs health services* for a medical condition. (Circle one).

\begin{abstract}
Parents $1 \quad 2$

Infrequently - every three months or so ........... intermittent - between weekly and monthly...2.....2

Often - between daily and weekly................3 Intensive - at least daily.................4 *Health services include in-home and office services from providers (Doctors, nurses, therapists, etc.).
\end{abstract}

Comments?

B. SELF CARE FUNCTIONS:

Describe how well your parent handles his or her self care activities, such as eating, dressing, \& bathing.

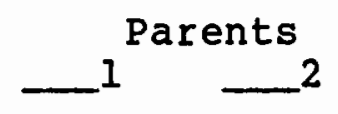

Independent - handles all self care..............

Limited - handles all self care, but with difficulty..........................2

Assisted - requires assistance and/or supervision.............................

Dependent - requires major assistance in self care............................4

Comments? 
C. MOBILITY:

Describe how well your parent gets about, such as walking, using stairs, and getting up from a chair. Does your parent need to use aids such as canes, braces, wheelchairs, etc.? (Circle one).

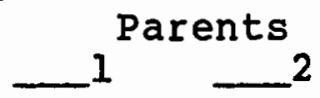

Independent - no mobility problems...............

Limited - able to get about but uses



Assisted - requires human assistance

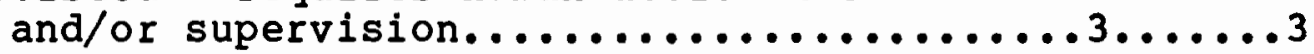

Dependent - unable to get about, requires assistance. .4. 4

Comments?

\section{D. SENSORY ABILITIES:}

Does your parent have any problems with speech, hearing or vision? (Circle one).

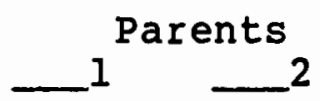

Independent - intact speech, hearing and vision*..............................

Limited - mild impairment or uses mechanical aid(s) $\ldots \ldots \ldots \ldots \ldots \ldots \ldots \ldots \ldots \ldots 2 \ldots \ldots \ldots 2$

Assisted - requires help, supervision



Dependent - severe speech, hearing or visual problems...................4....4

*includes corrected vision of minor nature. Comments? 
E. BOWEL AND BLADDER CONTROL:

Does your parent have any problems with bladder and bowel control? (Circle one).

Parents 1 2

Independent - complete voluntary control...........1

Limited-normal activity despite urgency,

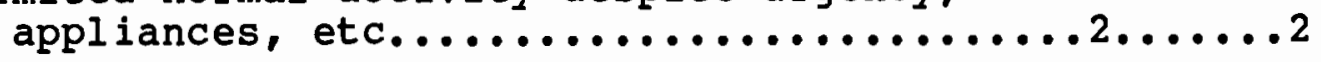

Assisted - requires help; may have

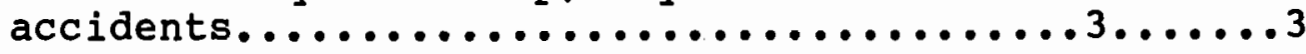

Dependent - frequent incontinence of bladder \&/or bowel.......................4

F. SUPPORT FACTORS:

What level of support, if any, is needed to enable your parent to carry out his/her usual life roles and tasks*. (Circle one).

Parents



Independent - able to carry out usual

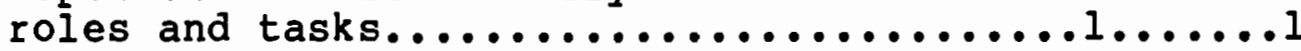

Limited - needs to modify usual roles and tasks...............................2

Assisted - requires informal support with

roles and tasks; may pay for assistance....3.....3

Dependent - unable to handle roles and

tasks or requires some formal support.....4.....4

Q28: Parent $1 \ldots$ Parent 2

Scoring: Least impaired $=6$; most impaired $=24$.

*Life roles and tasks =roles such as spouse, employee, volunteer, homemaker, handyman and associated tasks. 
29. How would you rate your parent's overall ability in the last three month period? (Circle one) excellent very good fair poor very poor 1 2 3 4 5

Parent 1 Parent 2

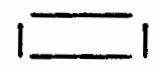

30. In your view, is your parent(s) mentally as sharp as before?

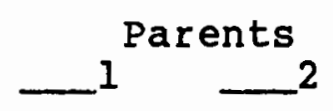

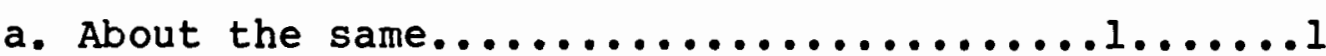

b. Somewhat less sharp....................2

c. Has a severe problem mentally...............3

SECTION 4 :

This section is concerned with your parent's response to being old, and possibly less able than previously. For each statement please use the last three months as a reference period. (Show response card; insert code for parent - M, F, M/L, F/L).

31. During the last three months or so, has your parent: not at some quite great all what a lot deal

1. attempted to plan and $\begin{array}{cccc}0 & 1 & 2 & 3\end{array}$ carry out activities independently?

2. actively attempted to cope with his or her needs?

3. preferred to let others manage his or her needs? 
4. had the opportunity to engage in decision making*?

5. taken responsibility for determining a course of action?

6. insisted on being independent, despite concerns from others

7. expressed feelings of helplessness over his or her situation?

8. used "good" judgment in requesting or not requesting assistance.

*Decision making: what to wear, what to do, etc. High autonomy level $=24 ;$ Low autonomy level $=0$ Note: Coding for questions 3 and 7 needs to be reversed. Parent 1 parent 2 Total Q30

32. Compared to other persons of your parent's age, do you think your parent has more or less control of outcomes in his/her life?

$$
\text { Parent } 1 \text { Parent } 2
$$

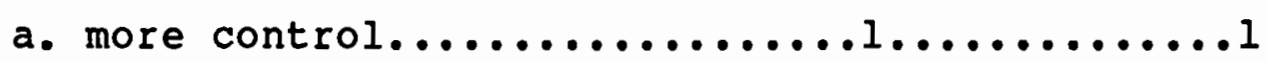

b. about the same.......................2

c. less control.........................3

33. Do you have any feelings about your parent(s) needs to have some control of his or her situation? Comments? 
34. Do you have any feelings about your parent(s) needs to have some control, versus your own needs for control of your caregiving routine? Can you comment?

SECTION 5:

In this section I would like to obtain some background information on your parent.

35. How old is your parent?

Parent 1_ Age last birthday $1-1 \quad$ Not sure $=9$

Parent 2 Age last birthday $\square$ Not sure $=9$

36. Is your parent currently

$$
\text { Parent 1_ Parent } 2
$$

Married..............................1

widowed...............................2

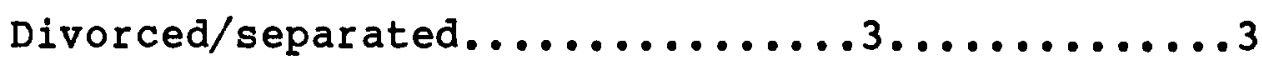

Never married..........................4

Living as a couple.....................5

Not sure.............................9

37. Other than working in the home, is your parent currently

$$
\text { Parent } 1 \text { Parent } 2
$$

Working full time.......................1

Working part-time.......................2

Not working........................... 
Unemployed, looking for work.....4.........4

Retired.............................

Not sure...........................9

38. What was/is your parent's PRIMARY occupational status?

Parent 1

Parent 2

39. How much schooling did your parent complete? (Do not read choices; circle one).

Parent 1

Parent 2

None..............................

1 - 8 years...........................1

Some high school.......................2

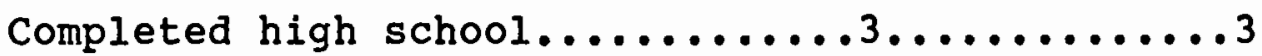

Some college or trade school.....4.........4

Completed college -4 years......5.........5

Graduate/professional school....6........6

Not sure............................9

40. Which of the following best describes your parent's total household income last year, before taxes? (Show card with response options; circle one).

Parent 1

Parent 2

Less than $\$ 4,000 \ldots \ldots \ldots \ldots \ldots \ldots \ldots . \ldots \ldots \ldots \ldots \ldots$

Between $\$ 4,000$ and $\$ 7,999 \ldots \ldots \ldots . \ldots \ldots \ldots \ldots \ldots 2$

Between $\$ 8,000$ and $\$ 11,999 \ldots \ldots \ldots . \ldots . \ldots \ldots \ldots$ 
Between $\$ 12,000$ and $\$ 15,999 \ldots \ldots \ldots 4 \ldots \ldots \ldots \ldots \ldots 4$

Between $\$ 16,000$ and $\$ 24,999 \ldots \ldots \ldots 5 \ldots \ldots \ldots \ldots \ldots$

Between $\$ 25,000$ and $\$ 34,999 \ldots \ldots \ldots 6 \ldots \ldots \ldots$

Between $\$ 35,000$ and $\$ 44,999 \ldots \ldots \ldots 7 \ldots \ldots \ldots \ldots 7$

$\$ 45,000$ or greater.....................8

Not sure/no answer.....................9

41. Has your parent experienced any of the following major life changes within the last year or so?

$\begin{array}{llll}\text { Parent } & 1 & \text { Parent } & 2 \\ \text { yes } & \text { no } & \text { yes } & \text { no } \\ 1 & 0 & 1 & 0\end{array}$

Death of a spouse.............

Major illness (e.g. stroke).

Death of close family member..

Retirement.

Death of close friend(s)

Change in living situation.....

Loss/decrease of independence. .

Other, specify.

Parent $1+1-1$ Parent $2-1 \square$ Total $041 \square$ Comments? 
SECTION 6 :

Finally, I would like some background information on yourself. Could you help me with these questions?

42. In what year were you born?

Year of birth Age (insert later)

43. Are you currently

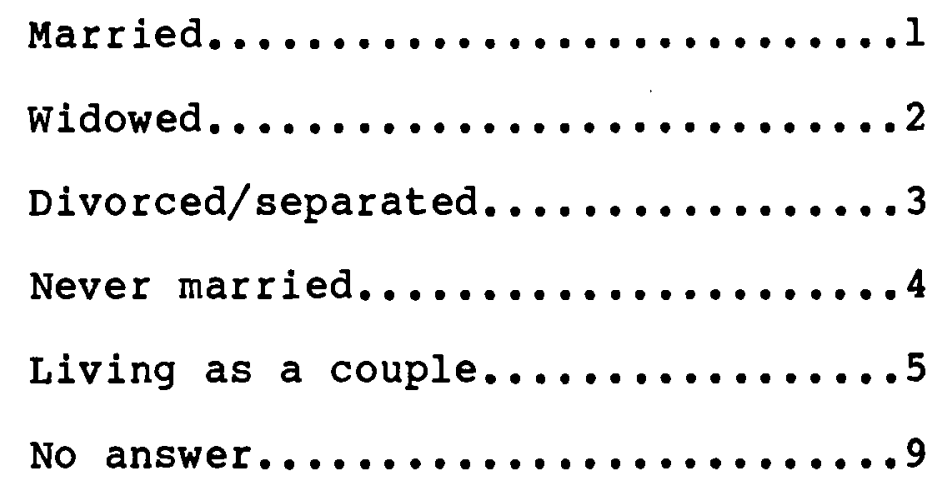

44. What is your relationship to your parent? Parent 1

Parent 2

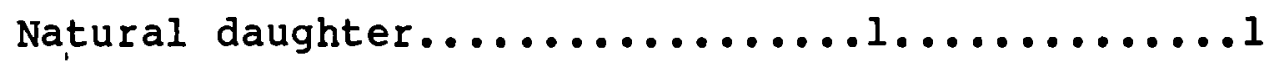

Adopted daughter.......................2

step-daughter.........................

Daughter-in-law......................4

45. If you have brothers or sisters, are they older or younger than yourself?

Insert birth order 
46. Do you have any children? If yes, please explain:



47. Has the presence or absence of children made a difference in your caregiving experience? In what way?

48. Other than working in the home and assisting your parent, are you currently:



49. What is/was your PRIMARY occupational status? Specify: Code $\square$ not sure $=9$

50. What is/was your spouse's PRIMARY occupational status? Specify: Code $\square$ not applicable $=9$ 
51. How much schooling did you complete?

(do not read choices; circle one).



$1-8$ years...................

Some high school..............2

Completed high school...........3

Some college or trade school.....4

Completed college - 4 years......5

Graduate/professional school.....6

Not sure/not applicable.........9

52. How much schooling did your spouse complete?

Use coding from $Q 51$ above, and insert:

53. Which of the following best describes your total household income last year, before taxes? (Show card with response options)

Less than $\$ 4,000 \ldots \ldots \ldots \ldots \ldots \ldots \ldots 1$

Between $\$ 4,000$ and $\$ 7,999 \ldots \ldots \ldots 2$

Between $\$ 8,000$ and $\$ 11,999 \ldots \ldots \ldots 3$

Between $\$ 12,000$ and $\$ 15,999 \ldots \ldots .4$

Between $\$ 16,000$ and $\$ 24,999 \ldots \ldots .5$

Between $\$ 25,000$ and $\$ 34,999 \ldots \ldots 6$

Between $\$ 35,000$ and $\$ 44,999 \ldots \ldots .7$

$\$ 45,000$ or greater............8

Not sure/ no answer............9 
54. Have you provided/ are you providing ongoing financial assistance to your parent? If so, does this represent a burden?

$$
\text { Parent } 1
$$

No financial assistance.................

Occasional assist, no burden...................

Regular assist, no burden.................2

Regular assist, a burden..................3

Regular assist, severe burden....4..........4

55. What is the approximate traveling time from your home to your parent's home? (Insert time in hours).



Lives with caregiver $=0$

THANK YOU FOR YOUR ASSISTANCE WITH THIS INTERVIEW. IF YOU KNOW OF ANY OTHER DAUGHTER OR DAUGHTER-IN-LAW WHO IS CARING FOR A PARENT AND WHO MIGHT BE INTERESTED IN BEING A PART OF THIS STUDY, PLEASE LET ME KNOW. IF YOU HAVE ANY QUESTIONS ABOUT THE INTERVIEW OR THE STUDY, DR. JONES (MY THESIS COMMITTEE CHAIRPERSON) OR I WILL BE HAPPY TO HELP.

NOTE: SPACE FOR THE OPEN-ENDED QUESTIONS HAS BEEN COMPRESSED IN THIS VERSION OF THE INTERVIEW SCHEDULE. 


\section{APPENDIX B}

CODING FOR OPEN-ENDED QUESTIONS

INTERVIEW \#

FOR EACH OF THE FOLLOWING QUESTIONS, SELECT A SINGLE STATEMENT WHICH BEST REPRESENTS THE SUBJECT'S DOMIMANT ORIENTATION. USE COMBINATION STATEMENTS ONLY WHEN DOMINANCE IS UNCLEAR. PLEASE CIRCLE YOUR CHOICE.

Q01. What is the meaning of "old age" for you today?

1. Inevitable deterioration and/or loss in areas of physical, intellectual, personal and social life.

2. Increased dependency on others for help with basic living - physical, emotional and financial.

3. A period of life based on advanced chronological age.

4. A life status, not necessarily based on actual age.

5. Accumulation of valued life skills and experiences.

6. A state of mind or attitude to life.

7. Any combination of non-dominant items listed above.

8. not applicable.

9. not ascertained.

Q03. Would your responses to questions about people over 85, be the same or different from responses about people over 65 ?

1. About the same.

2. Slightly more optimistic.

3. Slightly more pessimistic.

4. Considerably more pessimistic.

8. not applicable.

9. not ascertained. 
Q05. Has being a caregiver made a difference or not in the way you see your own aging? Comments?

1. No - sees own aging about the same as before.

2. Yes - better understanding of the aging process, both general and specific.

3. Yes - has forced acknowledgment of own aging and mortality, and its personal implications.

4. Yes - is fearful/anxious/negative about own aging.

5. Yes - has started active preparation/planning for own aging (modification of personal habits, planning for financial, health, housing, and social needs).

6. Yes - is more concerned with quality of life than life maintenance.

7. Any combination of non-dominant items 2 through 6 .

8. not applicable.

9. not ascertained.

Q10. If not currently providing caregiving services, why did this stop?

1. Parent died.

2. Parent was admitted to hospital.

3. Parent was admitted to nursing home.

4. Other.

8. not applicable - care is ongoing.

9. Not ascertained.

Q13. How did you happen to become the caregiver for your parent(s)?

1. Breakdown of previous care situation, with parent(s) unable to live alone.

2. Other siblings/close family members not available to help. 
3. Subject's resources are conducive to caregiving (proximity, housing, time, finances, energy, etc.).

4. Subject's personal traits, beliefs and skills are suited to caregiving.

5. Supportive and/or close relationship between subject, subject's family and parent(s).

6. Extension of prior conjoint living arrangement or pattern of assistance between subject and parent.

7. Responsibility associated with being only child, only daughter, eldest child or eldest daughter.

8. Any combination of non-dominant items above.

88. not applicable.

99. not ascertained.

Q15. Does your parent(s) living situation affect your ability to assist with care? If so, how?

1. Having parent(s) and subject / family live together enables care to be provided more easily - physically and emotionally.

2. Having parent(s) and subject/family live together is very difficult physically and/or emotionally.

3. Subject is very ambivalent regarding parent(s) living situation and her ability to assist with care.

4. Having parent(s) live separately but accessible to subject, allows privacy for each, yet still allows assistance from subject.

5. Other.

8. Not applicable.

9. Not ascertained.

Q20A. Has the caregiving experience affected your personal life?

A) Your spouse or significant other?

1. Husband is generally supportive and helpful in care of parent. 
2. Caregiving has imposed limitations or caused changes in their/her lifestyle.

3. Husband has difficulty with caregiving, but goes along with it.

4. Caregiving has caused or added serious problems to their marital relationship.

5. Not married - little opportunity/interest in personal social life while caregiving.

6. Not married - maintains personal social life despite caregiving.

7. Any combination of non-dominant items above.

8. Not applicable - include not married, widowed, divorced with no comments).

9. Not ascertained.

Q20B. Has the caregiving experience affected your personal Iife?

B) Your parent?

1. Relationship between parent(s) and subject is mostly positive.

2. Relationship between parent(s) and subject is changeable and/or ambivalent.

3. Relationship between parent(s) and subject is mostly negative.

4. Relationship is characterized by parent's dislike of being dependent and/or a burden.

5. Parent is largely unaware of and/or is unable to participate in a caregiving relationship.

6. Combination of item 4 and any other non-dominant item.

8. Not applicable.

9. Not ascertained. 
Q20C. Has the caregiving experience affected your personal life?

C) Your children, if any?

1. Experience has been mostly positive for the children and/or family.

2. Experience is characterized by losses in family time, activity and well-being.

3. Experience has been mostly negative for the children and/or family, not classifiable in \#2 above.

4. Caregiving has had a relatively neutral effect on the children and/or family.

5. Other.

8. Not applicable - no children.

9. Not ascertained.

Q20D. Has the caregiving experience affected your personal life?

D) Your work, if employed?

1. Caregiving affected subject's employment positively.

2. Caregiving affected subject's employment negatively.

3. Caregiving has not affected subject's employment.

4. Caregiving forced subject to quit or change employment.

5. Subject elected to retire early in order to care for parent (s).

6. Other.

8. Not applicable - not employed outside the home.

9. Not ascertained. 
Q20E. Has the caregiver experience affected your personal life?

E) Your personal time or any other personal factor?

1. Subject feels confined - has less freedom to act without prior arrangements for care of parent; feels pulled between parental and own family needs.

2. Caregiving has affected their/her ability to make long term plans (e.g. career, vacation), or to realize previous plans (e.g. retirement, lifestyle, employment).

3. Caregiving has compromised the quantity, quality and use of personal time.

4. Caregiving has changed/compromised subject/family life style, such as: priorities, social activities, privacy, finances, roles, etc.

5. Caregiving has compromised subject's physical and/or emotional health, with problems of "burn-out," fatigue, stress, resentment, grief, etc.

6. Any combination of non-dominant items above.

7. Other.

8. Not applicable.

9. Not ascertained.

Q21. Based on this experience, would you again become involved in caregiving for your parent(s)?

1. Yes - no reservations.

2. Yes - but hesitant.

3. Yes - but definite reservations.

4. No - would not care for parent(s).

8. Not applicable.

9. not ascertained. 
Q25. In what way has your own upbringing and experience prepared you to take on caregiving responsibilities for an elderly parent?

1. None or limited preparation for responsibilities of caregiving.

2. Had role models and/or experience with family care for older family members.

3. Was socialized to importance of family unit and family responsibility toward older members.

4. Pattern of caregiving by subject to siblings, parents and others was established early and then continued.

5. Education, training and/or employment contributed to preparation for caregiving.

6. Any combination of non-dominant items 2 through 5 .

8. Not applicable.

9. Not ascertained.

Q26. Do you feel that expectations of adult children caring for elderly parents have changed during the last, say 25 years?

1. No - limited or no change in expectations.

2. Yes, a change - greater expectations to provide care for parent(s).

3. Yes, a change - fewer expectations to provide care for parent (s).

4. Yes, a change - different expectations regarding care to parent(s) - mostly neutral or positive.

5. Yes, a change - different expectations regarding care to parent(s) mostly negative.

8. Not applicable.

9. Not sure/not ascertained. 
Q33. Do you have any feelings about your parent's needs to have some control of his or her situation?

1. Recognizes importance of parent's sense of control, dignity and independence.

2. Encourages/allows parent to exercise maximum control.

3. Has difficulty with parent's high control behaviors.

4. Parent is unable to exercise useful control.

8. Not applicable.

9. Not ascertained.

Q34. Do you have any feelings about your parent(s) needs to have some control, versus your own needs for control of your caregiving routine? Can you comment?

1. Sees caregiving routine as driven by parent's needs and behaviors, and thus problematic for herself to control.

2. Supports a division of control between parent and caregiver where possible.

3. Sees establishment of limits to caregiving as important to caregiver's health and continued care.

4. Sees parent as incapable of exercising control.

8. Not applicable.

9. Not clear/not ascertained.

Q47. Has the presence or absence of children made a difference in your caregiving experience?

1. Little difference in presence or absence of children.

2. Presence of children is generally helpful.

3. Presence of children makes caregiving harder.

4. Other, or undecided.

8. Not applicable.

9. Not ascertained. 


\section{APPENDIX C}

HUMAN SUBJECTS RESEARCH REVIEW COMMITTEE

June 10,1986

TO: Margaret A. Reynolds, SOC

FROM: Robert Holloway, Chair

In accordance with your request, the Human Subjects Research Review Committee has reviewed your proposal entitled, Daughters as Caregivers to Elderly Parents, for compliance with DHHS policies and regulations on the protection of human subjects.

The committee is satisfied that your provisions for protecting the rights and welfare of all subjects participating in the research are adequate and therefore the project is approved. Any conditions relative to this approval are noted below:

Conditions: Informed consent form should state that subject may withdraw from study if they so desire.

Please send modified inform consent form to HSRRC (OGSR) for files.

cc: Office of Graduate Studies and Research 
APPENDIX D

CAREGIVER STUDY - INFORMED CONSENT

I hereby agree to participate in the study of daughter - caregivers, conducted by Margaret Reynolds, a graduate student in Sociology and Aging at Portland state University. I understand that the purpose of the study is to learn about the concerns and opinions of adult daughters who are caregivers for elderly parent(s).

I understand that my participation will involve a single personal interview with Margaret Reynolds. I realize that some of the questions in the interview may be of a personal nature, and I reserve the right to talk only about topics which are comfortable for me. I also reserve the right to terminate the interview, to be given all notes of my responses, and to withdraw from the study. While I may not receive any direct benefit from participating in the study, I realize that I may be adding to knowledge which may benefit others in the future.

I understand that my responses will be anonymous, such that neither my name nor identifying personal information will ever be used. I further understand that my participation in the study is voluntary.

Margaret Reynolds has offered to answer any questions that I may have about the study. She has also given me the 
name of Dr. Joseph F. Jones, her study committee chairperson. I know that I can reach them both through the Sociology Department at Portland State University (503) 229-3926.

Respondent's signature Date

Interviewer's signature Date 